Florida International University FIU Digital Commons

$11-9-2016$

\title{
Management Optimization of Energy Consumption Reduction for Residential Hot Water
}

Francesco Cataldi

francesco.cataldi90@gmail.com

DOI: $10.25148 /$ etd.FIDC001227

Follow this and additional works at: https://digitalcommons.fiu.edu/etd

Part of the Mechanical Engineering Commons

\section{Recommended Citation}

Cataldi, Francesco, "Management Optimization of Energy Consumption Reduction for Residential Hot Water" (2016). FIU Electronic Theses and Dissertations. 2995.

https://digitalcommons.fiu.edu/etd/2995 


\section{FLORIDA INTERNATIONAL UNIVERSITY}

Miami, Florida

MANAGEMENT OPTIMIZATION OF ENERGY CONSUMPTION REDUCTION FOR RESIDENTIAL HOT WATER

A thesis submitted in partial fulfillment of the

requirements for the degree of

MASTER OF SCIENCE

in

MECHANICAL ENGINEERING

by

Francesco Cataldi

2016 
To: Interim Dean Ranu Jung

College of Engineering \& Computing

This thesis, written by Francesco Cataldi, and entitled Management Optimization of Energy Consumption Reduction for Residential Hot Water, having been approved in respect to style and intellectual content, is referred to you for judgment.

We have read this thesis and recommend that it be approved.

Leonel Lagos

Cheng-Xian Lin

Yiding Cao, Major Professor

Date of Defense: November 9, 2016

The thesis of Francesco Cataldi is approved.

Interim Dean Ranu Jung

College of Engineering \& Computing

Andrés G. Gil

Vice President for Research and Economic Development and Dean of the University Graduate School

Florida International University, 2016 


\author{
ABSTRACT OF THE THESIS \\ RESIDUAL HOT WATER \\ by \\ Francesco Cataldi \\ Florida International University, 2016 \\ Miami, Florida \\ Professor Yiding Cao, Major Professor
}

MANAGEMENT OPTIMIZATION OF ENERGY CONSUMPTION REDUCTION FOR

The objective of this thesis is to create an automatic water management system capable of optimizing the usage of warm water stored in two water tanks to reduce the monthly energy consumption of the instant water heater installed in a residential house. This system is called Water Mixing System (WMS). The two heat sources considered are: PV-T system and heat rejected by the air condition system. The PV-T system is a new technology that allows transformation of the sun radiation into both electricity and warm water, increasing the efficiency of the panel compared to either a common photovoltaic panel or solar collector. The air-conditioning heat source, instead, recovers the heat rejected by the condenser to the environment by employing a heat exchanger that stores the heat collected in the water tank. 


\section{TABLE OF CONTENTS}

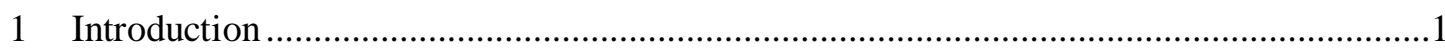

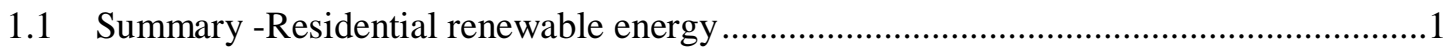

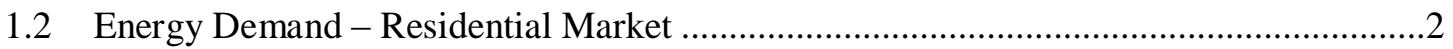

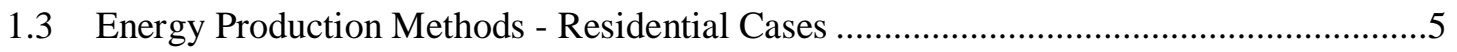

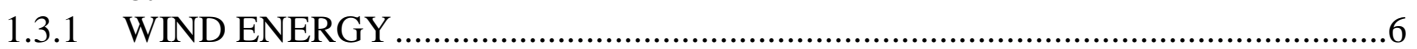

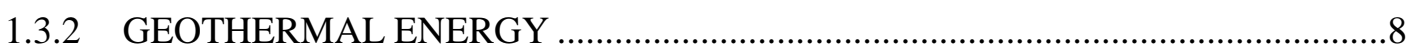

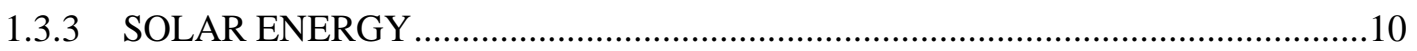

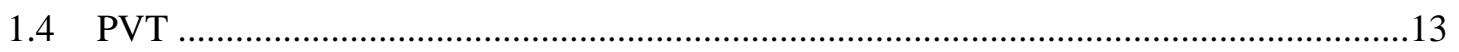

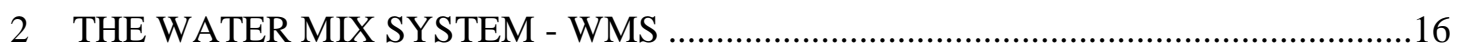

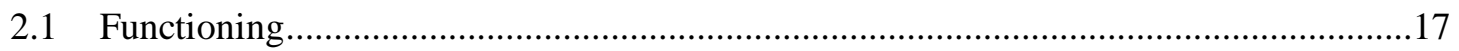

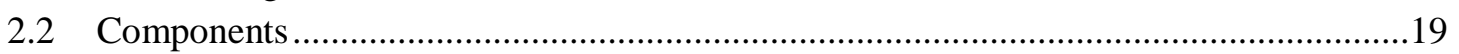

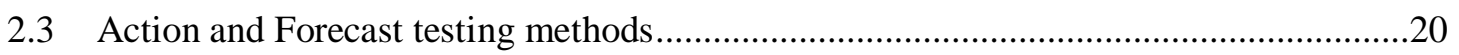

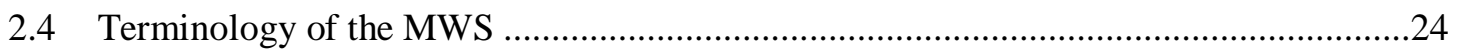

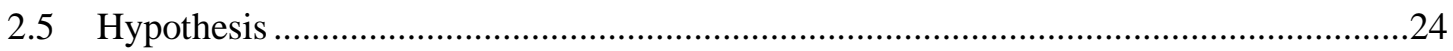

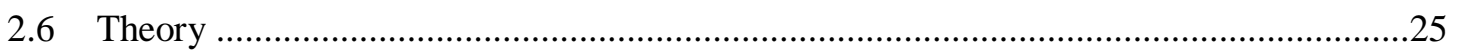

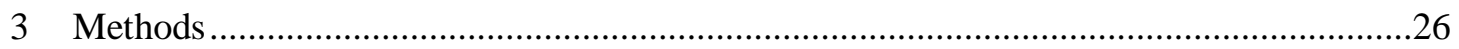

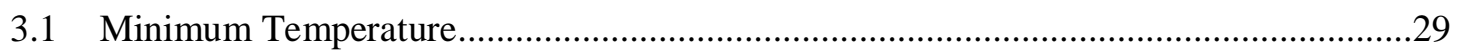

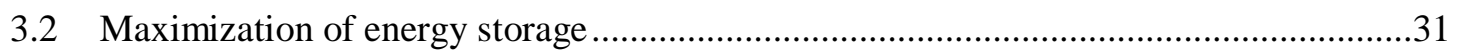

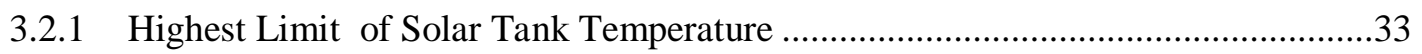

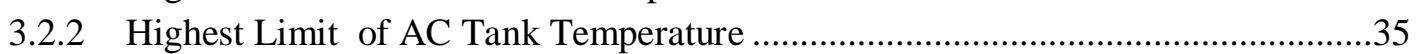

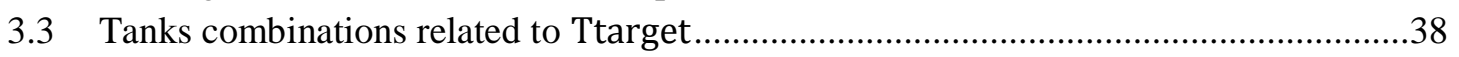

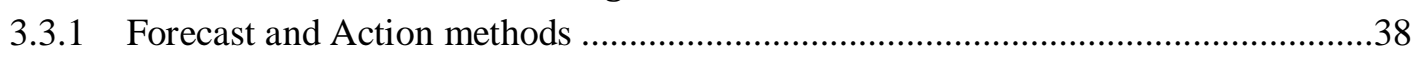

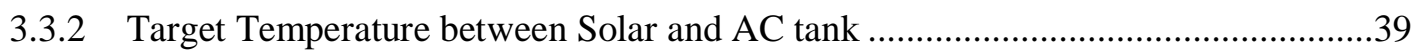

3.3.3 Target temperature between the AC tank and the water line temperatures...............45

3.3.4 Hot tank temperature lower than target temperature ...........................................48

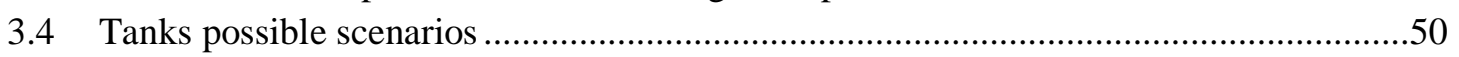

3.4.1 Evaluation of the amount of water extracted from each tank ..................................50

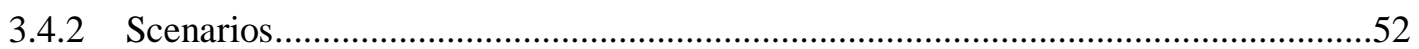

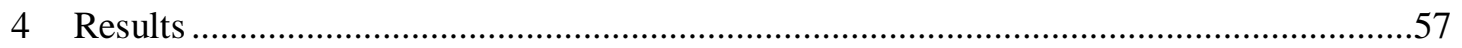

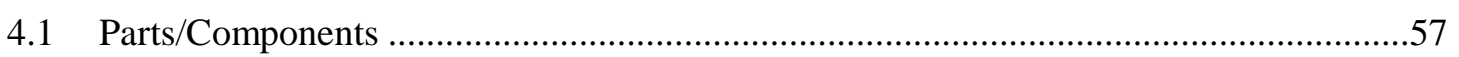

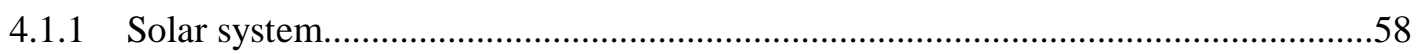

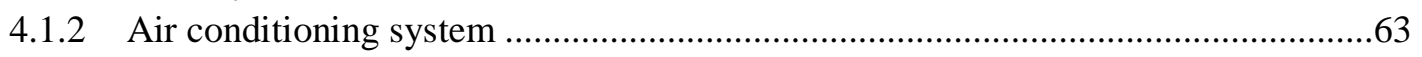

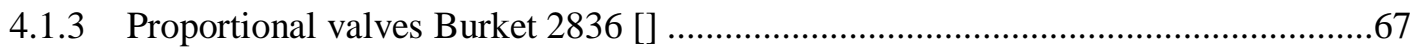

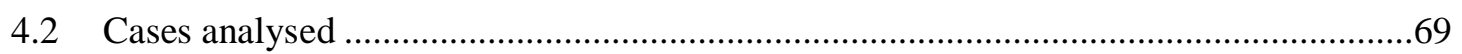

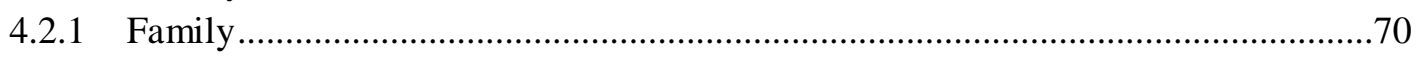

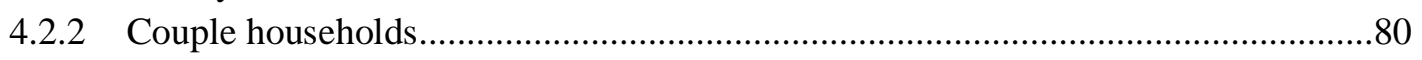

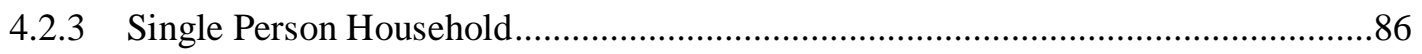

4.2.4 Water Heating Average Daily Cost with WMS for Single Person Household ........86

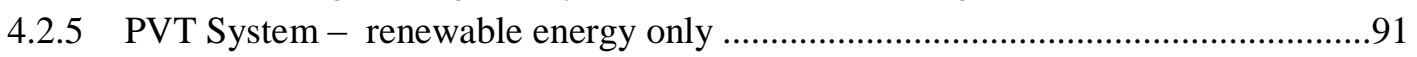

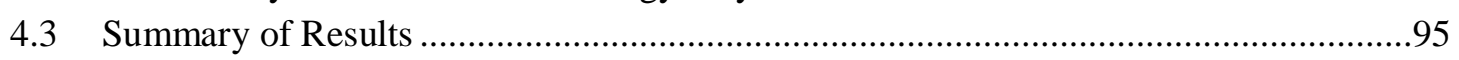

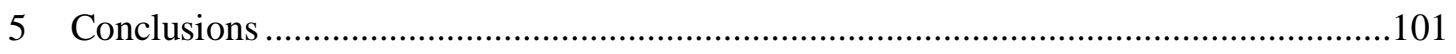

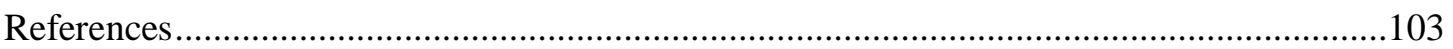




\section{TABLE OF FIGURES}

FIGURE

PAGE

Figure 2 - Energy Consumption in homes by end users [3] 3

Figure 3 - Residential Energy Consumption Estimates [5] 4

Figure 7 - Water Mixing System WMS 17

$\begin{array}{lr}\text { Figure } 8 \text { - Vapor Compressor Cycle [16] } & 18\end{array}$

Figure 16 - Trend of AC and Solar Tanks with highest limit temperature on the solar source 34

Figure 17 - Temperature trend of AC and Solar tanks without limit 36

Figure 18 - AC and Solar Tanks temperature trend with limit 37

Figure 19 - Temperature trend of AC and Solar tank managed with Forecast Method $\quad 40$

Figure 20 - Hot and Warm Tank combination forecast weather 43

Figure 21 - Hot Tank and Water line tank combination Forecast Method 43

Figure 22 - Trend temperature of Solar and AC tanks with target temperature lower than the AC tank 46

Figure 23 - Trend Temperature of Solar and AC tanks with target temperature lower than AC tank

Figure 24 - Tanks management when the warm tank becomes the hottest

Figure 26 - AC and Solar Tanks temperatures as demonstration of the recharge and discharge phases

Figure 27 - AC and Solar tanks temperature as demostration of the recharge and discharge phase

Figure 28 - PVT Panel [24]

Figure 29 - PVT Panel - side [24]

Figure 30 - Data for the Sizing of the PVT water aspect 62

$\begin{array}{ll}\text { Figure } 31 \text { Air compressor cycle [30] } & 64\end{array}$

Figure 32 - Pressure Entalphy Graph $\quad 65$

Figure 33 - AC System $\quad 66$

Figure 34 - Functional principle of direct acting solenoid control valves 68

Figure 35 - Comparison flat stopper design - conical stopper design [20] 69 
Figure 37 - Family - January - Action Method

Figure 38 - Family - April - Forecast Method

Figure 39 - Family - April - Action Method

Figure 40 - Family - August - Forecast Method

Figure 41 - Family - August - Action Method

Figure 42 - Family - November - Forecast Method

Figure 43 - Family - November - Action Method

Figure 44 - Couple - January - Forecast Method

Figure 45 - Couple - April - Forecast Method

Figure 46 - Couple - August - Forecast Method

Figure 47 - Couple - November - Forecast Method

Figure 48 - Single - January - Forecast method

Figure 49 - Single - April - Forecast Method

Figure 50 - Single - August - Forecast Method

Figure 51 - Single - November - Forecast method

Figure 52 - Savings $\%$ in the different months 99

Figure 53 - Saving \% depending on AC operating hours 100 


\section{Introduction}

\subsection{Summary -Residential renewable energy}

In recent years, renewable energies are widely used and have been found to be very effective in costs reduction, especially in terms of large plants for industrial applications. On the other end, for residential applications, it is harder to create and sell a plant that allows a small family to quickly recover the cost of the plant. For this reason, the application of renewable energies to households is under developed and is an ongoing study. It is therefor one of the objectives of this thesis to create a plant for residential applications that uses renewable sources to save energy.

The plant has been designed to save energy during the process of heating the water needed in the house for multiple purposes (showering, dish washer, washing machine, etc.). Therefore, the ultimate goal of this system is to reduce the energy consumed by the water heater. Cost efficiency will play an important role on the final conclusions of this thesis.

The system, termed as Water Mix System or WMS, faces the energy-cost challenge and produces energy in a smart and inexpensive way. Also, it manages and stores the energy produced, to avoid any waste.

The water heater under consideration is electrical; therefore the energy saved is electricity. The energy is collected by two different systems:

- PVT solar system that collects energy from the sun and,

- Air Conditioning circuit, integrated with a heat exchanger.

A computational program will manage the entire system. The main structural parts are some proportional valves, a heat exchanger and a water storage tank. The composition will be thoroughly examined in later sections. 
The system works efficiently when it provides a water temperature in between the one of the water line and the one produced by the instant water heater. When this affirmation is true, the target temperature will be either:

- Equal to the temperature requested by the user and the instant water heater will be no longer needed,

- Or closer to the temperature requested by the user, employing less energy from the instant water heater to meet the demand.

The analysis developed in this thesis will determine if it will actually reduce the electrical bill.

\subsection{Energy Demand - Residential Market}

To clearly understand the importance of this system, it is useful to have an overview on the residential energy demand.

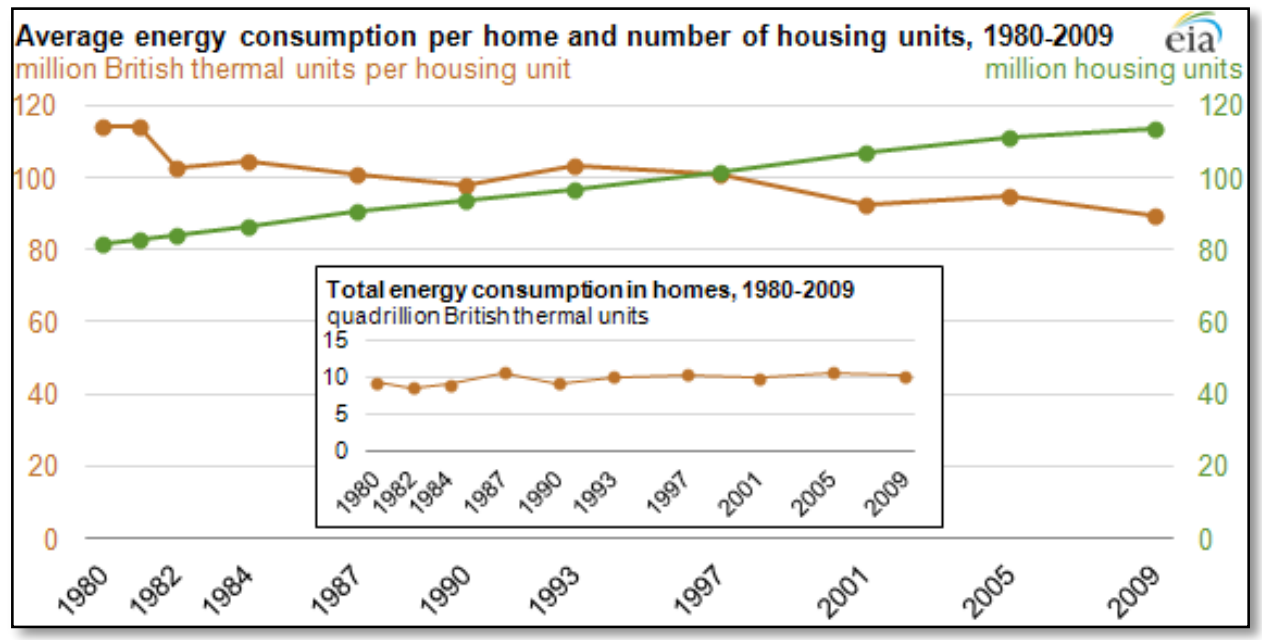

Figure 1 Average Energy Consumption per home and number of housing units[1]

Total U.S. energy consumption in homes has remained relatively stable for many years, because the increase in the number and average size of housing units has been compensated with improvement of the energy efficiency. This is stated by the latest results from the Residential Energy Consumption Survey (RECS).[1] 
In 2009, the British thermal unit (Btu)[2] consumed by an average household was 90 million, based on RECS data. This continues the downward trend in average perhousehold energy consumption of the last 30 years.

Improvements in the efficiency of space heating, air conditioning, and major appliances have led to a decrease in the average energy consumption per household, despite increases in the number of homes, the average size of the units, and the use of electronics. Recent homes also tend to feature better insulation and other characteristics, such as double-pane windows, that improve the building envelope.

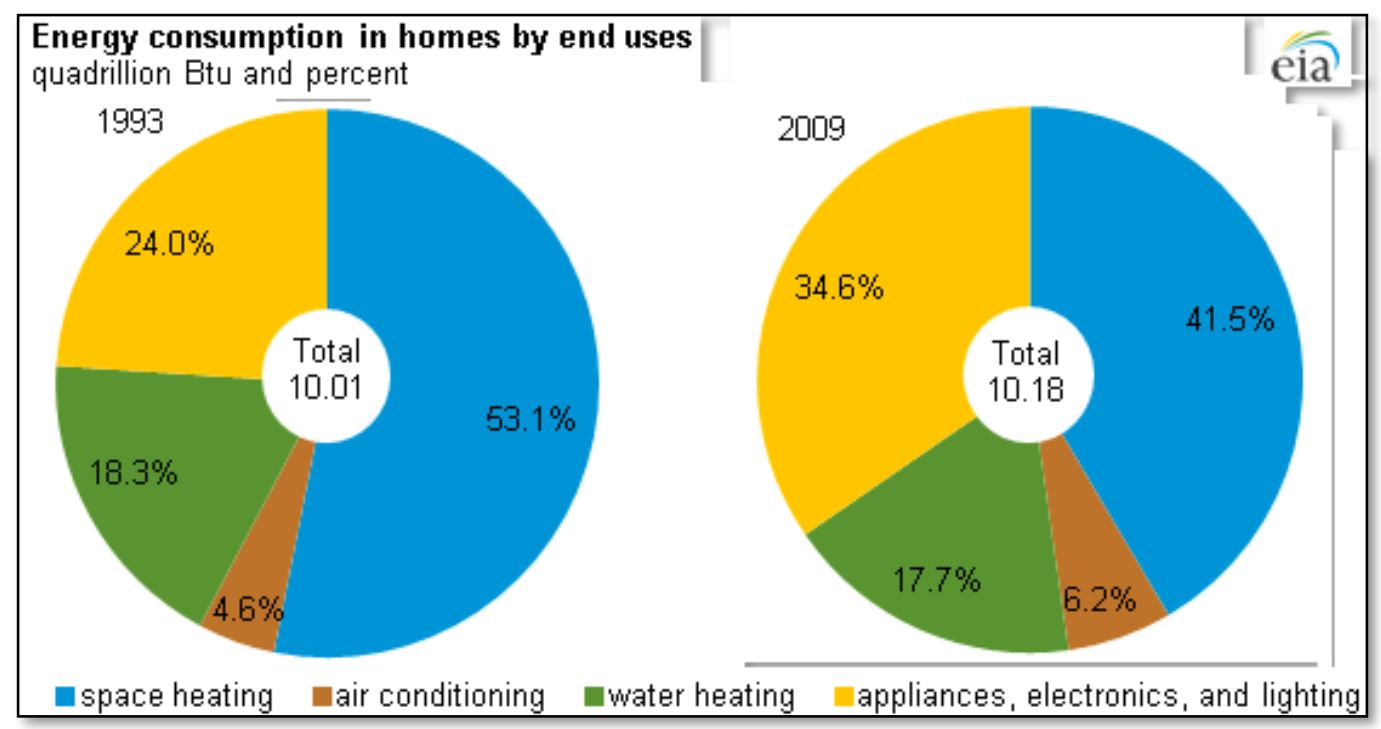

Figure 2 - Energy Consumption in homes by end users [3]

For decades, space heating and cooling (space conditioning) accounted for more than half of all residential energy consumption. Estimates from the most recent Residential Energy Consumption Survey (RECS), [3] collected in 2010 and 2011, show that 48\% of the energy consumption in U.S. homes in 2009 was for heating and cooling, down from $58 \%$ in 1993. 
Factors underpinning this trend are increased adoption of more efficient equipment, better insulation, more efficient windows, and population shifts to warmer climates. The change of how energy is consumed also results in the steady decrease of the energy consumption of the household.

As shown in Fig. 2, while energy used for space conditioning has declined, energy consumption for appliances and electronics continues to rise. Although, some appliances that are subject to federal efficiency standards, such as refrigerators and clothes washers, have become more efficient, the increased number of devices that consume energy in homes has offset these efficiency gains. Non-weather related energy use for appliances, electronics, water heating, and lighting now accounts for $52 \%$ of total consumption, up from $42 \%$ in 1993 . The majority of devices in the fastest growing category of residential end-uses are powered by electricity, increasing the total amount of Primary Energy ${ }^{4}$ needed to meet residential electricity demand.[5]

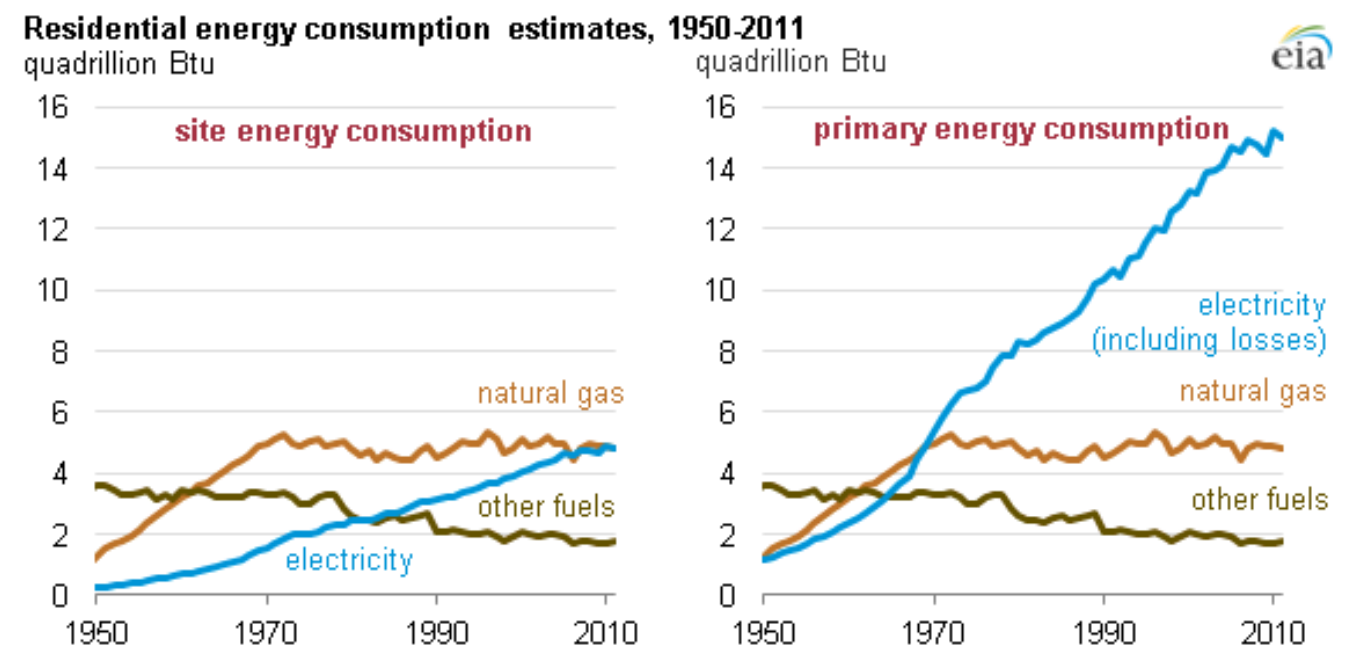

Figure 3 - Residential Energy Consumption Estimates [5] 
Fig. 3 shows that natural gas consumption in the residential sector has remained nearly flat for decades, and consumption of other fuels has declined. The use of electricity in the residential sector has grown, however.

Electricity and natural gas now account for approximately equal amounts of the energy consumed on site in U.S. households. But due to the fact that the production of electricity takes on average nearly three units of energy from primary fuels such as coal, natural gas, and nuclear fuel to generate one unit of electricity, increased electricity use has a disproportionate impact on the amount of total primary energy required to support site-level energy use. Electricity-related losses explain the difference between energy consumption in the residential sector as measured by energy consumption on site (left) and energy consumption of primary fuels (right).

Electricity powers most of machines in homes, including heating and cooling equipment, cooking appliances, refrigerators, dishwashers, and an ever-growing number of home entertainment and rechargeable devices. Although, many electric end-uses are covered by federal efficiency standards or voluntary programs like ENERGY STAR $®$, increases in both the percentage of homes with those devices and, in the case of electronics like televisions and computers, the number of devices per household have offset efficiency gains in residential electricity use.

\subsection{Energy Production Methods - Residential Cases}

The type of energy requested by the user is one of the most important factors to obtain an accurate house energy analysis. It can be produced in different ways and we can separate the energy sources in two main groups: renewable source and fossil fuel.[6]

Fossil fuel has been used for decades in the past, due to the huge amount available. It is relatively easy to store and transforms the Primary Energy into electricity with high 
efficiency conversion. Nowadays, we tend to produce energy using renewable sources in order to avoid pollution and because, unfortunately, we are running out of reserves. Another interesting characteristic of renewable energies is that they allow energy production for small systems, even in wild environments such as the desert or on high mountains and the user is able to manage its own production as needed.

Geothermal, Solar and Wind are the three major types of clean, renewable energy. They can be obtained in many different ways and can generate a huge amount of energy.

\subsubsection{WIND ENERGY}

Wind power is the use of airflow through wind turbines to mechanically power generators for electricity[7].

There are six main market applications for distributed wind: residential, agricultural, industrial, commercial, government, and institutional.

Residential applications include remote cabins, private boats, rural homesteads, suburban homes, and multi-family dwellings.

Agricultural applications include all types of farms, ranches, and agricultural operations. Industrial applications are facilities that manufacture goods or perform industrial processes (e.g. food processing plants and oil and gas operations).

Examples of commercial applications include offices, car dealerships, retail spaces, restaurants, and telecommunications sites. 
Government applications are projects for non-taxed entities such as cities, municipal facilities (e.g., water treatment plants), and military sites.

Institutional applications are also for entities that are typically non-taxed and mainly consist of schools, universities, and electric co-operatives.

Fig. 4 gives an explanation of the breakdown of market applications by capacity and

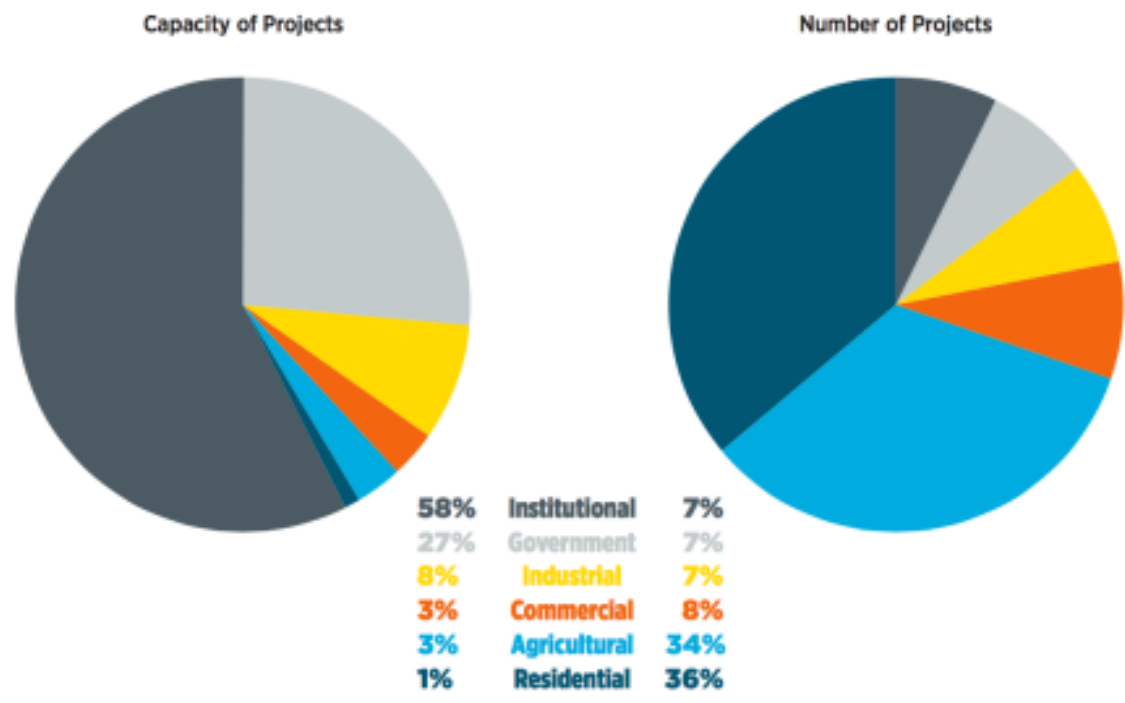

Figure 4 Market Application by Capacity and Projects[7]

by number of projects. It highlights the disparity between project and turbine sizes in each application. The few projects installed in the institutional and government applications mostly used large-scale turbines, while small turbines dominated deployment in the residential and agricultural applications.

Although they are not defined by project size, almost $80 \%$ of 2014 distributed wind projects were single-turbine projects. 


\subsubsection{GEOTHERMAL ENERGY}

Another widely used renewable energy in residential is geothermal. Geothermal energy is thermal energy generated and stored in the Earth [8].

The United States is currently the world leader in geothermal energy production. According to the Geothermal Energy Association, approximately $3.2 \mathrm{GW}$ of geothermal energy capacity is installed and multiple projects are proposed for the future. Since geothermal energy is most commonly found on plate boundaries, it is popular in western states such as California, Hawaii, and Alaska. Smaller projects can also be seen in Idaho, Nevada, New Mexico, Oregon, Utah, and Wyoming. California is the state leader with 2,600 MW of geothermal energy currently installed, while Hawaii has one major geothermal power plant that supplies $20 \%$ of all energy used on the Big Island.

Geothermal energy is used in three main ways: direct use, power generation, and ground source heating and cooling.[9]

Direct Use: Natural hot water is extracted by a well and then delivered through piping, a heat exchanger, and controls for its intended purpose.

Power Generation: Geothermal power plants capture deep deposits of geothermal energy, whether steam or hot water, and use this to drive turbines that sequentially produce electricity.

Ground Source Heating and Cooling is the most common use for geothermal energy today. As opposed to generally heating an area using heat found in the outside air, a ground source heat pump, or GSHP, taps into the constant temperature found within the earth's surface. 
Geothermal energy definitely dominated the renewable energy market in terms of the installed electricity power until 1990. The unfortunate fact is that the total installed capacity of geothermal electricity has been eclipsed by solar and wind in recent years. The graph below, Fig. 5, shows the effect previously described. It is possible to see that from 1992 the percentage of geothermal energy consumed is decreased.

Some of the reasons for this decrease are the minor environmental issues associated with geothermal power, the fact that they can cause earthquakes and the heavy upfront costs. 


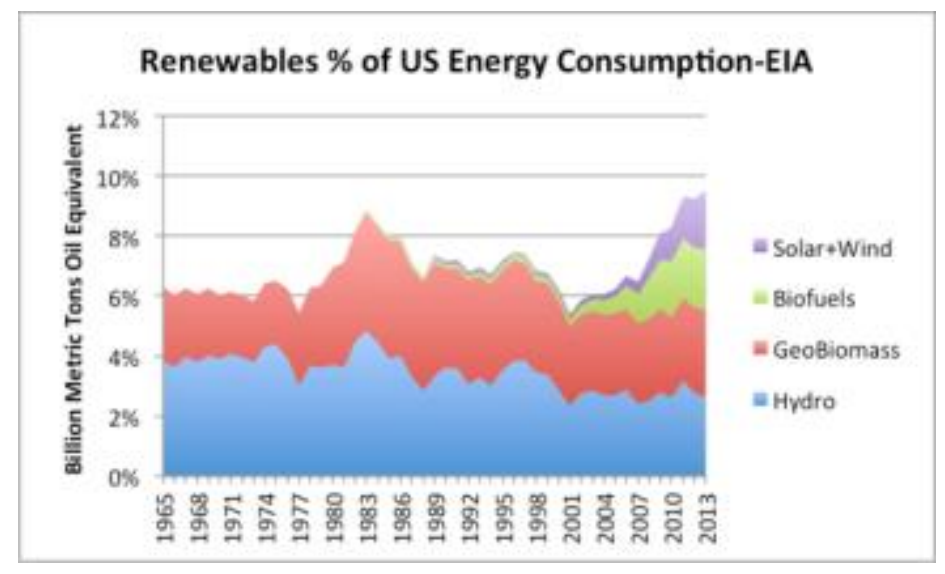

Figure 5 - Renewable \% of US Energy Consumption [9]

\subsubsection{SOLAR ENERGY}

Solar energy is the most diffuse power source nowadays and often, governments provide subsidies to allow this market to grow as fast as possible. For this reason solar energy source has been chosen as energy source for the system under analysis.

Two main types of solar collector can be suitable to collect solar energy:

- Photovoltaic cells;

- Solar heat water collectors.

Photovoltaic cells (PV) convert sunlight directly into electricity. PVs get this name from the process of converting light (photons) into electricity (voltage), which is called the $P V$ effect. The PV effect was discovered in 1954, when scientists at Bell Telephone discovered that silicon (an element found in sand) created an electric charge when exposed to sunlight.[10]

Since 2011 the residential PV market experienced its largest annual growth rate. An impressive feat allowed the market to obtain the fourth consecutive year of greater than $50 \%$ annual growth. 
Similar to prior years, California served as the primary driver of demand, fueling nearly $50 \%$ of annual residential PV installations. However, the residential market is showing glimpses of geographic demand diversification, with $20 \mathrm{MWdc}$ annual state markets for residential solar increasing threefold over the past four years. The total installation of PV system passed from 800 MWdc to 2200MWdc.

Overall system pricing fell by the $17 \%$ over the course of 2015 , depending on the market segment, with the largest declines in the utility fixed-tilt sector. On a quarterly basis, pricing continues to trend downward with some leveling-off in the residential sector in particular due to strong investment in customer acquisition and the stubbornness of other soft costs.

Average pricing for residential rooftop systems landed at $\$ 3.50 / \mathrm{Wdc}$ in fourth quarter of 2015 , with nearly $65 \%$ of costs coming from on-site labor, engineering, permitting and other soft costs. To provide an overall understanding of the cost of the energy production in the PV system other energy costs are going to be taken into consideration:

- Nuclear 1.72 cents/kWh

- Coal-fired plants 2.21 cents / $\mathrm{kWh}$

- Oil 8.09 cents / $\mathrm{kWh}$

- Natural gas 7.51 cents / kWh

While residential hardware costs have fallen by over $16 \%$ in the past year, soft costs have actually risen on an industry average basis by $7 \%$, primarily due to rising customer acquisition costs among national and local players alike.[11] 
Solar collectors, instead, transform solar radiation into heat and transfer that heat to a medium (water, solar fluid, or air). Then solar heat can be used for heating water, to back up heating systems or for heating swimming pools.

The heart of a solar collector is the absorber, which is usually composed of several narrow metal strips. For example in plate-type absorbers, two sheets are sandwiched together allowing the medium to flow between the two sheets. Absorbers are typically made of copper or aluminum.

Absorbers are usually black, as dark surfaces demonstrate a particularly high degree of light absorption. The level of absorption indicates the amount of short-wave solar radiation being absorbed that means not being reflected. As the absorber warms up to a temperature higher than the ambient temperature, it gives off a great part of the accumulated solar energy in form of long-wave heat rays. The ratio of absorbed energy to emitted heat is indicated by the degree of emission.[12]

The solar heat collector is widely spread, by the end of 2014, an installed capacity of 374.7 GWth corresponding to a total of 535.2 million square meters of collector area was in operation worldwide. The Average pricing for residential systems landed at $\$ 3.00 / \mathrm{Wdc}$ in 2016 . The vast majority of the total capacity in operation was installed in China (262.3 GWth) and Europe (44.1 GWth), which together accounted for 82\% of the total installed capacity. The remaining installed capacity was mainly shared between United States and Canada (17.7 GWth), Asia excluding China (10 GWth), Latin America (8.7 GWth) 


\subsection{PVT}

Integration of different energy production methods is a fundamental step in order for renewable energy to be competitive against fossil fuel and nuclear power. One interesting example is the combination of solar collector with photovoltaic panel called PV-T.

PV-thermal (PVT) collector is a module in which the PV is not only producing electricity but also serves as a thermal absorber. In this way both heat and power are produced simultaneously.[13] The dual function of PVT results in a higher overall solar conversion rate than that of solely PV or solar collector, and thus enables a more effective use of solar energy. Since the solar heat and electricity demand are often supplementary, it seems to be a logical idea to develop a device that can comply with both demands. Photovoltaic (PV) cells utilize a fraction of the incident solar radiation to produce electricity and the remaining is turned mainly into waste heat in the cells and substrate raising the temperature of PV as a result, the efficiency of the module decreased. The photovoltaic thermal (PVT) technology recovers part of this heat and uses it for practical applications.

The simultaneous cooling of the PV module maintains electrical efficiency at satisfactory level and thus the PVT collector offers a better way of utilizing solar energy with higher overall efficiency.

The attractive features of the PVT systems are:

- The dual-purpose: the same system can be used to produce electricity and heat output. 
- The efficiency and flexibility: the combined efficiency is always higher than using two independent systems and is especially attractive in building integrated PV (BIPV) when roof-panel spacing is limited.

- Wide viability: the heat output can be used both for heating and cooling (desiccant cooling) applications depending on the season and practically being suitable for domestic applications.

- Low cost and convenience: it can be easily retrofitted/integrated to building without any major modification and replacing the roofing material with the PVT system can reduce the payback period.

There are alternative approaches to PVT integration. Among many others, there are air, water or evaporative collectors, mono-crystalline/poly-crystalline/amorphous silicon (c-Si/pc-Si/a-Si) or thin-film solar cells, flat-plate or concentrator types, glazed or unglazed panels, natural or forced fluid flow, standalone or building-integrated features, etc. A major research and development work on the PVT technology has been conducted in the past few years with a gradual increase in the level of activities.

In this thesis only liquid PVT collector will be considered, using water as working fluid. On the market there are different types of liquid PVT collector depending on the section shape and set up of the refrigerant circuit. The two main section shapes are: square/rectangular or round. For both section shapes the fluid circuit can be oscillatory absorber circuit, spiral absorber circuit, rectangular absorber collector and web absorber circuit.

A lot of research projects have been published during the past years on this type of collector and the following are some of the proposed systems. 
Adnan Ibrahim[14],studied three different sets up: Spiral flow absorber collector, Web absorber collector and Oscillatory absorber collector. He defined and maintained the optimum operating temperature of the photovoltaic module and efficiency conversion for the entire period of the test. Results indicated that for Spiral flow absorber collector, at temperature of $55^{\circ} \mathrm{C}$ (Panel surface temperature), mass flow rate at $0.011 \mathrm{~kg} / \mathrm{s}$; the absorber collector generates combined PV/T efficiency of $64 \%$, with $11 \%$ of electrical efficiency. For Web absorber collector, at temperature of $60^{\circ} \mathrm{C}$ (Panel surface temperature), mass flow rate of $0.011 \mathrm{~kg} / \mathrm{s}$, the absorber collector generates combined PV/T efficiency of $44 \%$, with electrical efficiency of 5.9\%. For Oscillatory absorber collector, at temperature of $68^{\circ} \mathrm{C}$ (Panel surface temperature), mass flow rate of $0.011 \mathrm{~kg} / \mathrm{s}$, the absorber collector generates combined $\mathrm{PV} / \mathrm{T}$ efficiency of $40 \%$, with electrical efficiency of $5.4 \%$. As a conclusion, Spiral flow absorber collector is the best design to fulfill the aspect of integration between absorber collector and PV panel.

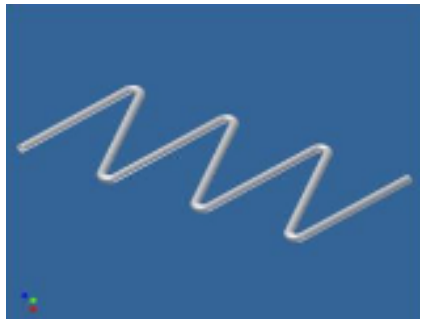

Oscillatory absorber

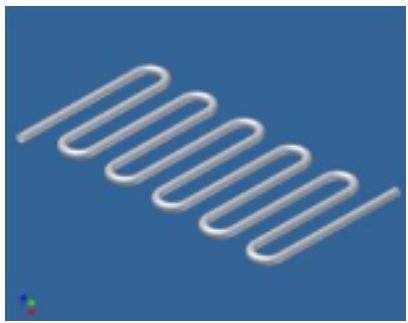

Web absorber collector collector

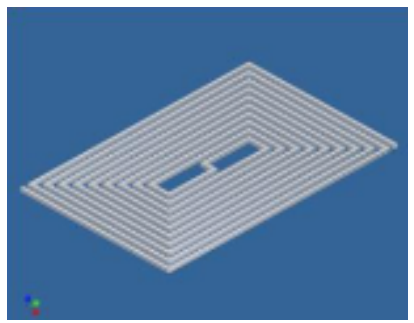

Spiral absorber collector

Figure 6 - Types of Collectors [14] 
A similar analysis has been done by Ibrahim et al. ${ }^{15}$. In this simulation, seven design configurations of absorber collectors have been designed and compared. The design shapes of the absorber collectors are either square or rectangular. Simulation has been conducted to analyze the parameters of the collectors such as the solar radiation, ambient temperature and mass flow rate. Also in this case the simulation results show that the best design configuration is the spiral flow design, with thermal efficiency of $50.12 \%$ and cell efficiency of $11.98 \%$. The two analyses provide two different value of efficiency due to the different ambient conditions during the test. Another important factor that allows improving efficiency is the optimization of the contact surfaces between the solar panel (PV module) and the tubes underneath.

\section{THE WATER MIX SYSTEM - WMS}

The purpose of this thesis is to create and test an automatic system that allows the management of hot water obtained from the PV-T collector or hot water recovered from other sources into the house that otherwise would be wasted. When the WMS is operating it allows increased the overall efficiency of the heat source use. When the WMS is not operational the hot water system works at their standard efficiency.

As previously stated, the WMS uses two source of energy: a PVT panel and the air conditioning (A/C) system already installed in the house. An outline of the Water Mix System is shown in Fig. 7. 


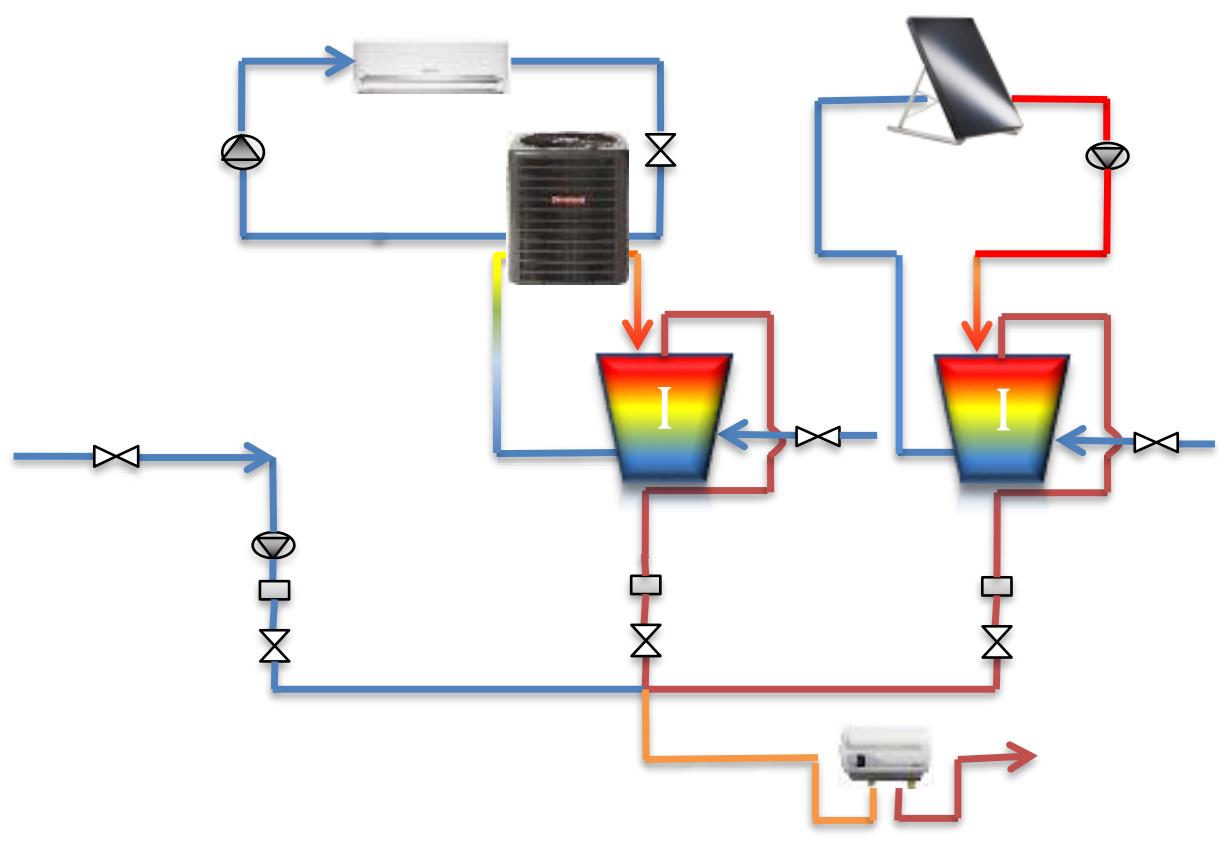

Figure 7 - Water Mixing System WMS

\subsection{Functioning}

Air conditioning (AC) is the process of altering the properties of air (primarily temperature and humidity) to more comfortable conditions, typically with the aim of distributing the conditioned air to an occupied space such as a building or a vehicle to improve thermal comfort and indoor air quality [16]. In common use, an air conditioner is a device that lowers the air temperature. The cooling is typically achieved through a refrigeration cycle.

To recover energy from the air conditioning system it is necessary to make some modifications on the refrigerant circuit.

Refrigeration thermodynamic cycles are the conceptual and mathematical models for heat pumps and refrigerators. A heat pump or refrigerator is a machine or device that moves heat from one location (the 'source') at a lower temperature to another location (the 'sink' or 'heat sink') at a higher temperature using mechanical work or a hightemperature heat source. 
Thus, a heat pump may be seen as a "heater" if the objective is to warm the heat sink (as when warming the inside of a home on a cold day), or a "refrigerator" if the objective is to cool the heat source (as in the normal operation of a freezer). In either case, the operating principles are identical and the result is that heat is moved from a cold place to a warm place.

The vapor-compression cycle is used in most household refrigerators as well as in many large commercial and industrial refrigeration systems. Fig. 7 provides a schematic diagram of the components of a typical vapor-compression refrigeration system.

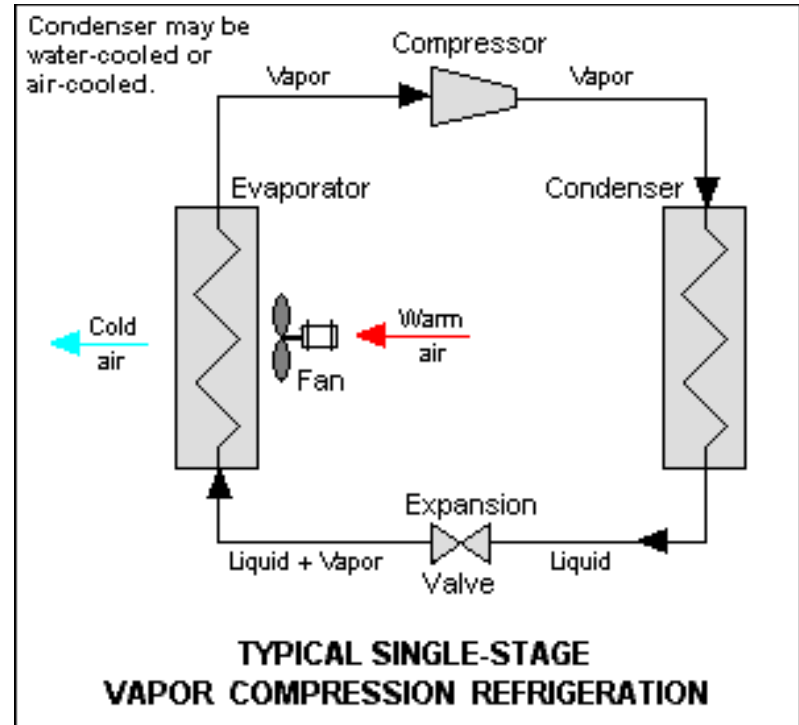

Figure 8 - Vapor Compressor Cycle [16]

The thermodynamics of the cycle can be analyzed on a diagram as shown in Fig. 7. In this cycle, a circulating refrigerant such as Freon enters the compressor as a vapor. The vapor is compressed and exits the compressor superheated. The superheated vapor travels through the condenser, which first cools and removes the superheat and then condenses the vapor into a liquid by removing additional heat at constant pressure and temperature. The liquid refrigerant goes through the expansion valve 
(also called a throttle valve) where its pressure abruptly decreases, causing flash evaporation and auto-refrigeration of, typically, less than half of the liquid.

That results in a mixture of liquid and vapor at a lower temperature and pressure. The cold liquid-vapor mixture then travels through the evaporator coil or tubes and is completely vaporized by cooling the warm air (from the space being refrigerated) being blown by a fan across the evaporator coil or tubes. The resulting refrigerant vapor returns to the compressor inlet to complete the thermodynamic cycle.

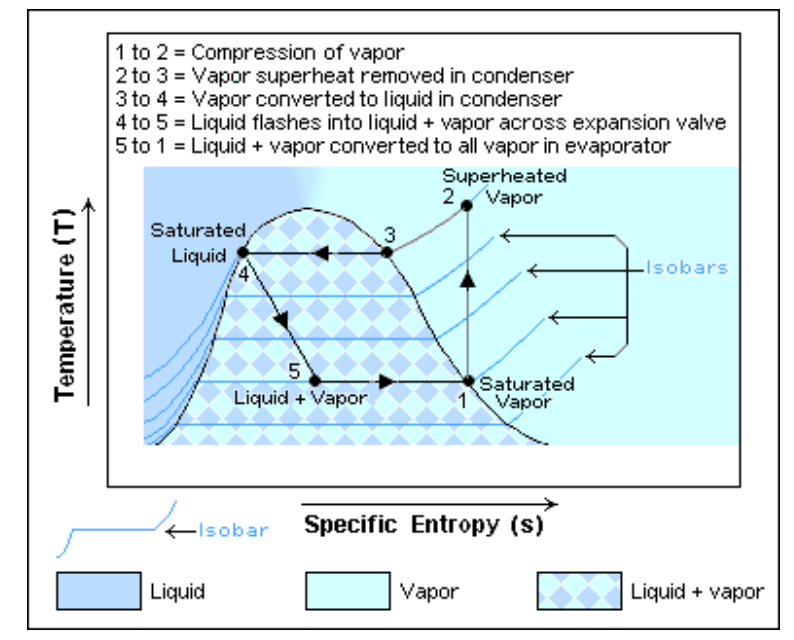

Figure 9 - Vapor Compressor Thermodynamic Cycle [16]

Therefore, the physical modification request on the refrigeration cycle is to add a heat exchanger between the compressor and the condenser. In this way it is possible to recover some of the heat from the condenser and use it to produce hot water, as well as for other applications.

\subsection{Components}

Daikin produces the air conditioner chosen for this test. The PVT collector used is series AL 275/280/285. All the technical specifications will be explained more in 
depth in sections. The other main component of the automation system is a set of proportional valves.

Proportional valves were developed for applications where the precision of a servo valve is not needed, but more accuracy is needed than a conventional valves[17].

There are various types of proportional valves: Force-Controlled, Stroke-Controlled, Proportional Pilot-Operated Relief Valve, Proportional Pressure Reducing Valve, and Proportional Directional Control Valve.

For the application to this System the valves needed are Stroke-Controlled valves. With a Stroke-Controlled valve, the stroke distance is proportional to the input signal and it provides an opening of the valve proportional to the magnitude of the milliamperes current applied to the valve.

In the present system, the proportional valves have two different functions and will be used at two different positions. The first position is at the outlet of the storage tank to control the amount of water needed from each tank to obtain the temperature desired by the water heater. The other valves are placed in the energy source loop to maximize the heat storage capacity

This project is not just a matter of enhancing the energy efficiency of the house, but it provides a technology easy to be integrated into the system already installed in the house. Therefore, it must be adaptable to most of the applications.

\subsection{Action and Forecast testing methods}

Two possible analysis methods have been provided, in order to thoroughly test the Water Mix System: 
- Action Method

- Forecast Method

The Action Method considers the temperature of the tanks in a specific moment and chooses the correct combination between them and the water line to optimize the temperature of the outcome water. This calculation is made very frequently, specifically every 5 minutes. In this way the system is always under active control. The Forecast Method, instead, is based on the weather forecast obtained from Italian national agency for new technology Association and on the air conditioning setup [18]. This method determines the tanks temperatures and the future water flow. Once the most efficient tanks combinations is obtained, the water temperature needed in a specific moment has to be determined.

Fig. 9 shows the forecast behavior of the warm and hot tanks during the phase of discharge and recharge. This graph provides the future temperature values for the information needed to decide how to manage the system.

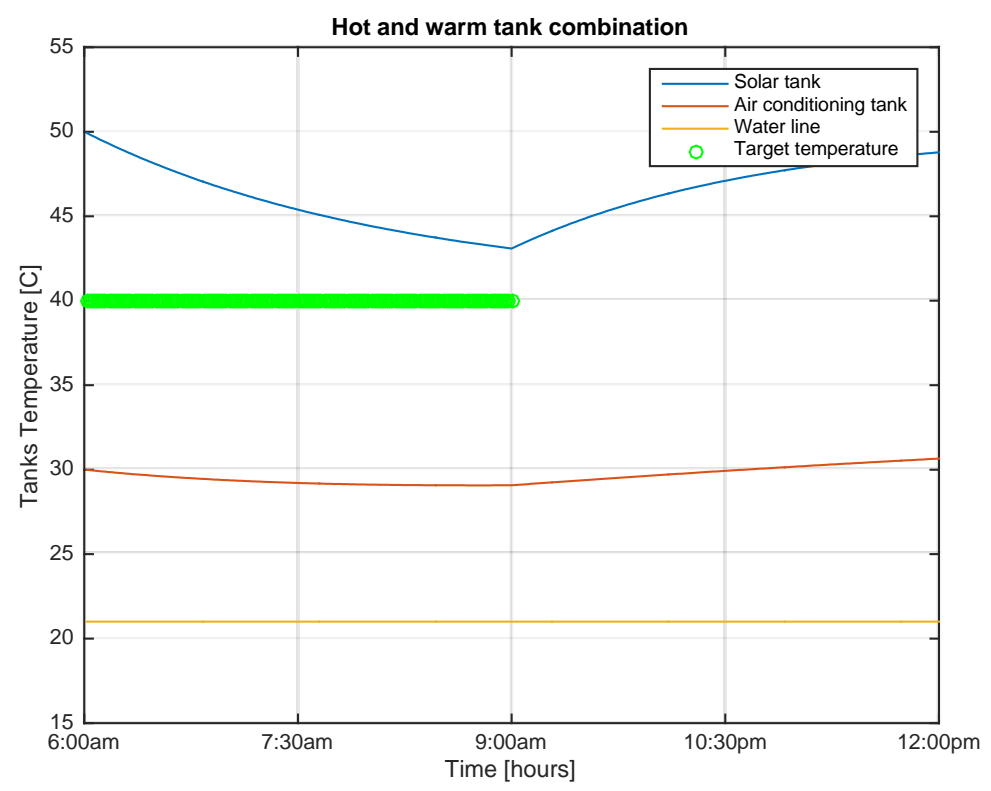

Figure 10 - Forecast Behavior of the Tanks Temperature when the Target Temperature is Between the Warm and the Hot Tank 
The computer software will create different graphs depending on whether the water provided to the water heater has a temperature between the ones from the hot and warm tanks or in case this water temperature is between the warm tank temperature and water line's temperature. As in the previous method the calculation is carried out very frequently. This allows compensating for possible mistakes or variations in the weather forecast. Both testing methods use the proportional valves integrated in the WMS to control the water flows. The valves receive the information from a computer basing on the thermocouple feedback on the water temperatures. Finally the software evaluates each tank temperature, flow rates, and the output temperatures provided to the water heater. Thus, it is possible to define the amount of energy saved using these methods and to determine the most efficient use of each tank. During the prediction phase, the system will also consider different user demands for thermal energy and different thermal tank volumes. By knowing the results of each different set up, the correct dimension of the tanks will be determined. This is an important analysis that had to be done before

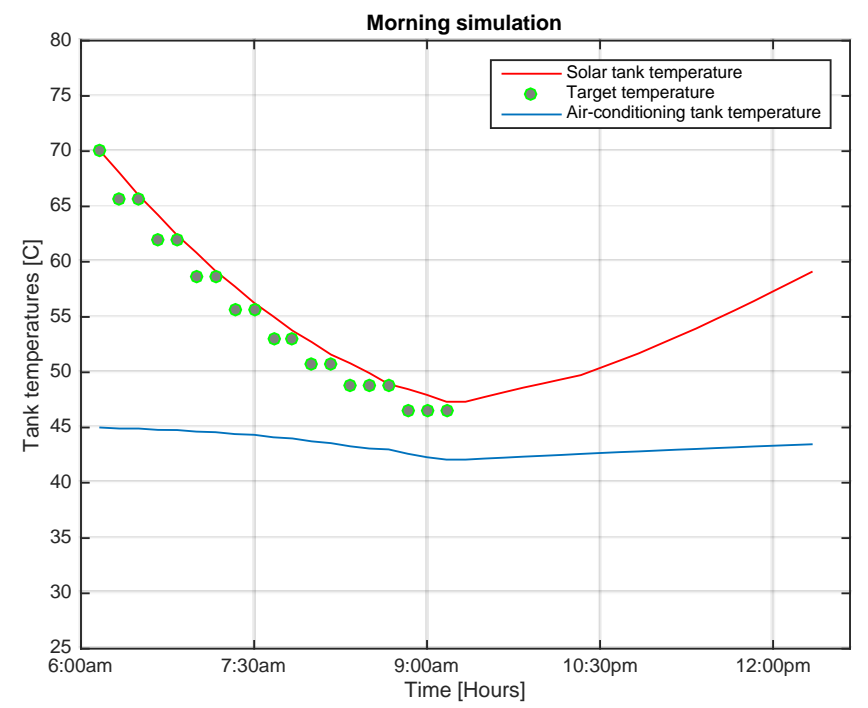

Figure 11 - Forecast Method: real temperature trend of warm and hot tanks and of outcome water 
implementing the system.

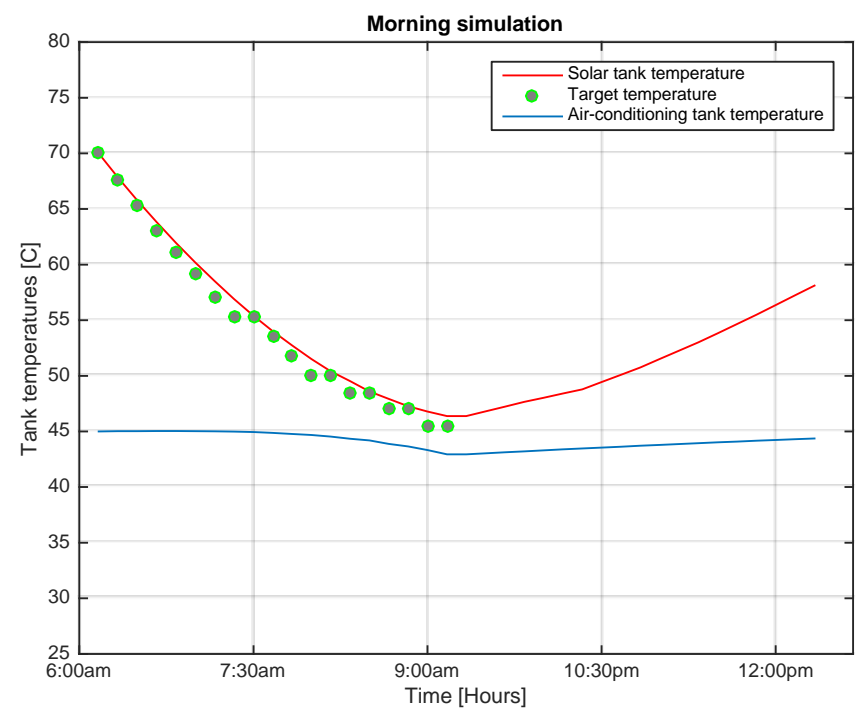

Figure 12 - Action Method: real temperature trend of warm and hot tanks and of outcome water

Fig. 11 shows the trend of the actual temperature during the period of discharge and recharge using the Forecast Method. Here we can see that the temperature to the water heater is automatically set, to always provide the highest temperature the tank can dispense.

Fig. 12 shows the same outcome values using the Action Method. The average

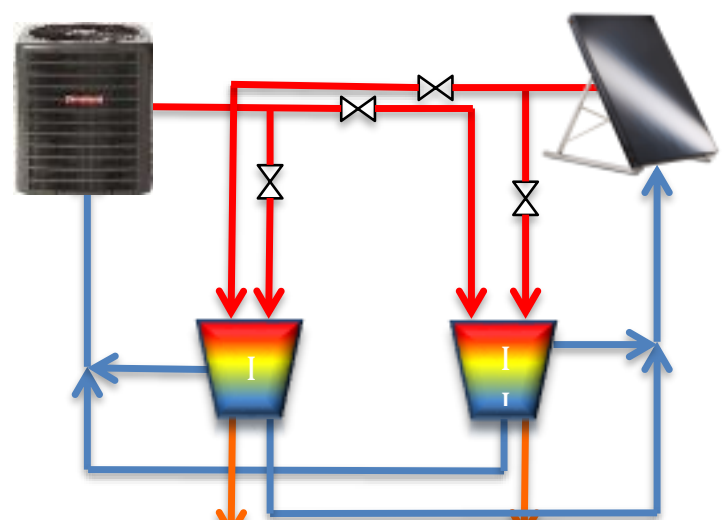

Figure 13 - Storage management system 
temperature provided to the water heater in the Forecast Method is higher than that in the Action Method.

Fig. 13 shows an implementation to the initial system with a goal to improve the energy storage. The waste of the energy surplus must be avoided. For example, if a tank reached its maximum temperature but the source is capable of furnishing more energy at the same or higher temperature, the heat surplus would not be wasted but instead, stored in the tank at a lower temperature, if available.

\subsection{Terminology of the MWS}

For a better understanding of the following data, it has been decided to give specific names to the main parts of the MWS.

The two heat sources will be called "Solar Heat Source" and "AC Heat Source"; the respective tanks will be seen as "Solar Tank" and "AC Tank". The water temperature in each tank will be referred to as "Solar Water Temperature" and "AC Water Temperature". The water temperature obtained after the mix will be generally called "Outcome Temperature" or "Target Temperature" when speaking of a specific outcome. Finally, the temperature demanded by the user will be called "User Temperature".

\subsection{Hypothesis}

The Water Mixing system automatically decide the most efficient combination of the two water tanks and the water line, in order to provide the water temperature needed by the water heater in a specific moment. 
By employing this system, the residential energy consumption of the water heater can be substantially reduced. It possible to see the effect of this system not only when it is capable to provide the water temperature requested by the user but also, during all cases, when the water provided to the instant water heater has temperature higher than the water line temperature. The reduction of energy consumption can reach substantial savings, with an average of $70 \%$ during the entire year. More specifically, it has been verified that in some cases in April the savings reach $100 \%$. Clearly during the winter time the percentage of saving is going to be reduced due to the use of the PV-T system only. Finally, to understand the effectiveness of the Water Mixing System, it can be notice an increase of the savings up to $10 \%$ compared to the PV-T system only. This is an excellent result considering the low water temperature provided by the air condition system.

\subsection{Theory}

Mass Balance and Energy Conservation for a closed control volume are the basic concept behind this construction of the WMS. The project will involve mixing water from two different tanks at different temperature and times. Therefore the mass balance theory is employed [19] :

$$
m_{\text {waterheater }}=m_{\text {hottank }}+m_{\text {warmtank }}
$$

The corresponding energy conservation (or energy balance) equation is [20]:

$$
m_{\text {waterheater }} c_{p} T_{\text {waterheater }}=m_{\text {hottank }} c_{p} T_{\text {hattank }}+m_{\text {warmtank }} c_{p} T_{\text {warmtank }}
$$


Clearly, this is just one example of the combinations. During the calculation phase all the possible combinations are taken into consideration. Regarding the energy provided from the different sources the following Heat Transfer equation is used [21]:

$$
Q=m c_{p}\left(T_{\text {out }}-T_{\text {in }}\right)
$$

When using solar energy as a heat source, it is necessary to examine the variation in input temperature to the tank from the solar water heater. Therefore, the variation of the sun radiation as well as the variation of the average temperature inside the tank will be analyzed. Air conditioning (AC) heat sources, instead, have a constant value of heat transfer and the average temperature inside the tank changes as in the previous case.

Different cases will be proposed in order to understand when is worth to use this technology. The scenarios proposed are: a family composed by four people, a couple, and a single person.

The final goal of this Master Thesis is to calculate the Pay Back Time in order to understand if the installation of this system can provide an actual benefit on the final utility bill.

\section{Methods}

In order to understand the thermodynamic properties behind this process, it is fundamental to develop in depth analytical calculations. Furthermore, to simulate the process for a longer timeframe, computational analysis is necessary.

The objective of this project is to manage the hot water obtained from the different sources for the reduction of the energy used by the instant water heater. The Target Temperature has to be either equal or as close as possible to the User Temperature. 
Two hot water tanks and the water line are the main components of this system. The latter is used in case the target water temperature needs to be cooler. The two tanks store hot water and they are heated by different sources, such as solar panels or air conditioning system.

The water line has a starting temperature of $70^{\circ} \mathrm{F}$. The two hot water tanks have different temperatures, mainly depending on the heat source. The hottest one starts at $160^{\circ} \mathrm{F}$, thanks to solar sources, the other is considered to start at $100^{\circ} \mathrm{F}$ and it is heated by the air conditioning heat exchanger. The average water temperature of each tank changes continuously, depending on three factors: the water flow rate employed, the necessary target temperature, and the heat sources.

It is assumed that the amount of fluid employed by the user is rapidly and automatically replenished by the water line to keep the tanks always full. Also, when the water of a heated tank needs to be warmed up, a specific water flow rate will be extracted by the tank, heated by the respective heat source and reinserted into the tank. Therefore, the thermodynamic equations that describe the system are the Conservation Equation and Mass Balance Equation. While the water line temperature is assumed to be constant during the year.

The daily peaks of hot water demand are considered to be: from 5:30 to 8:00 AM, from 10:00 AM to 1:00 PM, and from 6:00 to 7:00 PM. These three daily peaks are considered to be equal. 


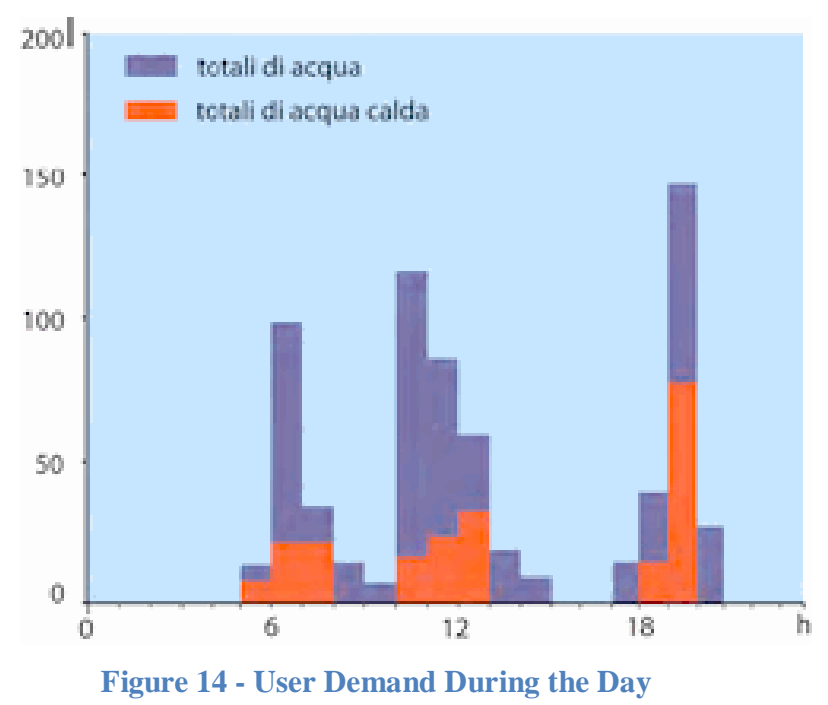

In order to make this study more realistic, different households will be taken into consideration: single person, a couple, and 4 family members. In all these case the flowing values will be constant:

- 60 Liter person/day

- 1 washing per day (20 liters)

- 1 dishwashing per day (20 liters)

The total water demand of the single person is:

$$
60 l * 1+20 l+20 l=100 \frac{l}{d a y}
$$

The total water demand of the couple is:

$$
60 l * 2+20 l+20 l=160 \frac{l}{d a y}
$$

The total water demand of the family is: 


$$
60 l * 4+20 l+20 l=280 \frac{l}{d a y}
$$

The water temperatures usually requested are:

- Shower: $120-140^{\circ} \mathrm{F}$

- Washing machine: $140^{\circ} \mathrm{F}$

- Dishwasher: $140^{\circ} \mathrm{F}$

\subsection{Minimum Temperature}

Before going any further, it is necessary to define the minimum water temperature of the hottest tank. The minimum temperature is a very important parameter. It has to be carefully calculated in order to guarantee that the system produces more energy than what it uses. The energy used by the system is calculated by taking into consideration the pumps, the proportional valves and the appliances.

The energy used by the instant water heater to warm up the water from $70^{\circ} \mathrm{F}$ to $140^{\circ} \mathrm{F}$, in absence of the system that has been evaluated, is:

$$
Q_{\text {boiler }}=\dot{m} * c_{p} *\left(T_{\text {out }}-T_{\text {in }}\right)=\dot{m} * c_{p} *(140-70)
$$

Where:

$Q_{\text {boiler }}$ is energy provided by the instant water heater to warm up water from $70^{\circ} \mathrm{F}$ to $140^{\circ} \mathrm{F}$

$\dot{m}$ is the flow rate that flows through the instant water heater

$c_{p}$ is specific heat of the water

$T_{\text {out }}$ is outlet temperature after the instant water heater 
$T_{\text {in }}$ is water temperature insert in the instant water heater

MWS allows saving energy used by the instant water heater since the inlet instant water heater temperature will be higher than the water line temperature. For this to be true, the energy necessary to increase the water line temperature $\left(70^{\circ} \mathrm{F}\right)$ to the minimum outlet temperature has to be greater than the energy used by the MWS. Under a limiting case that this system is still useful is when the two energies are identic.

Therefore, the minimum energy that must be provided by the system is:

$$
Q_{\text {gen }}=\dot{m} * c_{p} *\left(T_{\min }-70\right)
$$

The condition that must be verified is:

$$
Q_{\text {gen }}-Q_{\text {used }} \geq 0
$$

$Q_{g e n}$ is the minimum energy the system has to generate to guarantee that it produces more energy than what it uses,

$Q_{\text {used }}$ is the total energy used by the pumps and the appliances, and $T_{\min }$ is the minimum temperature of the target water temperature. This means that the tank temperature has to be greater than $T_{\min }$. If the tank does not reach that temperature, the usage of the instant water heater is unavoidable.

When hottest tank temperature is equal to $T_{\min }$, it will provide $100 \%$ of the flow rate required (a limiting condition). 
The minimum temperature is related to the structure of the system; therefore it needs to be calculated in the overall analysis.

\subsection{Maximization of energy storage}

In addition to the minimum temperature, it is important to consider the maximum temperature that the tanks can reach. Certain components of the plant related to the energy collection cannot reach determined temperatures for safety reasons, but it is still important to attain the target temperature to avoid energy wasting. This means that the maximum target temperature should be the temperature requested by the user. For safety, this maximum temperature should avoid expansion of the liquid and damages to the components.

Temperatures above the boiling point can damage the solar panels and the $\mathrm{A} / \mathrm{C}$ system. Therefore, if the tank temperature heated by the solar panel is close to the boiling temperature, it is mandatory to stop energy collection or to divert the energy collected to the other tank. This problem can be solved automatically by managing correctly the proportional valves or by covering the solar collector to stop the absorption of sun radiation. The correct management of the valves would also solve the similar issues for the $\mathrm{A} / \mathrm{C}$ system. When the system is safe and the valves are correctly managed, the only concern will be to avoid providing the user with more energy needed. The energy waste occurs when cold water has to be used to cool down the mixture provided by the system.

The following is a graphical explanation of the storage capacity of the plant that maximizes the energy collected. 


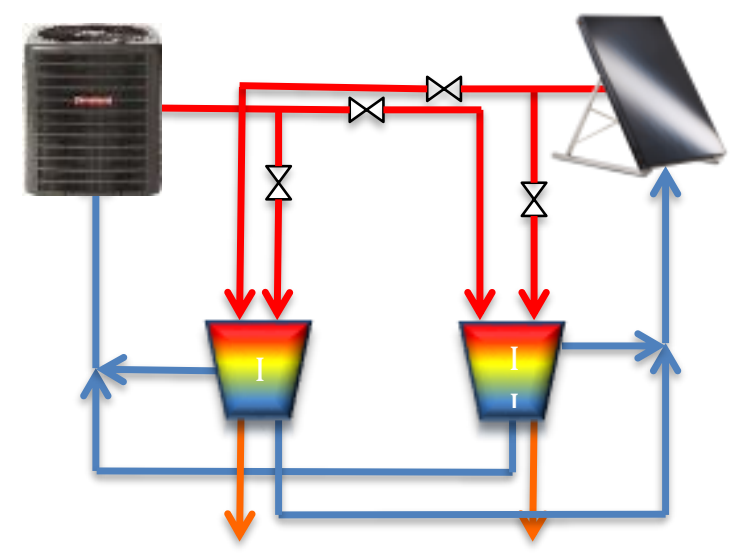

Figure 15 - Storage Capacity

This specific section of the MWS includes 4 valves; they are opened and closed depending on the data provided by the thermocouple in the tanks.

Each heat source has two loops. The primary loop connects the heat source with its own tank and one valve that controls the flow rate. The valve is kept open until either the temperature of the water provided by the heat source is lower than the average temperature in the tank or the temperature provided by the heat sources is higher than the maximum temperature allowed. Therefore, if the valve of the primary loop is closed, a check will be done on the temperature of the fluid into the other tank. If the temperature measured is lower than the temperature of the primary tank the system will automatically start filling the other one. The second tank will be heated by two heat sources until its temperature does not reach the maximum allowed. This process avoids energy waste and actually makes the system even more efficient.

The following code shows how the system evaluates the average temperature of each tank. In particular this is the regular case in which the capacity management does not affect the regular loops of the system.

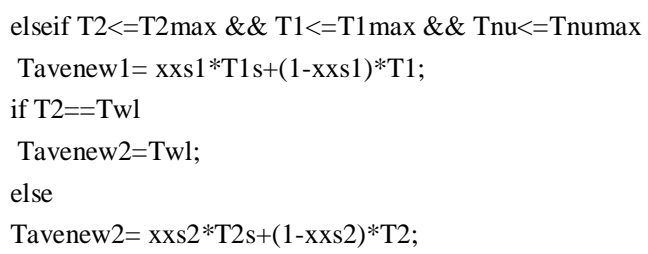




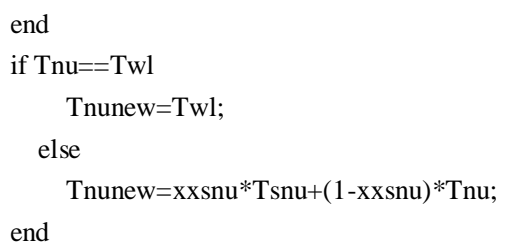

To have a better understanding of the code, all the parameters in this code are defined here. $\mathrm{T} 1$ is the temperature of the hottest tank, $\mathrm{T} 1 \mathrm{~s}$ is the temperature of the water from the heat source linked to the hottest tank, Tavenew1, Tavenew2 and nu are the new average temperature of each tank and water line just calculated.

The code instantly understands which, $\mathrm{T} 2$ or Tnu, represents the water line temperature. It does so by knowing that the water line is constant during the entire year. In the mean time, the system evaluates the new average temperature of the tanks.

\subsubsection{Highest Limit of Solar Tank Temperature}

The following examples are special cases where the capacity management has to intervene to increase the energy storage and avoid energy waste. 


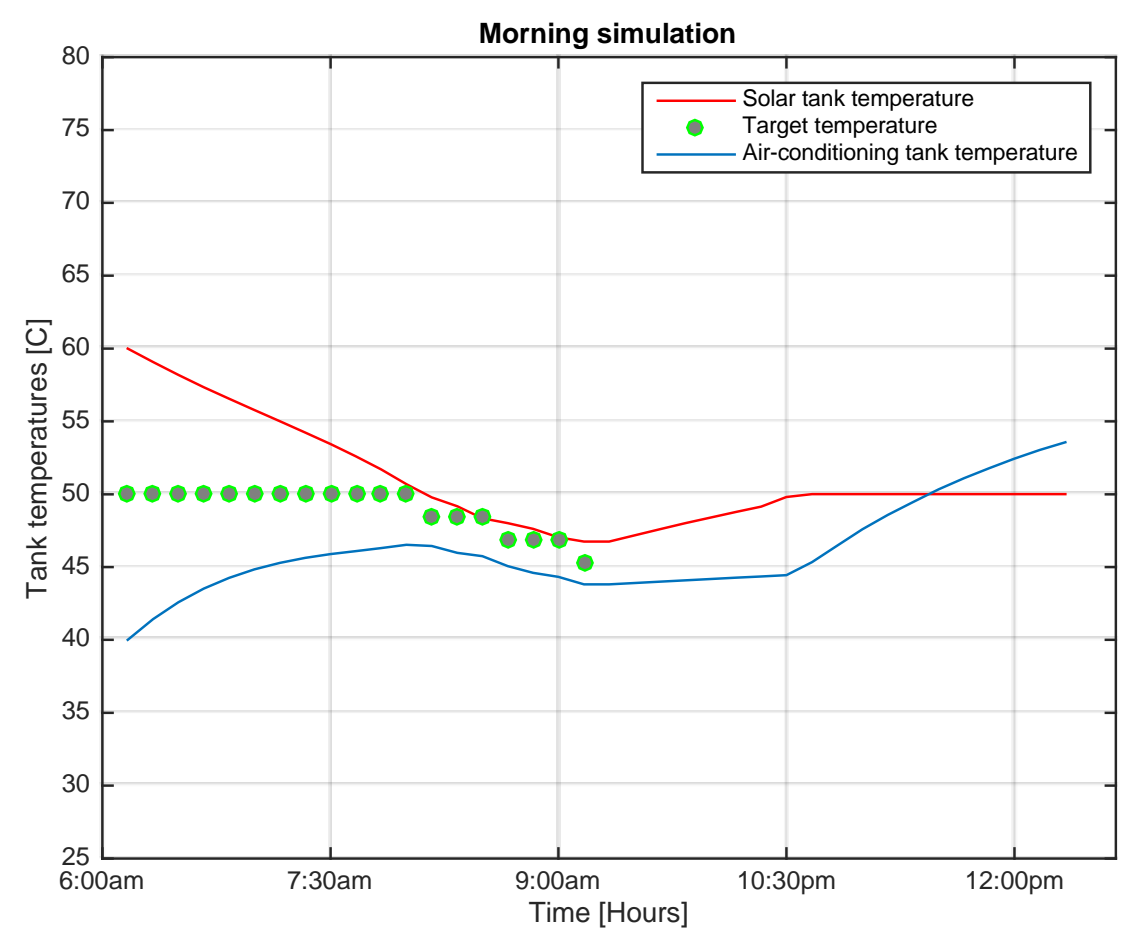

Figure 16 - Trend of AC and Solar Tanks with highest limit temperature on the solar source

In the graph above, the blue line represents the solar tank temperature trend, the green one represents the $\mathrm{AC}$ tank and the red one is the outcome temperature. It has been set a limited maximum temperature for each tank: $50^{\circ} \mathrm{C}$ for the solar tank and $100^{\circ} \mathrm{C}$ for the AC tank. With this set up, it is possible to see the capacity management system in action.

The solar tank can decrease its temperature by providing the outcome temperature alone until its temperature is below the maximum set. Then, both tanks will collaborate to provide the target temperature. When the demand is satisfied (demand equal to zero), the temperature of the solar tank does not exceed the maximum limit of $50^{\circ} \mathrm{C}$. Therefore, the extra energy provided by the solar panel, which was supposed to be received by the solar tank, is provided to the air conditioning tank, increasing its temperature faster. 


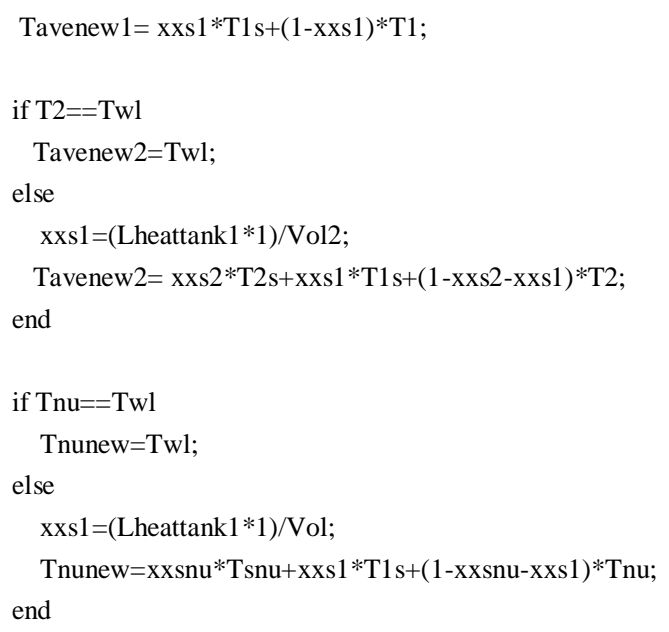

The code shown above explains this process. In this case, T1 is the temperature of the solar tank, T2 is the temperature of the AC tank, Tnu is the water line temperature, and Ts1 is the temperature of the heat source coming from the tank associated with T1.

A very important parameter in this code is $\mathrm{xxs} 1$, which is the percentage of water coming from the heat source to that going into warm tank.

In the example discussed above, xxs1 equals to zero because there is no fluid provided from source 1 to tank 1 . Instead, when xxs 1 is referred to tank 2 it is going to be equal to (Lheattank $1 * 1) / \operatorname{Vol} 2$ when the temperature of the flow rate from the heat source $1(\mathrm{~T} 1 \mathrm{~s})$ is higher than the temperature in tank $2(\mathrm{~T} 2)(\mathrm{T} 1 \mathrm{~s}>\mathrm{T} 2)$. It is possible to see in the code that if the temperature of tank 1 is higher than the maximum temperature allowed, the flow rate that is supposed to enter tank 1 would enter tank 2, avoiding the waste of warm water in the water line.

\subsubsection{Highest Limit of AC Tank Temperature}

The graphs below have been created to show the proper functioning of the system in the case where the AC tank reaches the highest temperature allowed. The first graph 
demonstrate that the maximum $\mathrm{AC}$ level does not influence the management of the two tanks; each tank receives energy from its own heat source. The second graph reproduces the case when the $\mathrm{AC}$ has a maximum temperature limit that is lower than the average temperature of the solar tank and at a certain point it becomes constant. Therefore, all the valves in the AC heat source loop close. In this case, if the excess of heat from the air conditioning would have been provided to the solar tank, it would have caused the average temperature to cool down.

This comparison is a proof that in both cases the solar tank temperatures does not receive energy from the $\mathrm{AC}$ heat source. Therefore, when the air conditioning tank has a maximum temperature limit that is lower than both tanks' average temperature, the system will stop supplying water to both tanks, closing all the valves in the heat sources loops.

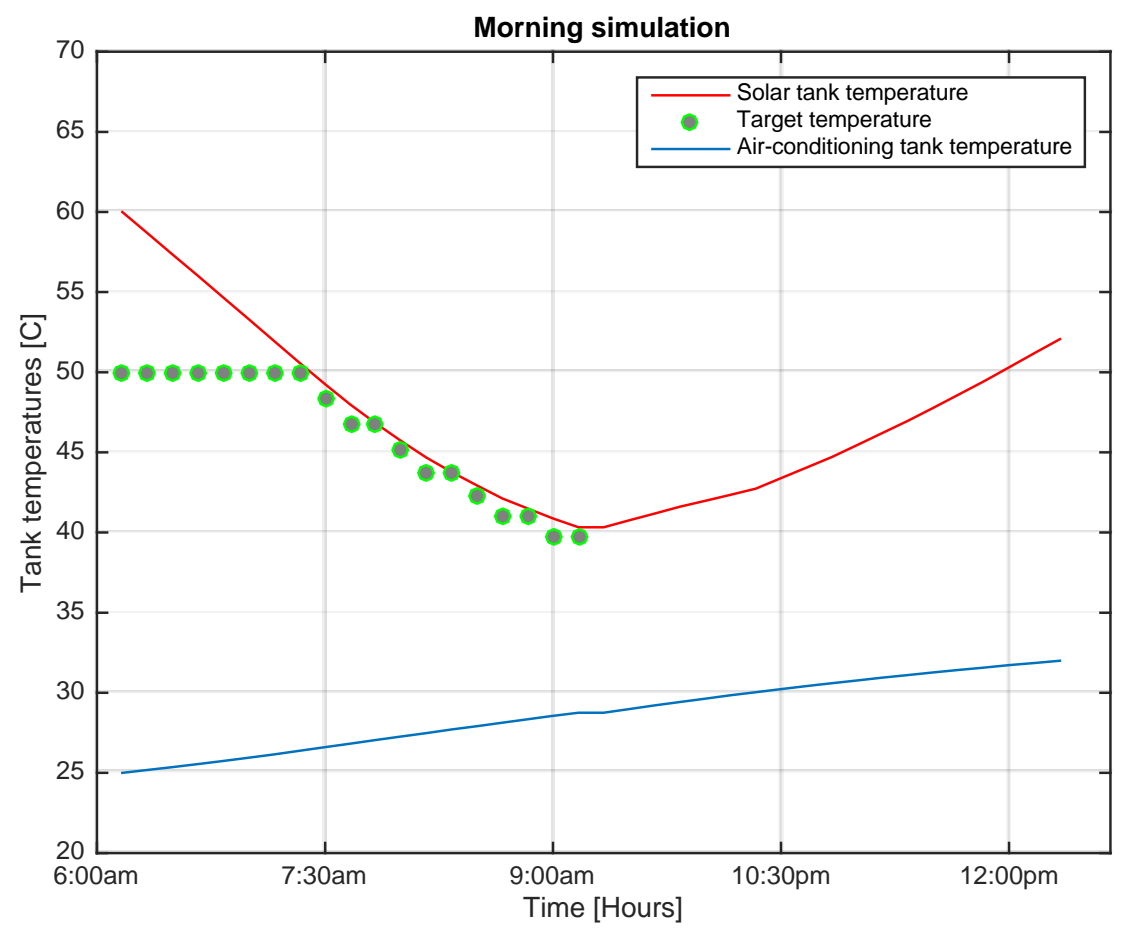

Figure 17 - Temperature trend of AC and Solar tanks without limit 


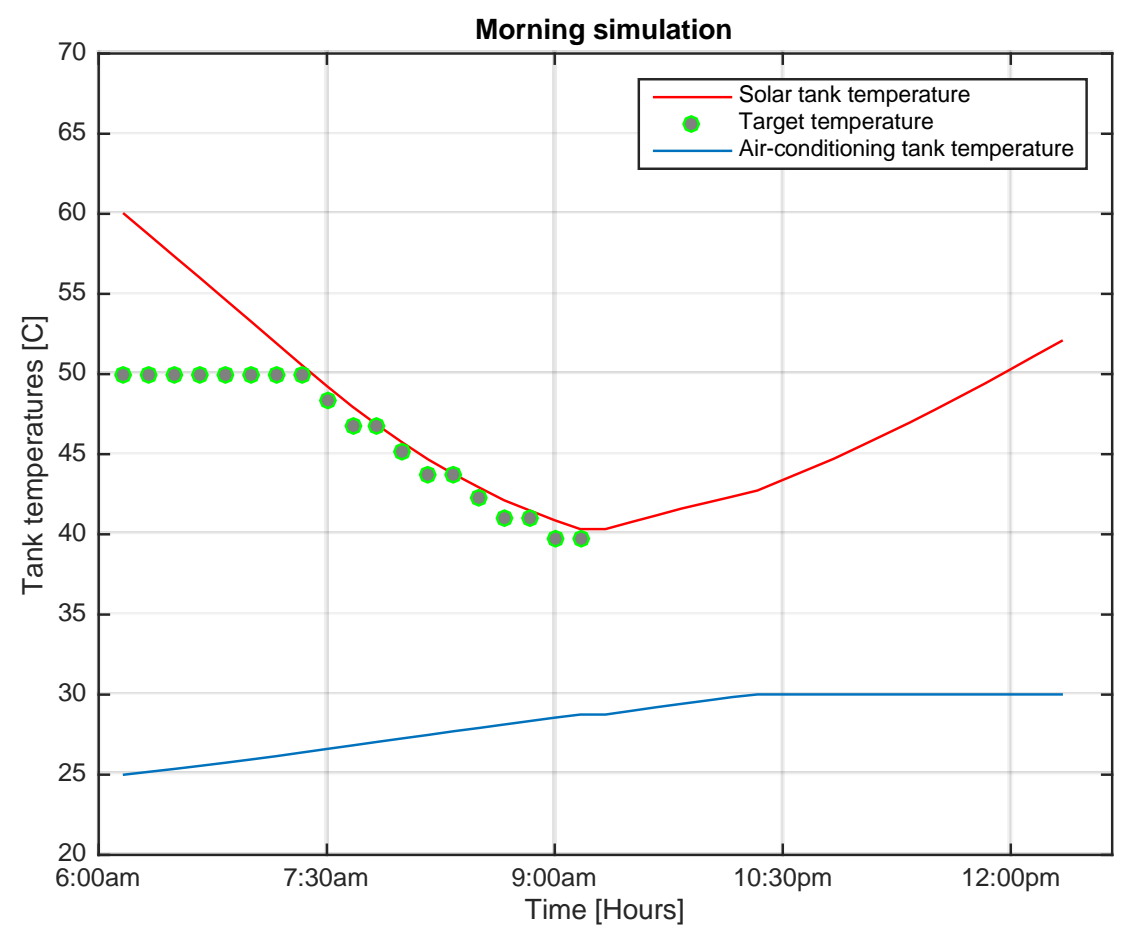

Figure 18 - AC and Solar Tanks temperature trend with limit

The following is a portion of the proposed code that defines the situation shown in Fig. 17, where $\mathrm{T} 2$ is bigger than or equal to T2max. AC tank (tank 2) cannot be filled with hot water and in parallel the temperature of water from the heat source of tank 2 (T2s) is colder than the temperature in the solar tank (T1) that is the hottest. As shown in the code below, the fraction of flow rate provided by heat source 2 (xxs2) is zero because there is no tank that can have any benefit to receive that flow rate. Tank 2 is already too hot and tank 1 would be cooled down. In this set up the water line temperature is defined as Tnu and it is not affected by the flow rate received.

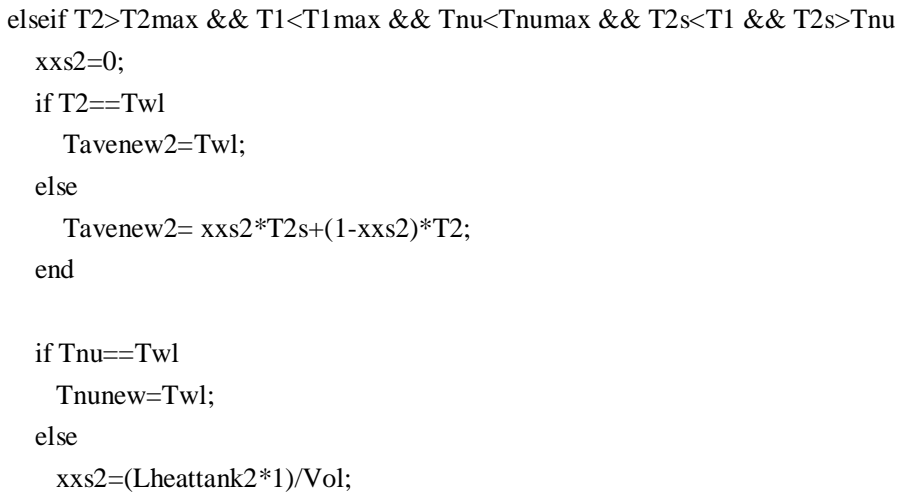




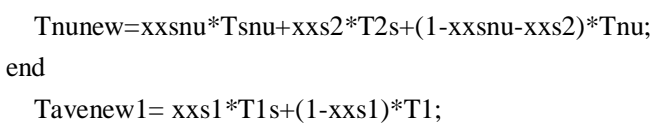

All the possible combinations are considered in the script in order to avoid any waste of energy.

\subsection{Tanks combinations related to $\boldsymbol{T}_{\text {target }}$}

\subsubsection{Forecast and Action methods}

As previously mentioned, in order to better test WMS, two computational analysis methods have been used: the Forecast Method and Action Method. The purpose of both methods is to provide the target temperature for the longest period possible, after the mixing of the three tanks available. If it is not possible to provide the temperature requested, the outcome must be as close as possible.

The Forecast Method manages the warm water storage to predict the availability of energy produced by the heat sources. In this way the excessive use of one tank will be avoided if there is not enough energy to recharge the tank. Let's suppose that the AC tank is close to being completely empty. The Forecast Method prevents it from going lower than the minimum level and allows a faster recharge. Another advantage of this method is that it limits the number of times that the valves are opened and closed. Therefore, less electric energy is consumed.

The Action Method, instead, is more straightforward. It checks the actual temperature of both tanks and then, depending on the value obtained, manages the valves. The advantage of this method is its simplicity. It does not require an additional Internet connection to obtain the weather forecast and it avoids all the further issues related to wrong forecasts. The weather forecast performed is just for 10 minutes; therefore the 
values obtained are very accurate. For these reasons the tests that use both methods will be proposed..

\subsubsection{Target Temperature between Solar and AC tank}

The target temperature is the temperature of the water obtained by mixing the three heat sources: air condition tank, solar tank and water line. If the target temperature is between the temperatures of the two tanks, the ideal combination does not involve the usage of the water line. This would avoid the water line cost and would fully take advantage of the energy sources.

There are other situations that this system must manage. In the following pages all of the possibilities will be discussed. To obtain a clear overview it is useful to provide a description for all possible ways to obtain the target temperature as output.

\subsubsection{Forecast method}

The target temperature can be either:

- A value between the hottest tank and the warm tank or,

- A value between the warm tank and the water line.

In the first case, as already mentioned, the best combination is to mix the hot tank and the warm tank. If the water into the hot tank and the water line are mixed, it is possible to obtain the same output. Only in the limiting case where the target temperature is equal to the hottest tank temperature, the $100 \%$ of the flow rate provided comes from the hot tank, until the system is able to provide it. Afterwards, the instant water heater has to be involved until the system is re-charged. 


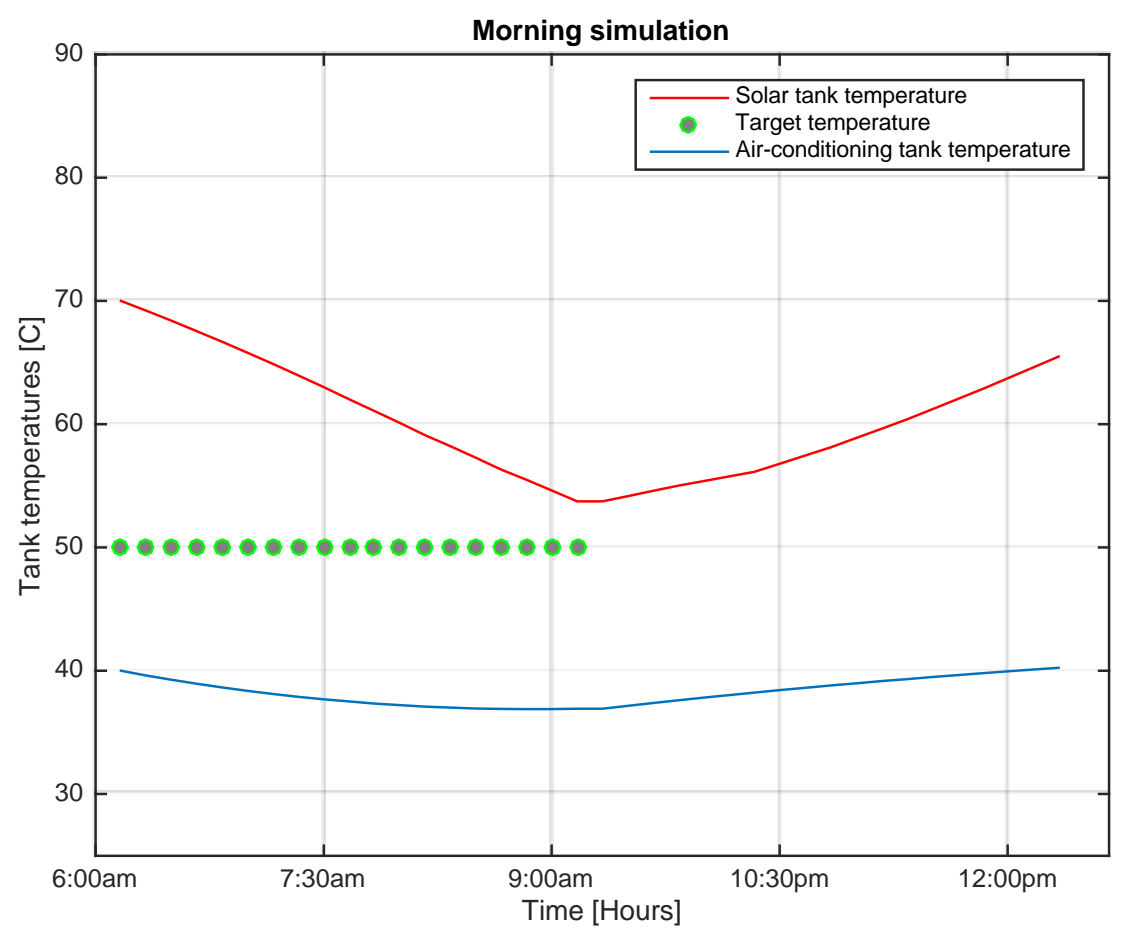

Figure 19 - Temperature trend of AC and Solar tank managed with Forecast Method

The graph above shows the case in which the target temperature is between the temperatures of the two tanks. It is possible to see how both temperatures decrease during the user demand period, from minute 0 to minute 175 . The recharge period, instead, goes from minute 175 to minute 350 .

Some specific applications are described to have a better understanding of the Forecast Method and the Action Method.

The following code is proposed for the mixing combination with the Forecast Method.

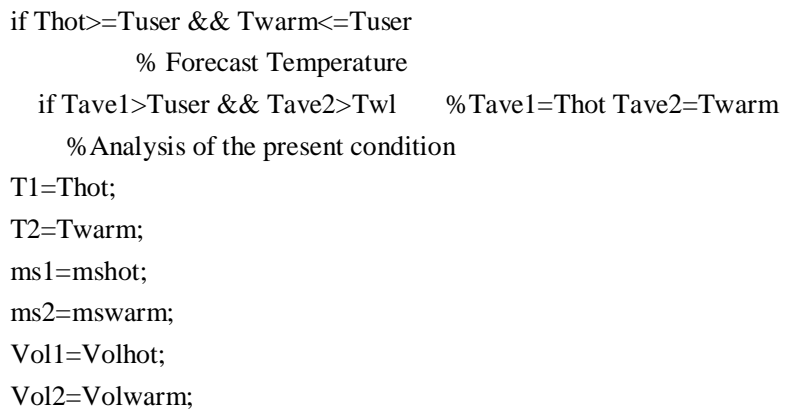




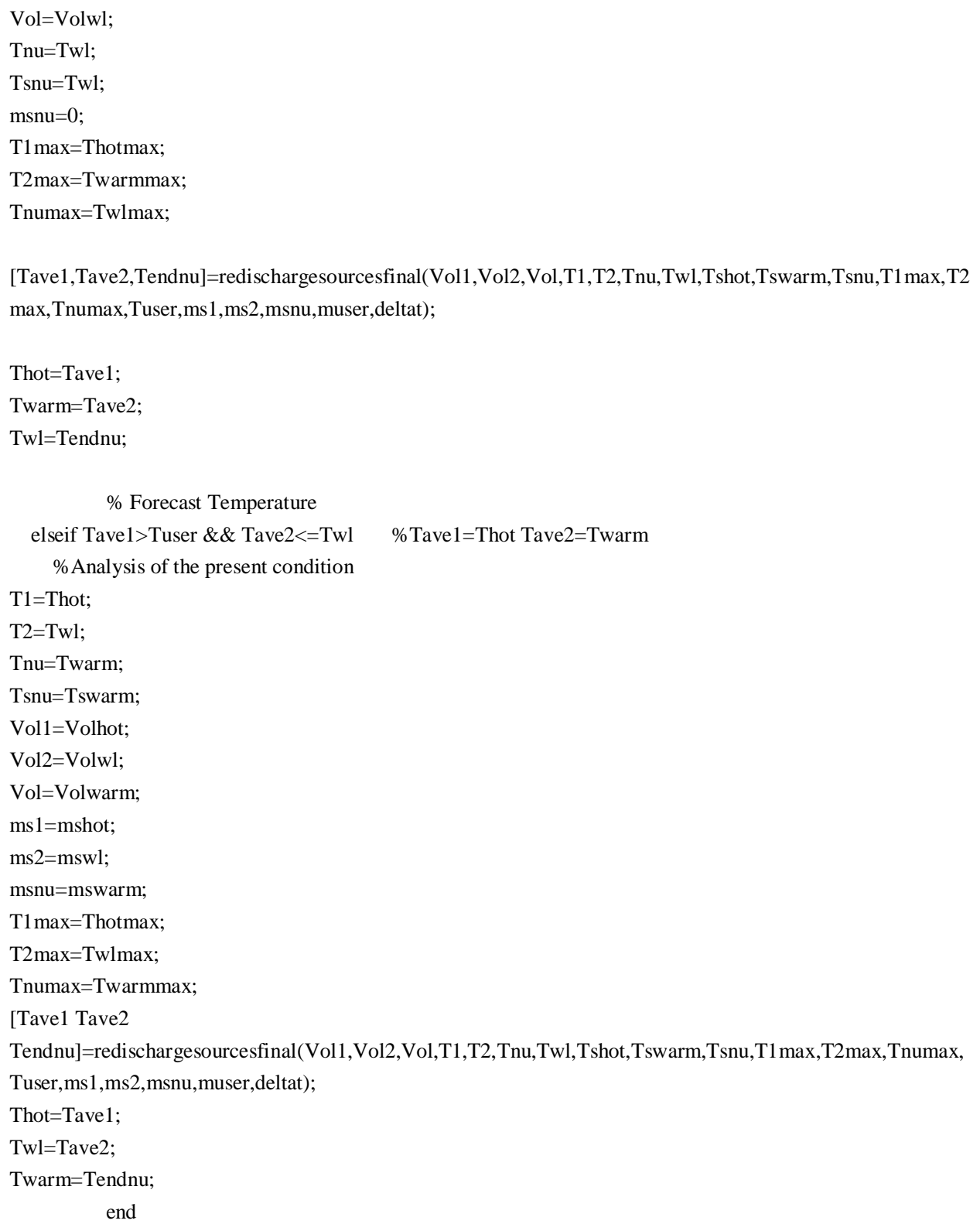

Initially, the code utilizes "if" cycle to check if the value of the target temperature is between the temperature of the two warm tanks. After that, the parameters Tave1 and Tave 2 are introduced. These are the temperatures of the hot and the warm tanks after ten minutes. It has been assumed that the Internet weather forecast of the next hour is correct and that a timer controls the AC in the house. The Forecast method appears to be very useful when all tanks are almost fully discharged and the system needs to become more efficient. The forecast allow the identification of the tank with faster recharge, which means higher availability of heat from the heat sources. The tank 
with this characteristic will be the one used. Once the tanks combination has been decided, as it can be seen in the code above, it is possible to define $\mathrm{T} 1$ and $\mathrm{T} 2$, named previously in the section of maximization of energy storage. T1 is always going to be the hottest temperature available and $\mathrm{T} 2$ instead, can be either the warm tank temperature or the water line temperature.

Finally, the function "redischargesourcesfinal" is used. The purpose of this function is to evaluate the temperature of both tanks after one minute from the present time. In the real case analysis, these two temperatures are evaluated by thermocouples.

\subsection{Definition Tave1, Tave2 and "test" function}

The function "test" allows the combination of the tanks in all the possible ways to obtain a specific target temperature. In this case, Tave1, Tave2, Tave12, and Tave22, are the temperatures in the tanks that are being mixed. For example if the target temperature is between the hot and warm tank temperatures, this temperature is shown in the following two graphs. 


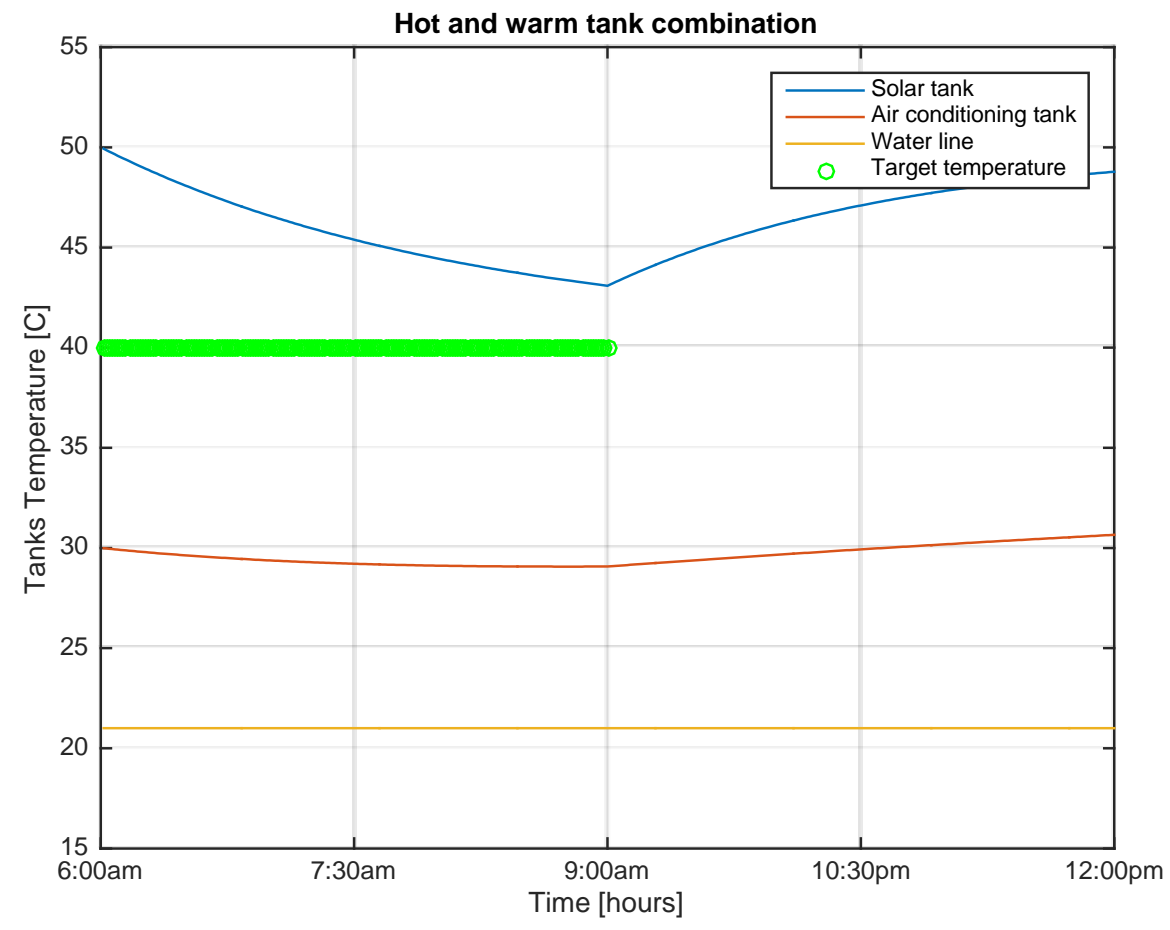

Figure 20 - Hot and Warm Tank combination forecast weather

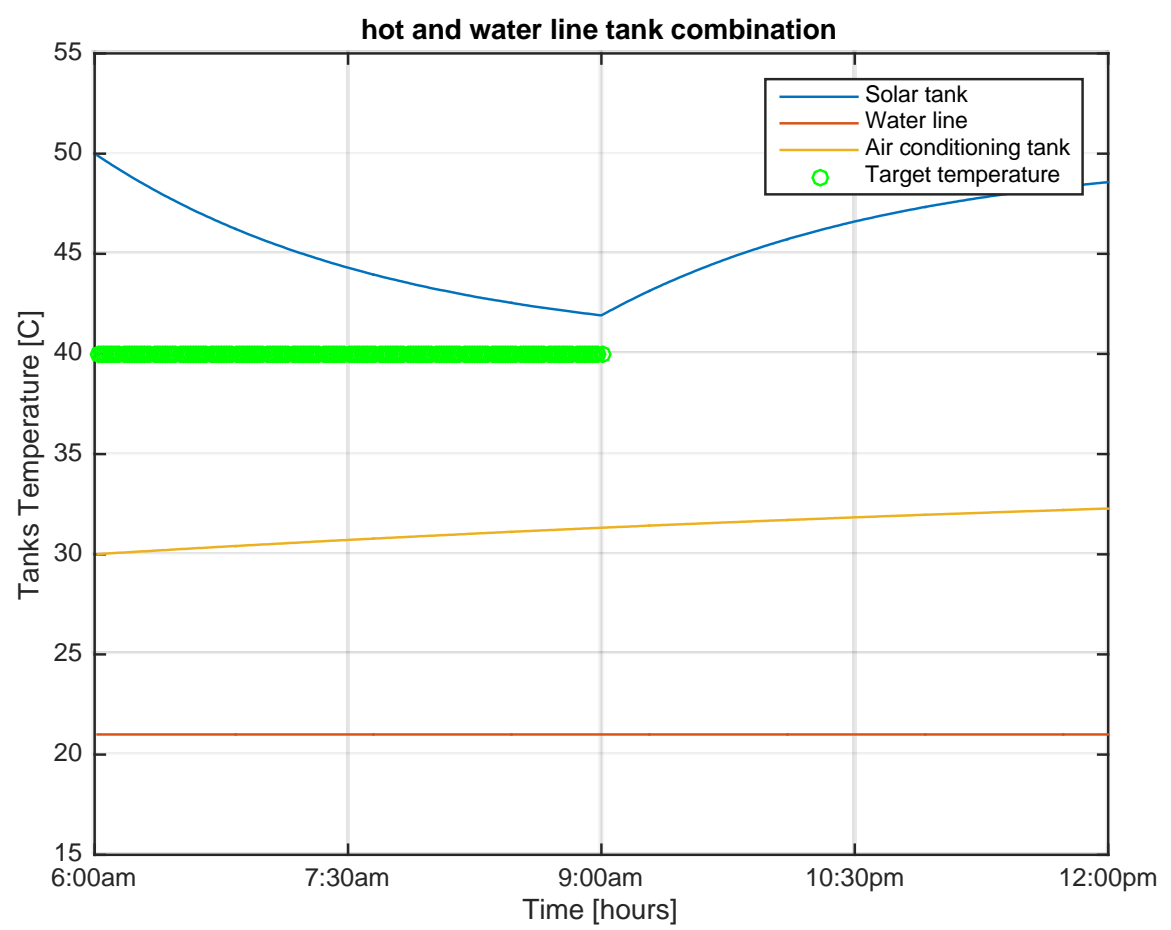

Figure 21 - Hot Tank and Water line tank combination Forecast Method

After a graphical representation of the tank's temperature trend, it is clear that the combination between the hot tank and the water line combination is not worth to be considered. 
Thanks to the analysis on Tave1 and Tave2 we can highlight multiple reasons that lead to this conclusion.

The first is that this system has been proposed in order to recover as much energy as possible. Therefore, if one of the two tanks has collected energy and it has not been used, it means that there are thermal losses. The second reason, as can be noticed in the graph (Image ??), is that the temperature inside the hot tank drops faster when the hottest tank is combined with the water line. Therefore, it is more likely that the target temperature has to be decreased because none of the tanks can provide it. The last reason is related to the time needed to recharge the tank. It clearly depends on the heat source availability and the user demand, but the lower is the temperature the longer is the time needed to reach the maximum temperature. Therefore, the use of both warm tanks together allows a higher average temperature and this means higher probability to be able to provide the target temperature.

\subsubsection{Action Method}

The second example proposed would take the advantage of the Action Method. It follows the same concept but the way to proceed is more straightforward. There is no weather forecast but the actual hot and warm tank temperatures are compared to the target and the water line temperatures. The rest of the code is written for the Forecast Method.

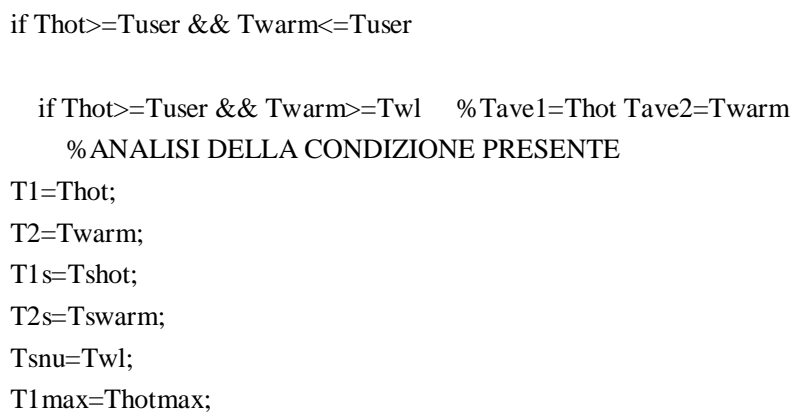




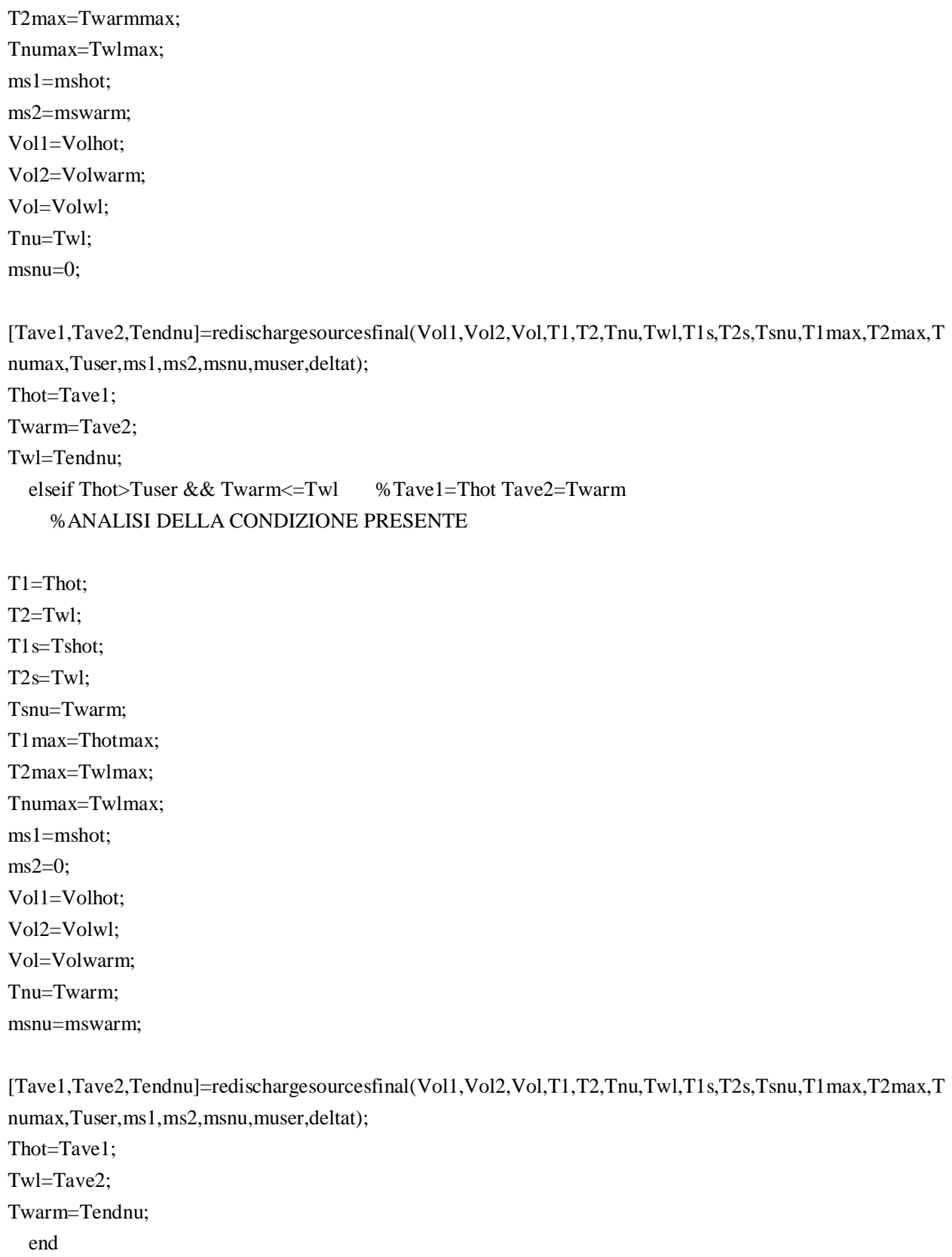

\subsubsection{Target temperature between the AC tank and the water line temperatures}

Following the same concept, the case, in which the target temperature is between the warm temperature and the waterline temperature, has been considered. The only difference compared to the previous situations is how the tanks are chosen.

The graph below shows how the management works in this case. 


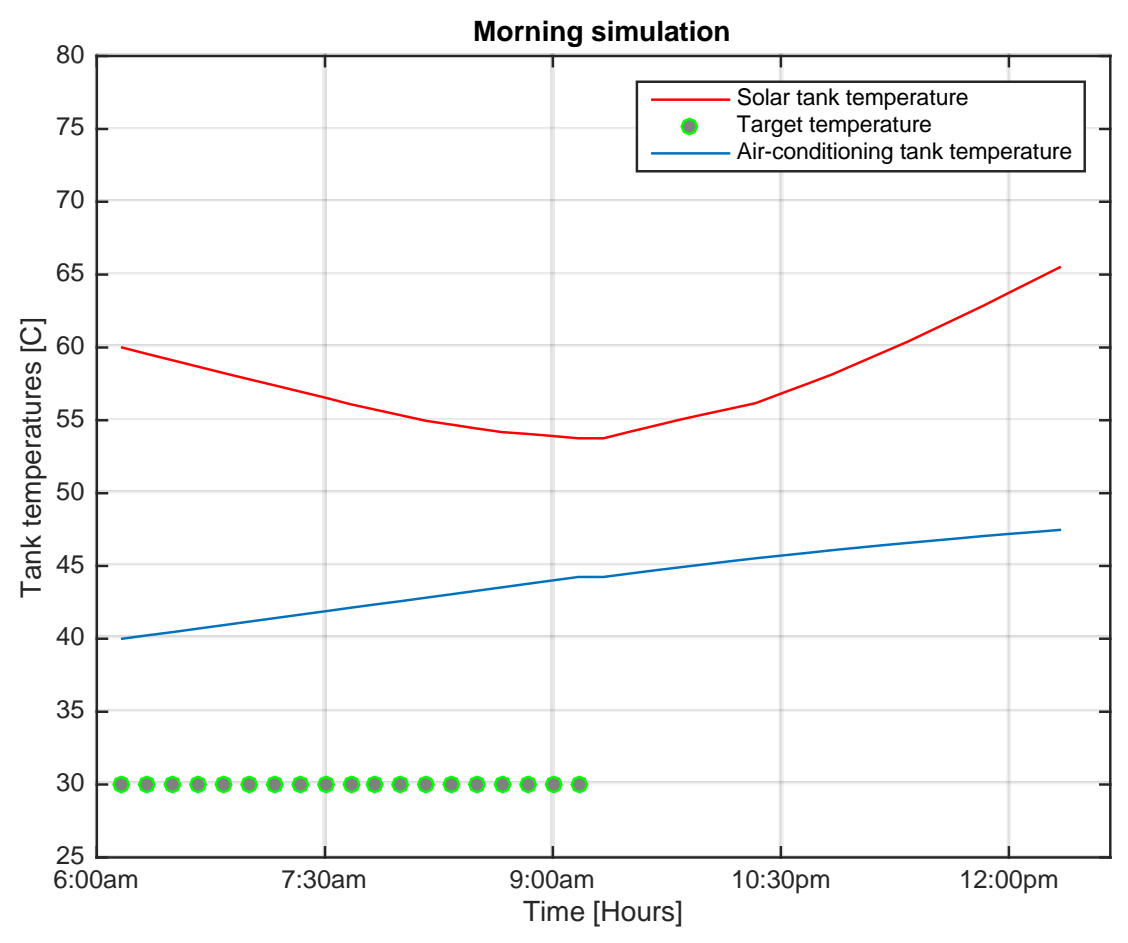

Figure 22 - Trend temperature of Solar and AC tanks with target temperature lower than the AC tank

The hottest tank has been mixed with the water line and the air conditioning tank has not been used and therefore it keeps recharging itself.

The evaluation of Tave1, Tave2, Tave12, and Tave22 in the Forecast Method, as in the previous case, has been very useful to decide the strategy to follow in order to properly manage the water into the tanks. The combination of the hottest tank with the waterline has been chosen for two main reasons. First, the hottest tank has more thermal losses than the warm tank. Secondly, to obtain the target temperature at constant flow rate, the user needs less amount of water from the hottest tank. Therefore, if the warm tank were used, it would have been discharged faster than the hot tank. By mixing the hottest tank with the water line instead, it is possible to obtain a steadier discharge of both tanks, especially after their temperature becomes more similar. Also, both of them will have some extra energy stored. 
To further clarify this concept, the graph below shows how the trend of the hot tank is unchanged compared to the previous graph where the air conditioning energy source is completely absent. Therefore, it is proven that when the target temperature is lower than the warm tank temperature, and the system will mix the hot tank with the water line.

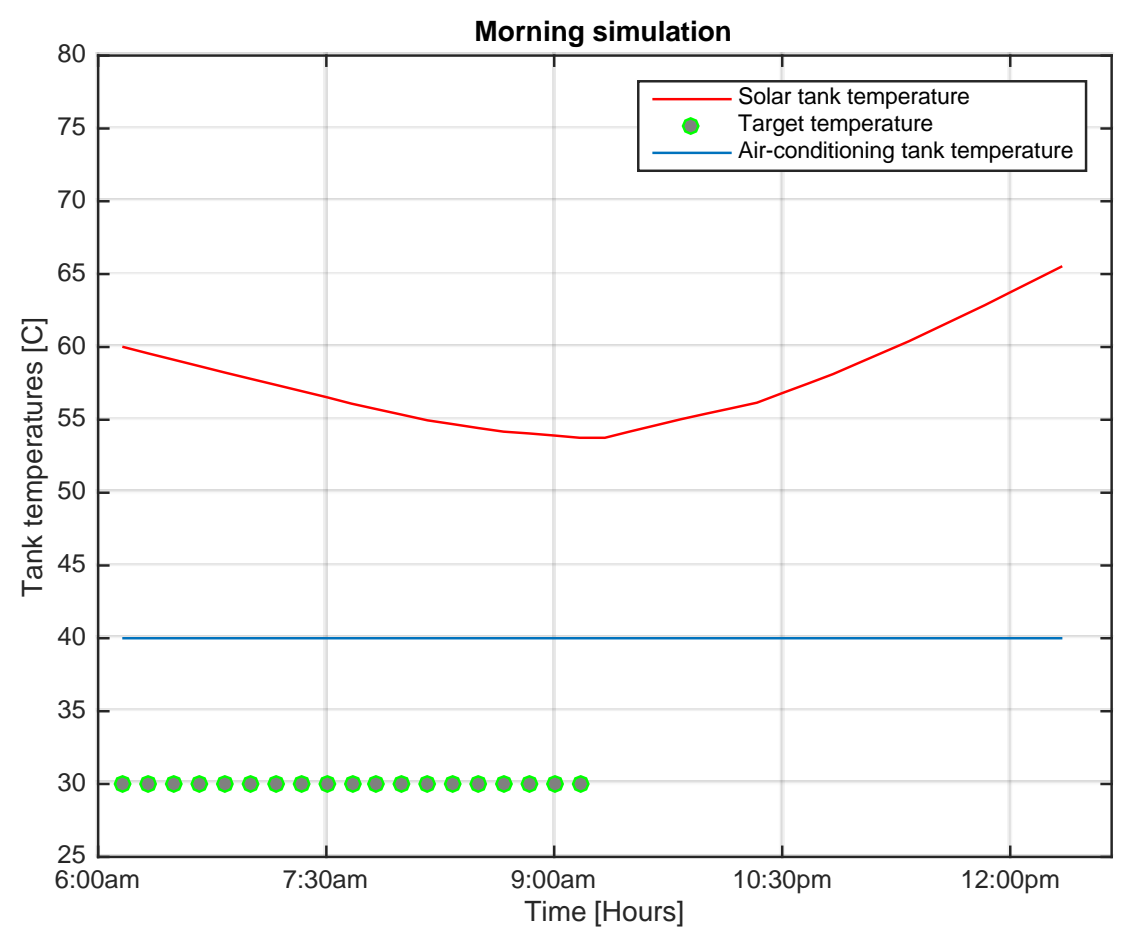

Figure 23 - Trend Temperature of Solar and AC tanks with target temperature lower than AC tank

The following graph has been shown to explain the behavior of WMS in case the temperature of the solar tank becomes lower than the temperature of the AC tank. As previously defined the hottest tank is mixed with the water line to obtain the target temperature. Therefore, it is possible to see the blue dot line decreasing until it becomes lower than the green line. Then, it starts increasing again. Finally, when the demand is null, the red dot line is absent, both tanks will increase their temperatures quicker. 


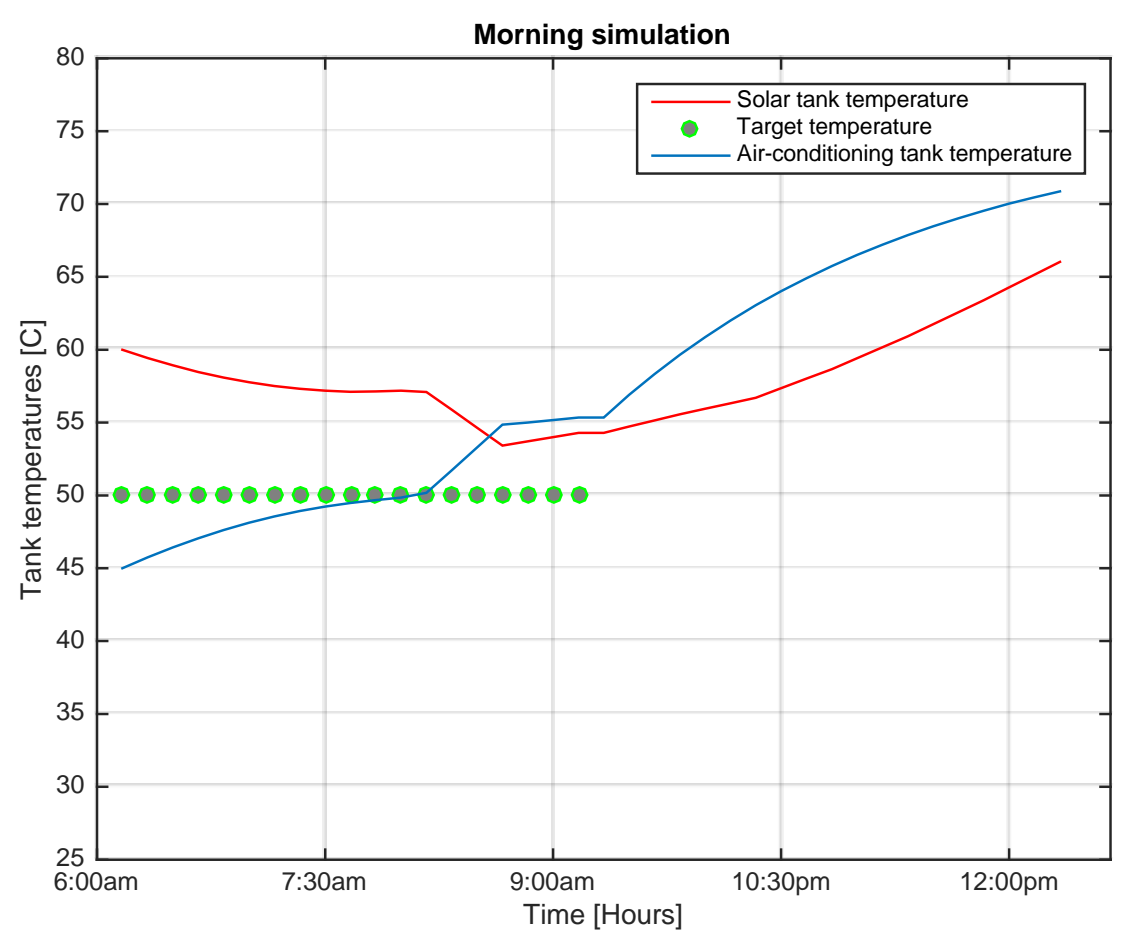

Figure 24 - Tanks management when the warm tank becomes the hottest

\subsubsection{Hot tank temperature lower than target temperature}

There is another situation that has to be clarified. It is possible that during the extraction of warm water from the two tanks, the temperatures of both tanks become lower than the target temperature, it means that the system is not capable of providing the outcome requested anymore.

To keep using the energy stored it is necessary to lower the target temperature at least below the hot tank temperature. There are different approaches to manage this condition but the fundamental goal of the system is to provide the highest temperature possible for the longest period possible.

For this reason the following conditions have been defined:

- Forecast Method

if Tave $1<$ Tuser

$\%$ Tave1=Thot in the future

Tuser=Tave1-(1/32)*Tave1;

end 
Action Method

if Thot<Tuser

Tuser=Thot- $(1 / 32)^{*}$ Thot;

end

In both cases the concept used is the same: the target temperature is lowered to $1 / 32$ below the temperature of the hot tank.

The difference between the two methods is that in the Forecast Method the hot temperature used is the one expected 10 minutes later and in the Action Method, instead, the hot temperature used is the actual temperature of the hot tank. In this way it is providing the highest temperature possible considering the heat source available.

The code reported above has one issue. Every time that the function runs it first checks the target temperature and if the WMS is not able to provide it, the target temperature is lowered. This means that at the beginning of every recharge phase the first element of the target temperature array saved is the original target temperature, even if it is not provided.

To obtain only the values of target temperature effectively, the code below has been added outside the "ThoTwarmTwlnofuture" function and "ThoTwarmTwl" function, which evaluate all the temperatures obtained during the recharging phase.

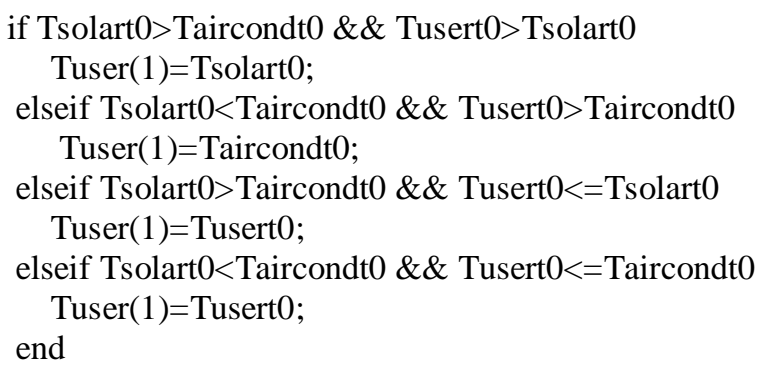




\subsection{Tanks possible scenarios}

The core of the program is the possibility to evaluate the average temperature inside the tanks during different situations. Average temperature is defined, as the temperature of the tank with a perfect mixing. Perfect mixing means that there is the same value of temperature in each point of the tank.

There are multiple inputs needed to evaluate the average temperature inside the tank.

The main inputs are:

- Target temperature

- Flow rate from each tank.

- Solar radiation

- Flow rate from each energy source

\subsubsection{Evaluation of the amount of water extracted from each tank}

The starting point to evaluate the average temperature of the tank is the calculation of the flow rate extracted from the tanks or the water line.

The theory behind this process can be explained thanks to the energy conservation equation and mass balance equation:[22]

$$
m_{1}+m_{2}=m_{3}
$$

where $m_{1}$ and $m_{2}$ are the flow rates unknown. $m_{3}$, instead, is the total amount of flow rate that goes to the instant water heater and it is a known value[23].

$$
m_{1} c_{p} T_{1}+m_{2} c_{p} T_{2}=m_{3} c_{p} T_{3}
$$


$T_{1}, T_{2}$ are known as water temperatures of the tanks and $T_{3}$ is the target temperature.

The conservation equations been written again with $\frac{m_{1}}{m_{3}}$ and $\frac{m_{2}}{m_{3}}$ that are respectively the fraction of the flow rate coming from tank 1 and tank 2 over the total amount of flow rate needed.

$$
\frac{m_{1}}{m_{3}} T_{1}+\frac{m_{2}}{m_{3}} T_{2}=T_{3}
$$

Therefore, integrating the mass balance equation with the conservation of energy equation, the following equation is obtained:

$$
\frac{m_{1}}{m_{3}} T_{1}+\left(\frac{m_{1}}{m_{3}}-1\right) T_{2}=T_{3}
$$

Now the fraction of flow rate from tank 1 is the only unknown so it is possible to solve this equation.

The computational way to solve this problem has been found by assuming an initial value of $\frac{m_{1}}{m_{3}}$ and attempting to increase its value until the target temperature is found. In the following, the entire code of the flow rate percentage evaluation is reported.

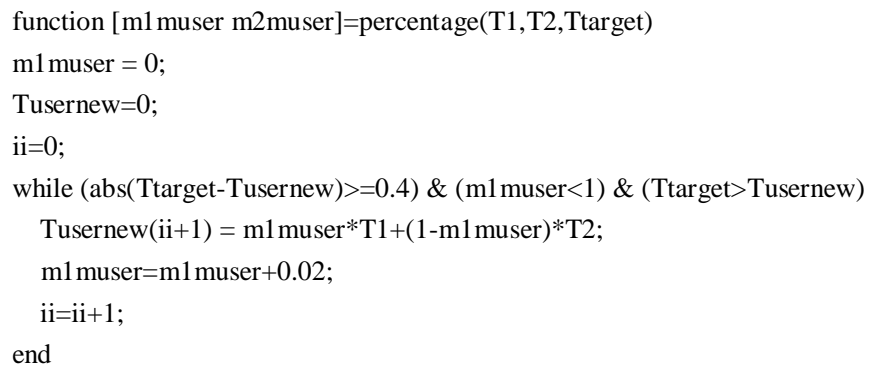


m1 muser $=$ m1 muser -0.02 ;

$\mathrm{m} 2$ muser=1-m1 muser;

end

The inputs for this function are T1, T2 and Ttarget, where temperatures 1 and 2 can be associated with the hot tank, warm tank, or the water line. The only condition applied is that $\mathrm{T} 1>\mathrm{T} 2$.

Where the temperatures, $\mathrm{T} 1$ and $\mathrm{T} 2$, are the temperature values of the tanks evaluated in the previous step.

\subsubsection{Scenarios}

To sum up: first, the system decides which combination has to be tested, therefore, the values of $\mathrm{T} 1$ and $\mathrm{T} 2$ are decided. Then the flow rate from each tank involved has to be calculated by the function just described. Finally, the system has to evaluate the average temperature of the tanks to see if it is in either discharge phase, recharge phase, or recharge/ discharge phase at the same time.

There are four possible scenarios for the tanks:

- Discharge

- Recharge

- Discharge and recharge at the same time

- Neither recharge or discharge (night time) 


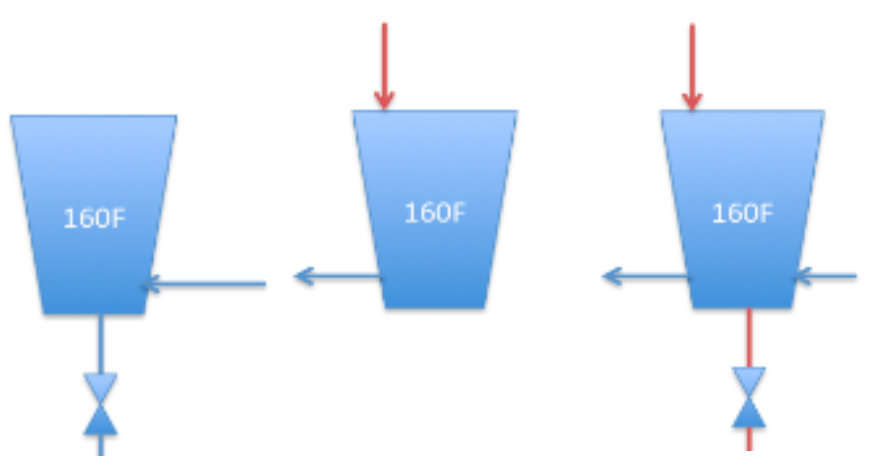

Figure 25 - Tanks Scenarios

The discharge phase is the part of the process in which the warm water is extracted from the tanks but the heat sources do not supply energy. The recharge and discharge phase, is when the warm water is extracted from the tanks and the heat sources supply energy. The final goal of this calculation is to evaluate the average temperature of the tanks after a certain period of time. In the code the period of time is defined by the "for" cycle and every cycle is equivalent to 1 minute of simulation. The first step of this analysis is the evaluation of the flow rate percentage taken from each tank. Then the percentage has to be converted into an actual flow rate value; this is done by multiplying it by the total flow rate: $\mathrm{m} 1=\mathrm{m} 1$ muser*muser.

The multiplication of the flow rate by the period of time provides the number of liters extracted from the tank during that period: liter $1=\mathrm{m} 1 *$ deltat. Thanks to the value just obtained it is possible to derive the fraction of the total volume that has been extracted: $\mathrm{xx} 1=($ liter $1 * 1) / \mathrm{Vol1}$. The same concept is proposed for the evaluation of the fraction of the total volume that goes to the heat source that is equal to the amount that goes back to the tank. For construction reason it has been assumed that the same amount of water extracted from the tank to the instant water heater is inserted through the water line. Therefore, the system has been projected to keep all tanks constantly full. Ones all the fractions of water inserted or extracted have been evaluated it is 
possible to evaluate the average temperature for each tank: Tavenew $1=$ $\mathrm{xxs} 1 * \mathrm{~T} 1 \mathrm{~s}+\mathrm{xx} 1 * \mathrm{Tw} 1+(1-\mathrm{xxs} 1-\mathrm{xx} 1) * \mathrm{~T} 1$.

The code of the recharge and discharge phase is reported below. This is an easier version of the final one. The final version considers all the possible combinations to increase the heat storage capacity. This code describes only the combinations where the average temperatures of the tanks are below their maximum temperatures.

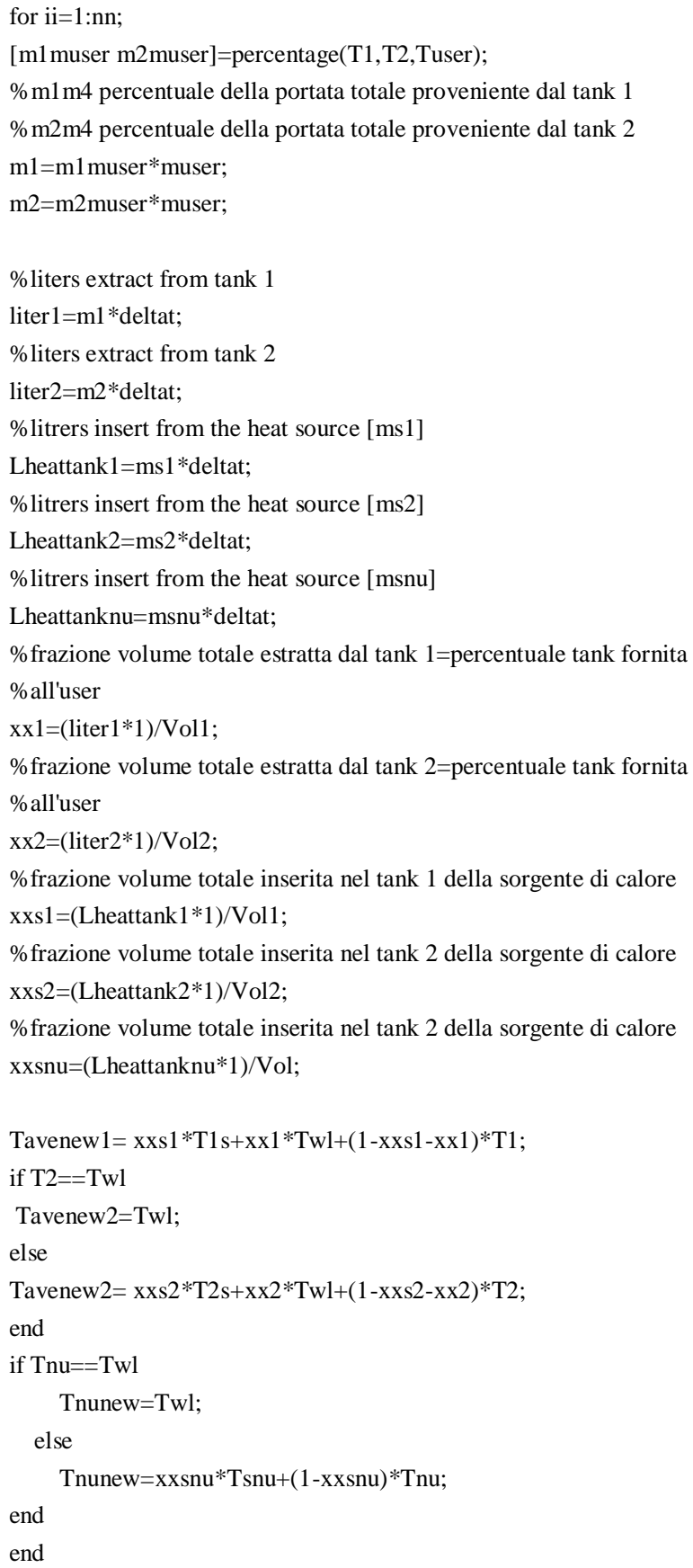




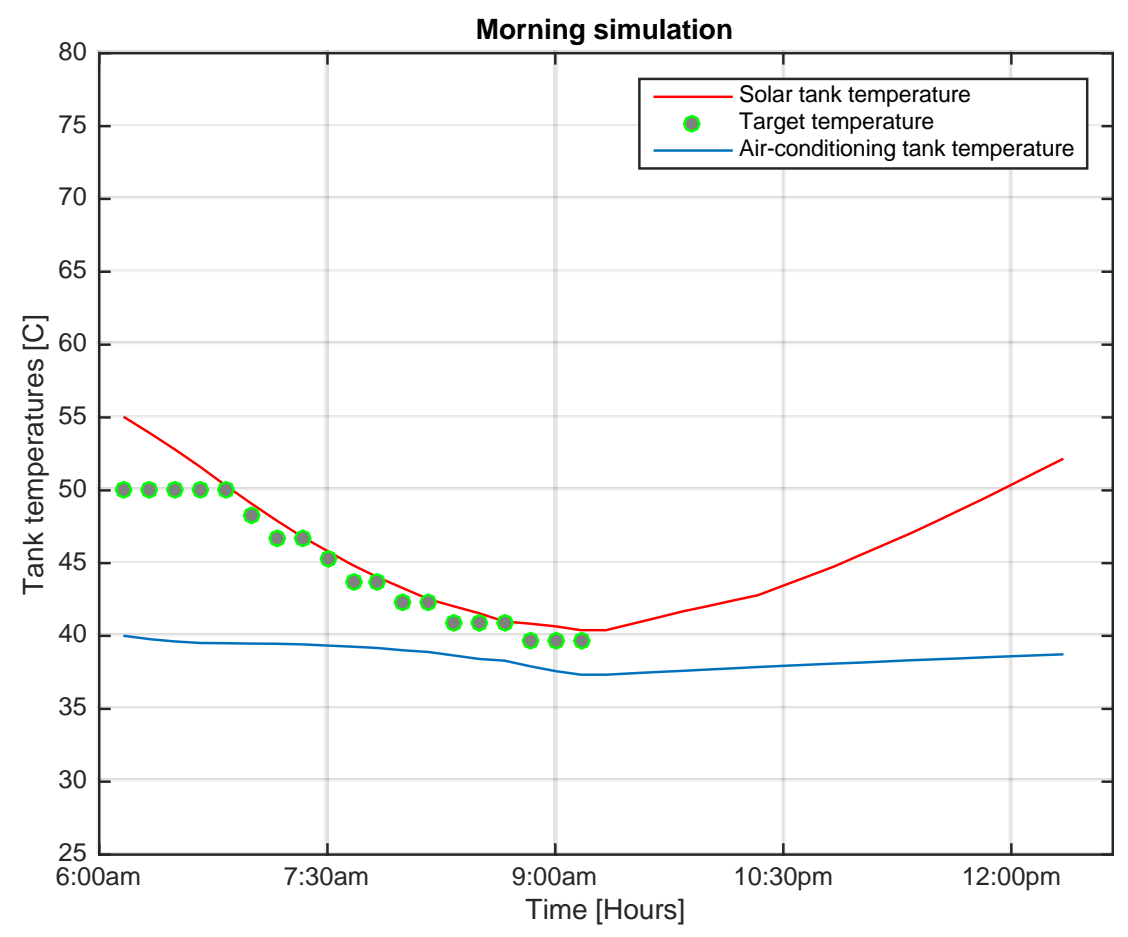

Figure 26 - AC and Solar Tanks temperatures as demonstration of the recharge and discharge phases

The graph above shows the trend of the average temperatures of the warm and hot tanks when the target temperature is between the hottest temperature and the medium temperature of the tanks. It is possible to see the action of the function that simulates the recharge and discharge phase. Therefore, from minute zero to minute 175 there is user demand and also energy is provided by the heat sources. The minimum value reached by the hottest tank is around $45^{\circ} \mathrm{C}$ and after that, the temperature keeps increasing due to the absence of demand by the user. The air-conditioning tank temperature, instead, is almost constant during the discharge phase, thanks to the energy provided and it suddenly increases its temperature when the user demand goes down to zero. 
The following graph, instead, is an example of discharge phase, from minute 0 to 175 , and "recharge phase", from minute 175 to minute 350 , in absence of heat provided by both sources.

The proof of what it has been assumed can be given by comparing Image?? with Image ??. In the graph below the minimum temperature reached by the solar tank is $38^{\circ} \mathrm{C}$ that is lower than the minimum temperature registered in the previous case due to the absence of heat supply. Another characteristic that proves that the program works is that the temperature of the AC tank is always decreasing and when there is no demand from the user the air conditioning tank temperature is steady.

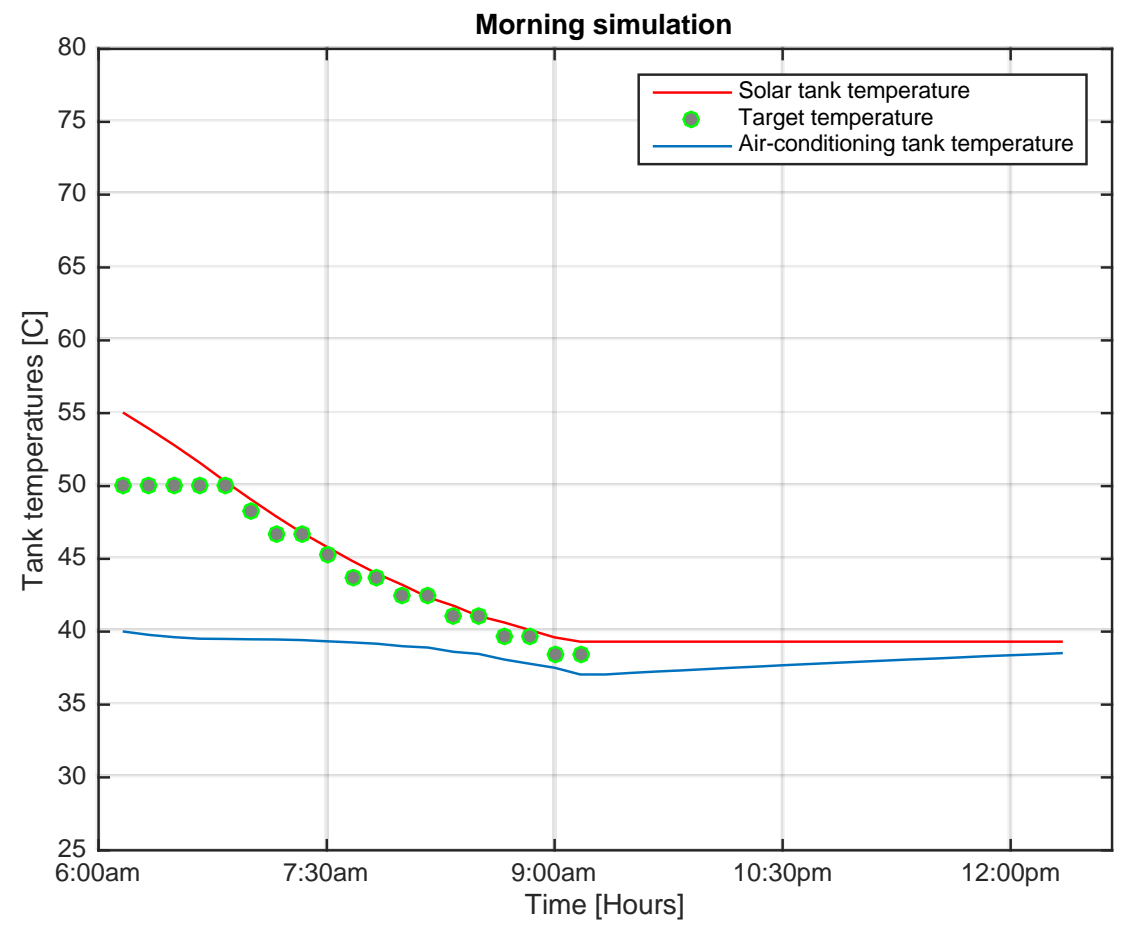

Figure 27 - AC and Solar tanks temperature as demostration of the recharge and discharge phase

A function for the recharge phase has been developed. It is equal to the function just explained but the part regarding the demand from the user has been erased. It is possible to find the code related to the recharge phase only, as shown below 


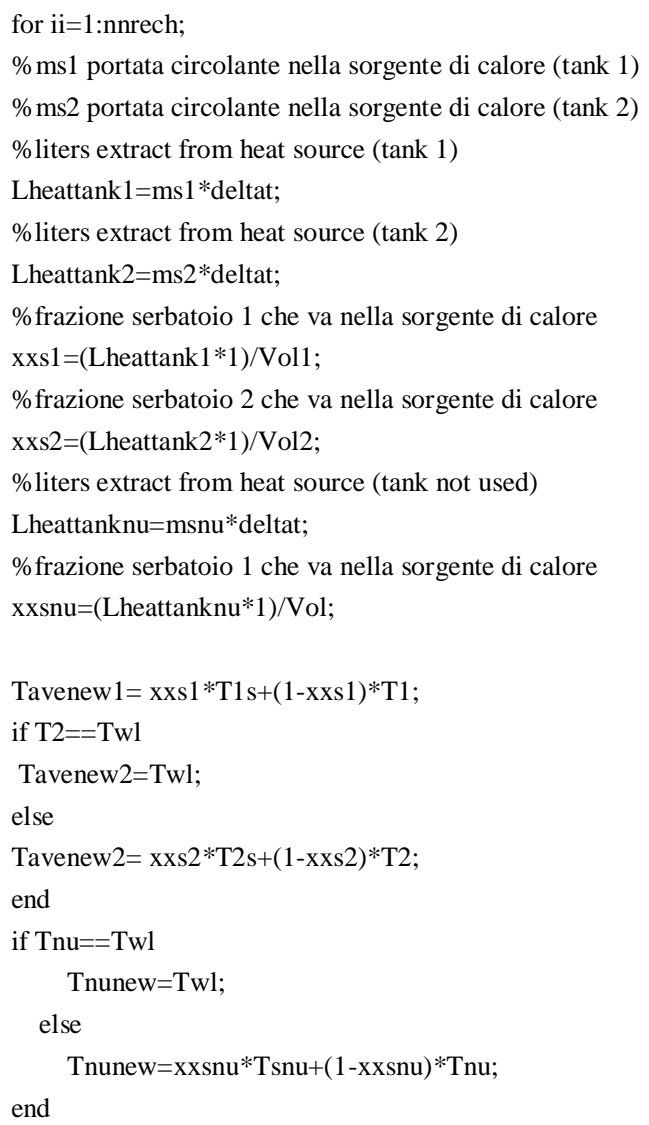

The main parameter that defines the solar energy supply is the solar radiation. It has been found thanks to National Solar Radiation Data Base that provides radiations value for the entire year. The air conditioning source, instead, provides a constant water temperature to the tank. Therefore, the parameter controls the recharge of the tank is the flow rate through the air conditioning heat exchanger circuit.

\section{Results}

\subsection{Parts/Components}

An in depth analysis of the costs involved is provided in order to evaluate the financial aspects of the project. All of the parts that make up the system have been analysed separately for the selection of suitable and cost effective components. 
As previously mentioned, the WMS takes advantage of both a PVT system and an air conditioning system as heat sources. In order to manage and store the energy collected, some proportional valves and two tanks have been installed

The solar sources will be explained first in section 4.1.1 and the $\mathrm{A} / \mathrm{C}$ source will be decribed in section 4.1.2

\subsubsection{Solar system}

\subsubsection{PVT Panel description}

The main part of the solar system is the collector. The PVT collector selected is

PowerTherm [24] from SOLIMPEKS Solar Energy Corporations, as shown in Figs. 28-29.
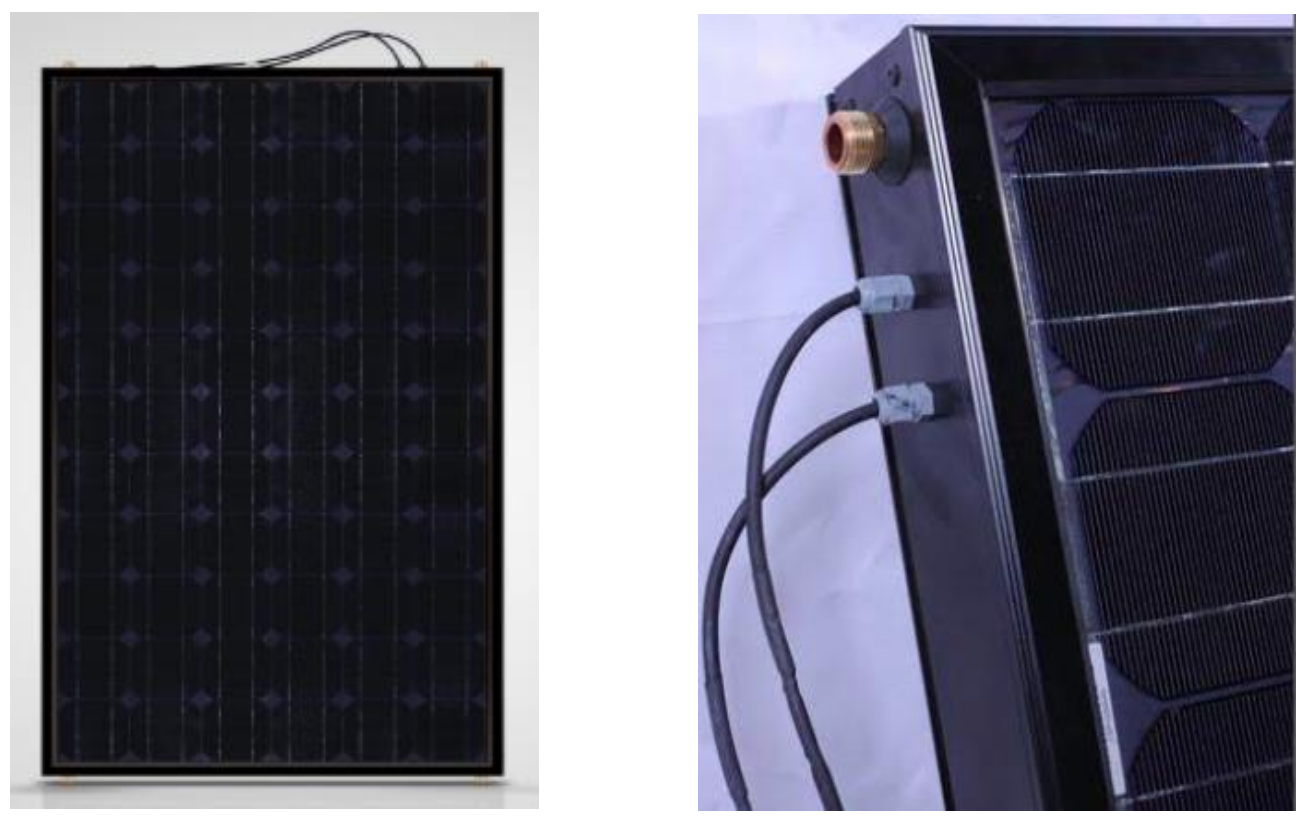

Figure 28 - PVT Panel [24]

Figure 29 - PVT Panel - side [24] 
This panel has been developed to maximize the thermal return of the hybrid panel. It also contains an extra layer of low-iron solar glass to aid heat retention. The latest model of panel produces approximately $80 \%$ of an equivalent standard thermal collector while producing electricity. The peaks output from this panel are:

- $190 \mathrm{~W}$ electrical

- $460 \mathrm{~W}$ Thermal $(1,570 \mathrm{Btu} / \mathrm{hr})$

The dimensions of the panel are $870 \times 1660 \times 105 \mathrm{~mm}$ and the gross area is $1,4 \mathrm{~m}^{2}$, with Mono-crystalline PV cell installed on it. The cost of this part is about $\$ 250.00$.

\subsubsection{Simplified Sizing Procedure For Solar Domestic Hot Water System[25]}

Once the PVT collector has been chosen, there are different ways to find the correct dimension of the solar system. Florida Solar Energy Centre provides the sizing method as used in this thesis. It is called Simplified Sizing Procedure For Solar Domestic Hot Water System and it is divided into seven steps. As previously introduced, there are different cases that will be taken into consideration. The sizing of the solar system for a family composed of four people will be demonstrated, in order to explain how this sizing method works. It can also be applied to a two or a single person household, and the final results for these three cases will be provided.

The seven steps are summarized as follows:

1. Estimating the daily hot water use (Gallons) and selecting the minimum tank size needed.

2. Determining the proper water line temperature. 
3. Calculating the amount of energy needed to heat water to $122^{\circ} \mathrm{F}\left[50^{\circ} \mathrm{C}\right]$ (BTUNEED)

4. Defining the PENALTY factor.

5. Calculating the rating requirement for the solar system (RATREQD) to provide $70 \%$ of the annual hot water energy needs.

6. Rating the thermal performance at the intermediate temperature (BTURATING) in Btu/day and the gross collector area (GROSSAREA) in square feet

7. Selecting the actual number of collectors that need to be used .

Step 1 provides the daily amount of water needed for four people and the minimum tank size that is necessary to be installed. The hot water demand for the family case is $70 \mathrm{gal} /$ day and the minimum tank size is $80 \mathrm{gal}$.

Step 2 defines the water temperature depending upon the location. In this case the system is located in South Florida, therefore, the temperature of the water line is taken to be $76^{\circ} \mathrm{F}\left[25^{\circ} \mathrm{C}\right]$.

Step 3 allows for the evaluation of the energy needed to heat the water to $122^{\circ} \mathrm{F}$ $\left[50^{\circ} \mathrm{C}\right]$, using the formula reported [16] below:

BTUNEED $=8.34 \times$ (gallons per day) $\mathrm{x}(122-$ Cold temperature $) \times$ Tank Insulation Factor $=25564$ Btu/day .

In this case the Tank Insulation Factor is equal to 1 because there are no back-up tanks for the system. 
Step 4: The Penalty factor is the parameter that affects the amount of energy collected from the sun, therefore, the bigger the Penalty, the higher the number of collectors installed.

The Penalty factor is determined with the help of three other factors. The first is the System Factor that changes depending on the way how the heat is transferred from the solar collector to the energy storage tank. In this case it is 1.20 because the system here is a direct system with no heat exchanger. It is important to note that the more efficient the transport of heat, the lower the System Factor.

The second factor is the Tilt Factor, which is equal to 1.12 with a $45^{\circ}$ roof tilt, which is typically used for a system installed in South Florida.

The last parameter is the Orientation factor. The PVT panel installed is toward south so the factor will be equal to one. The Southern direction allows the panel to be hit by the sun's rays for a longer period of time during the day with respect to the other directions. Finally, it is possible to determine the Penalty Factor, which is the product of the following three factors[26].

PENALTY $=$ System Factor $\mathrm{x}$ Tilt Factor $\mathrm{x}$ Orientation Factor $=1.8$

Step 5: The rating requirement for the solar system (RATREQD) based on the 70\% of the annual hot water energy needs is calculated as follows[27]:

$$
\text { RATREQD = BTUNEED } \times 0.70 \times \text { PENALTY = } 23979 \text { Btu/day }
$$

The panel chosen can provide a BTURATING equal to 18840 Btu/day and it has a gross area of $4.738 \mathrm{ft}^{2}\left[1,444 \mathrm{~m}^{2}\right]$. Due to the parameters previously determined, the number of panels requested can be identified. 
Number $=$ RATREQD/BTURATING $=(25173$ Btu/day $) /(18840$ Btu/day $)=1.53=2$

Therefore, in order to satisfy the energy demands, a maximum of two PVT panels are necessary with a total area of $9.5 \mathrm{ft}^{2}$ for the family.

\begin{tabular}{|c|c|c|c|c|c|c|c|c|}
\hline & 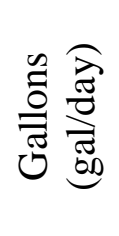 & $\begin{array}{l}\stackrel{\tilde{N}}{w} \\
\frac{1}{\tilde{E}} \\
\vec{E}\end{array}$ & 罣全 & 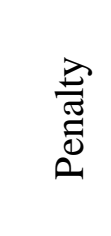 & 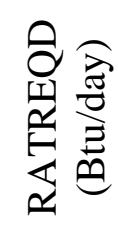 & 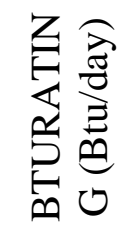 & 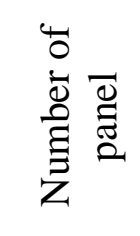 & 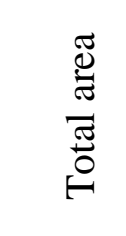 \\
\hline Family & 70 & 80 & 25564 & 1.344 & 23979 & 18840 & $1.4=2$ & $9.4 \mathrm{ft}^{\wedge} 2$ \\
\hline Couple & 40 & 40 & 15345 & 1.344 & 14393 & 18840 & $0.76=1$ & $4.7 \mathrm{ft}^{\wedge} 2$ \\
\hline Single & 20 & 20 & 7672 & 1.344 & 7196 & 18840 & $0.4=1$ & $4.7 \mathrm{ft}^{\wedge} 2$ \\
\hline
\end{tabular}

Figure 30 - Data for the Sizing of the PVT water aspect

\subsubsection{Water temperature outlet from the PVT panel}

The function "Toutsolar" has been written to determine the temperature of the outlet water from the PVT panel. This function is base on the four main parameters:

- Sun radiation [Q]

- Temperature from the tank [Tavetank]

- Flow rate of water inside the panel [mssolar]

- Solar conversion efficiency $[\eta]$

function [Tssolar]=Toutsolar(Tavetank,Q,mssolar)

$\mathrm{cp}=4186 ; \% \mathrm{~J} / \mathrm{kg} \mathrm{K}$

Tssolar $=(\eta * \mathrm{Q} . /($ mssolar*cp $))+$ Tavetank;

end

The values of the sun's radiation have been taken from National Solar Radiation Data Base (NSRDB [28]). It provides the sun's radiation every ten minutes for main locations in the world. For the purpose of this thesis, Miami, Florida has been chosen as the testing location. 
The water temperature from the tank is a fundamental parameter because it affects the amount of heat that is possible to be transferred to the water inside the PVT panel and subsequently the increase of the water temperature in the solar tank.

The Flow rate of water inside the panel is a fixed value. The value has been suggested on behalf of the company that produces the panel, in order to have the most efficient panel possible[29].

\subsubsection{Air conditioning system}

\subsubsection{Air conditioning description}

In the United States air conditioning is widely used. For this reason there are several applications and consequently different types of systems available. The refrigeration cycle is at the base of the concept, which can provide a wide range of temperatures: from ambient to very low temperatures. As aforementioned, for the purpose of this thesis, the air conditioning system needed is a common system used for residential applications.

To choose the correct type and size of refrigeration system, there are different parameters that need to be taken into consideration. First of all, the number of people and the activities performed in the various rooms have to be analysed. Information regarding the energy efficiency of the house is also necessary. Some parameters include: the type of windows installed, the heat gain through the heat transfer across the walls, and the ambient temperature outside of the house.

A precise energy demand analysis would be required. Due to the fact that this is not the main purpose of the thesis, a common air conditioning system will be chosen, assuming also that in the house analyzed the air conditioning is already installed. To 
provide an idea on the Air Conditioning system size an average central ac will use 3000 to 5000 watts of power every hour for around 9 hours a day during the hotter months. Therefore, the air conditioning system it is around 3.5 tons. The parameter needed for the WMS analysis is the outlet temperature from the compressor, because it is going to be the temperature that enters the heat exchanger which in turn heats up the Air Conditioning tank. Another fundamental parameter is the flow rate of the Air Conditioning system. The value used is $10.8 \mathrm{l} / \mathrm{sec}$. This value has been taken as average value for a common residential air conditioning system with the size previously defined.

In Fig. 31, a special type of air conditioning cycle is considered for demonstration purpose [30]. The temperature of interest, T2, is quite high in this case. It is interesting to see that depending on the refrigerant used and the pressures inside the loop, the temperature reached can be substantially different.

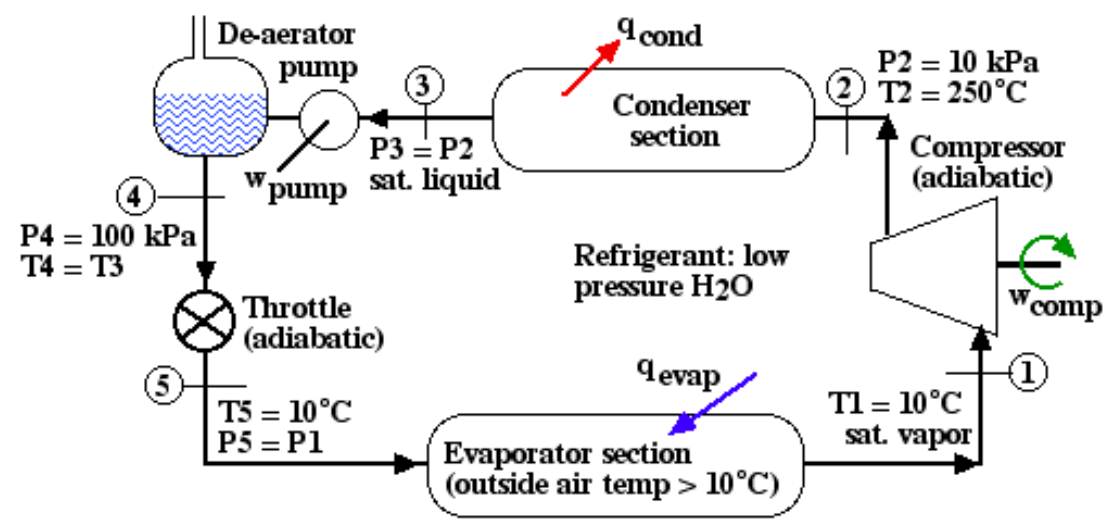

Figure 31 Air compressor cycle [30]

A corresponding Pressure-Enthalpy graph is shown in Fig. 32. It is used to define all the temperatures reached in the refrigeration cycle. It is also used during the projecting phase to check whether all the parts used have compatible temperatures and pressures. 


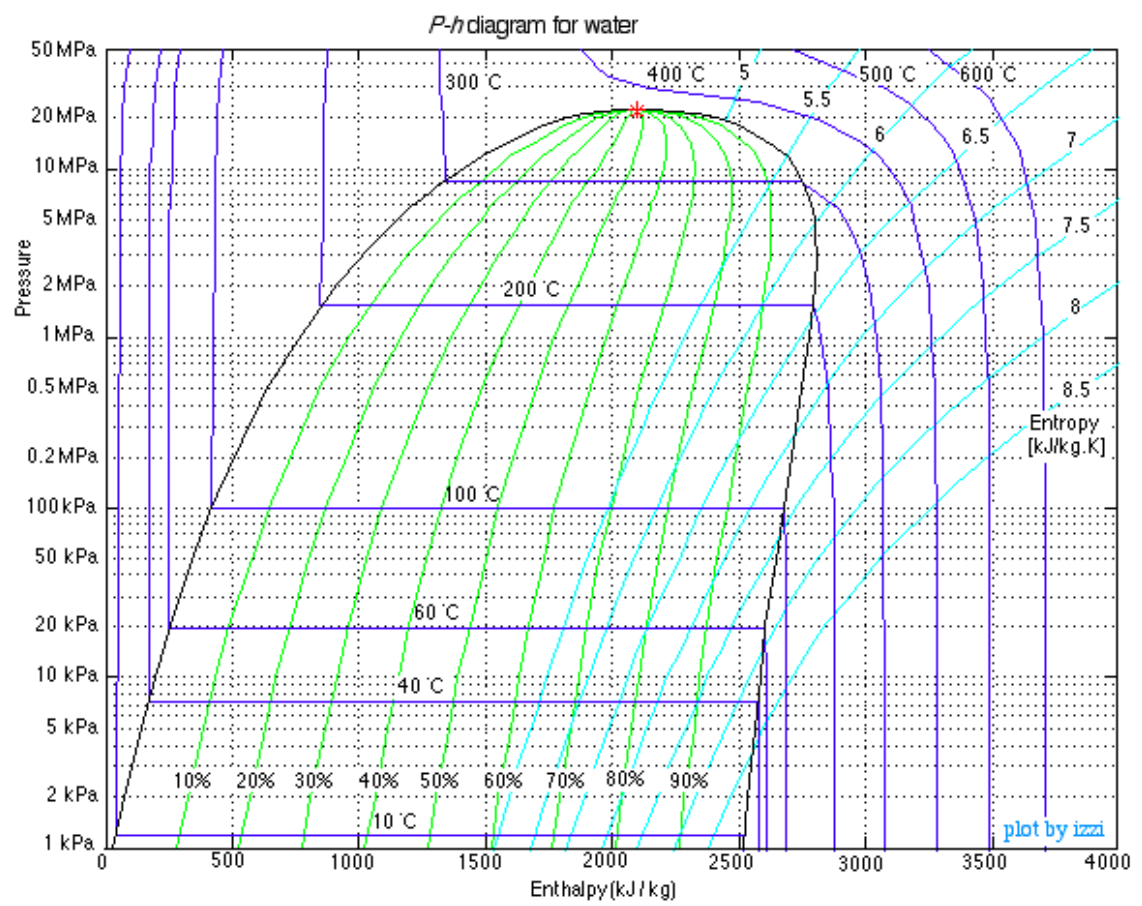

Figure 32 - Pressure Entalphy Graph [31]

Finally, a more common AC for cooling is considered, as shown in Fig. 33. This is the type of system selected for the study of the thesis. The temperature reached in the compressor is $150^{\circ} \mathrm{F}\left[65.5^{\circ} \mathrm{C}\right]$. This is going to be the temperature needed to size the heat exchanger. 


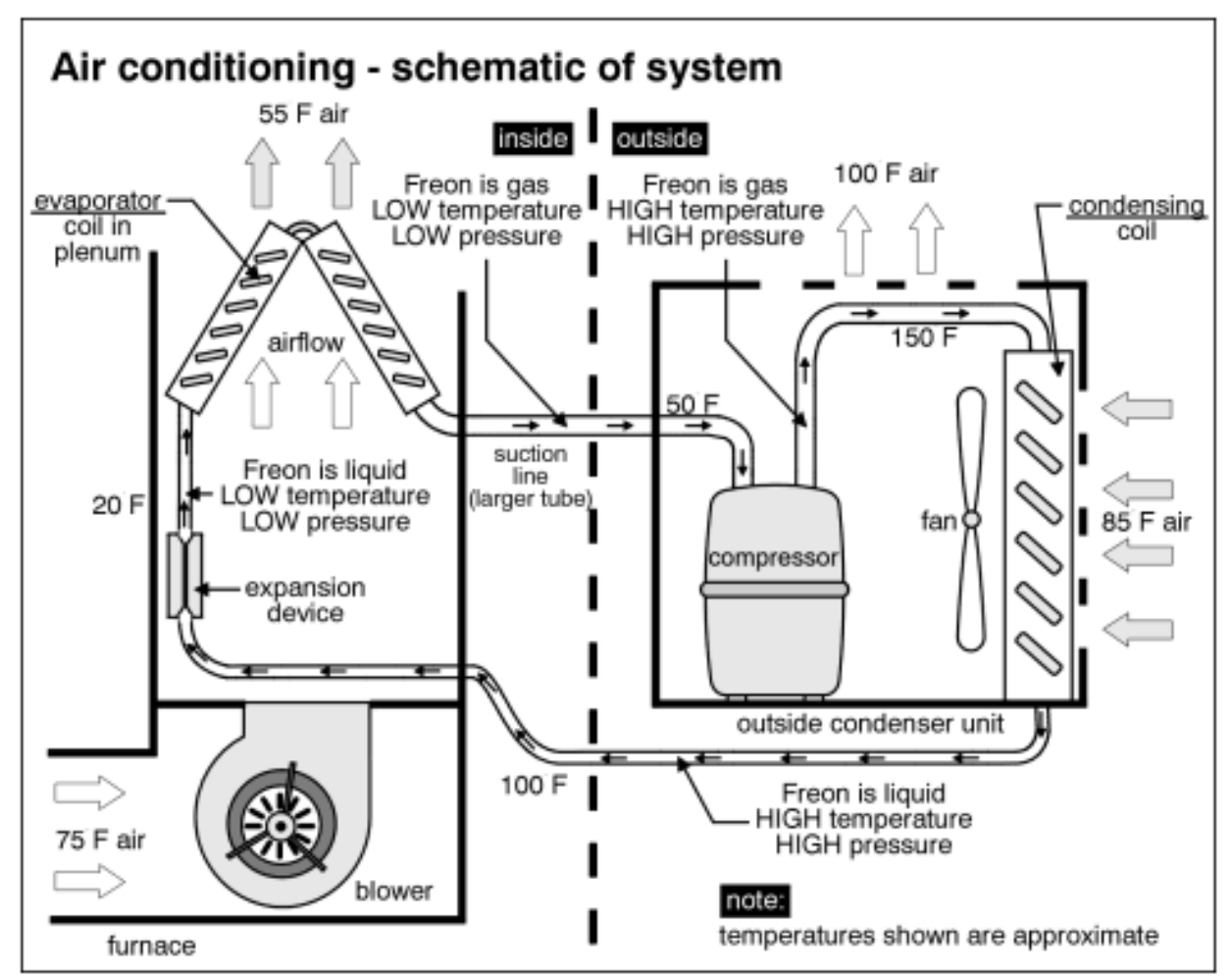

Figure 33 - AC System [32]

\subsubsection{Water temperature outlet from air conditioning heat exchanger}

The main parameter needed for the WMS analysis is the outlet water temperature from the A/C condenser, which enters the air conditioning tank. To evaluate this temperature, the equation of the energy balance has been used. In order to do so, some assumptions have been made:

- The inlet temperature from the air conditioning side is $65.5^{\circ} \mathrm{C}$.

- The outlet temperature from the air conditioning side is equal to $40^{\circ} \mathrm{C}$. Thanks to this assumption, it guarantees that the condenser that is placed after the heat exchanger will keep working.

With these assumptions in place, it is possible to evaluate the temperature inlet into the AC tank as shown in Fig.7. 
Below, a code is written to calculate this temperature, by taking into consideration that the average temperature from the air conditioning tank is quite volatile.

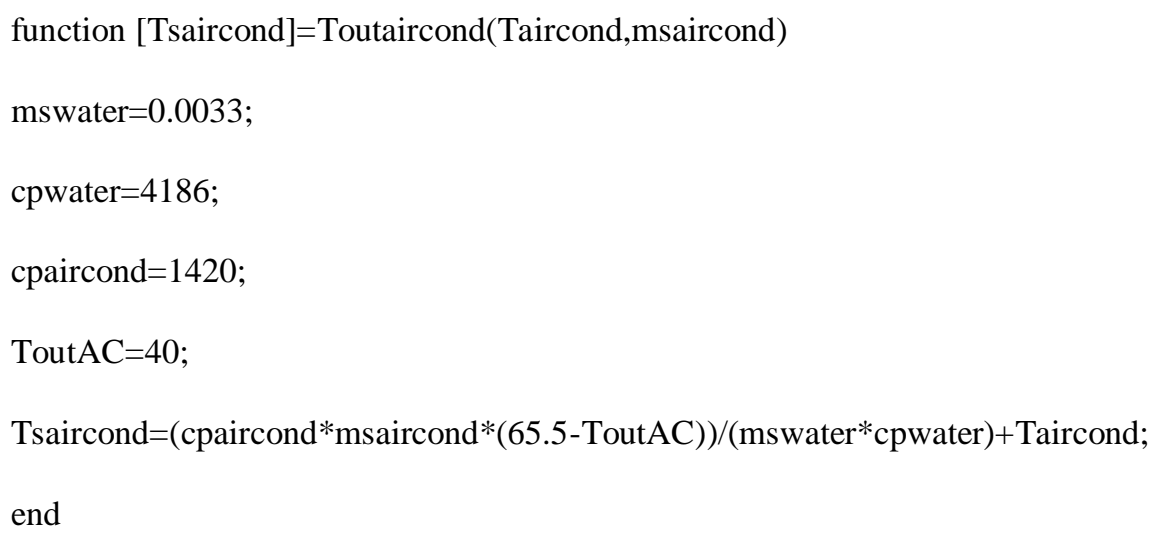

\subsubsection{Proportional valves Burket 2836 [33]}

Proportional valves control and regulate the rate of flowing media (gases or liquids), which can operate pneumatically, piezo-electrically, or electromagnetically.

The various actuating principles essentially differ in price, size, type of media separation, dynamics and force properties. The one used in this thesis is the solenoid proportional valve and costs around $\$ 150.00$.

Solenoid valves selected are the top products from Bürkert Company [34]. Without electrical power the spring forces the plunger directly onto the valve seat, which in turn shuts off the valve. Electrical current through the solenoid (coil) causes a magnetism that lifts the plunger against the spring force, which in turn opens the valve. With constructive changes in the solenoid valves, a balance between spring and magnetic force can be produced for any coil current. The intensity of the coil current, or the magnetic power influences both the stroke of the plunger and the valve opening degree, whereby valve opening (flow rate) and coil current (control signal) are ideally linear dependent on one another. 
For the reason above, it makes sense to set the minimum and maximum flow rate values of the working range (coil current) under operating conditions. Bürkert solenoid control valves are closed without electrical power (normally closed, NC).A seal is integrated at the bottom of the plunger which ensures the fluid does not leak through the closed valve.

The plunger is guided precisely through the valve unit by a guide pin (top) and a flat spring (bottom). The more flexible the plunger slides through the coil, the more pronounced the response sensitivity and the more reproducible the control positions. Because of this, in addition to the magnetic force and spring force, there is also the friction force. Friction disturbs the adjustment characteristic. However, it can be significantly reduced with a precise guiding of the plunger and special electronic controlling, as shown in Figs. 35 and 36.
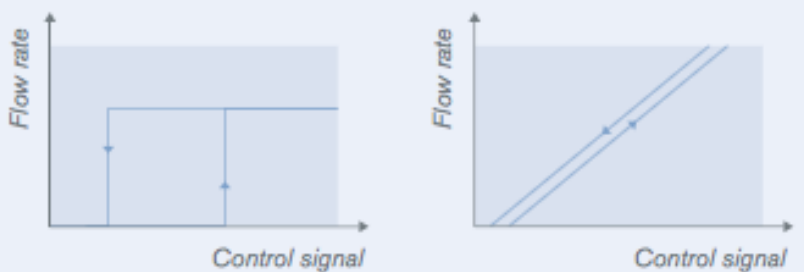

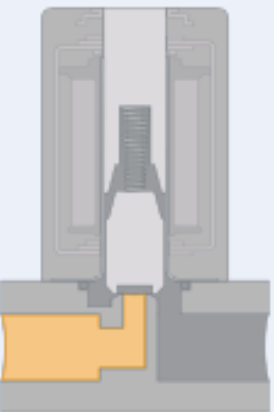

Closed state

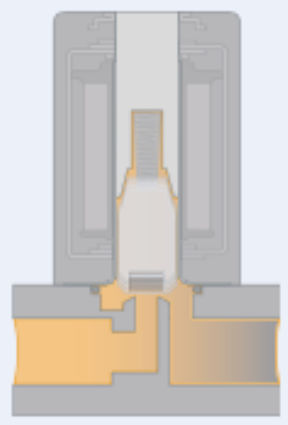

Controlled inclined position

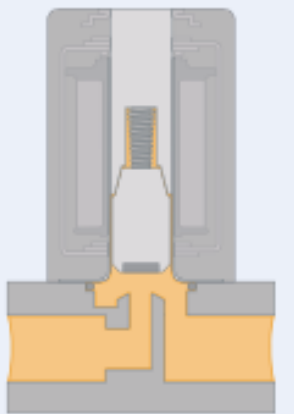

Opened state

Fig. 2: Functional principle of direct-acting solenoid control valves

Figure 34 - Functional principle of direct acting solenoid control valves [35] 


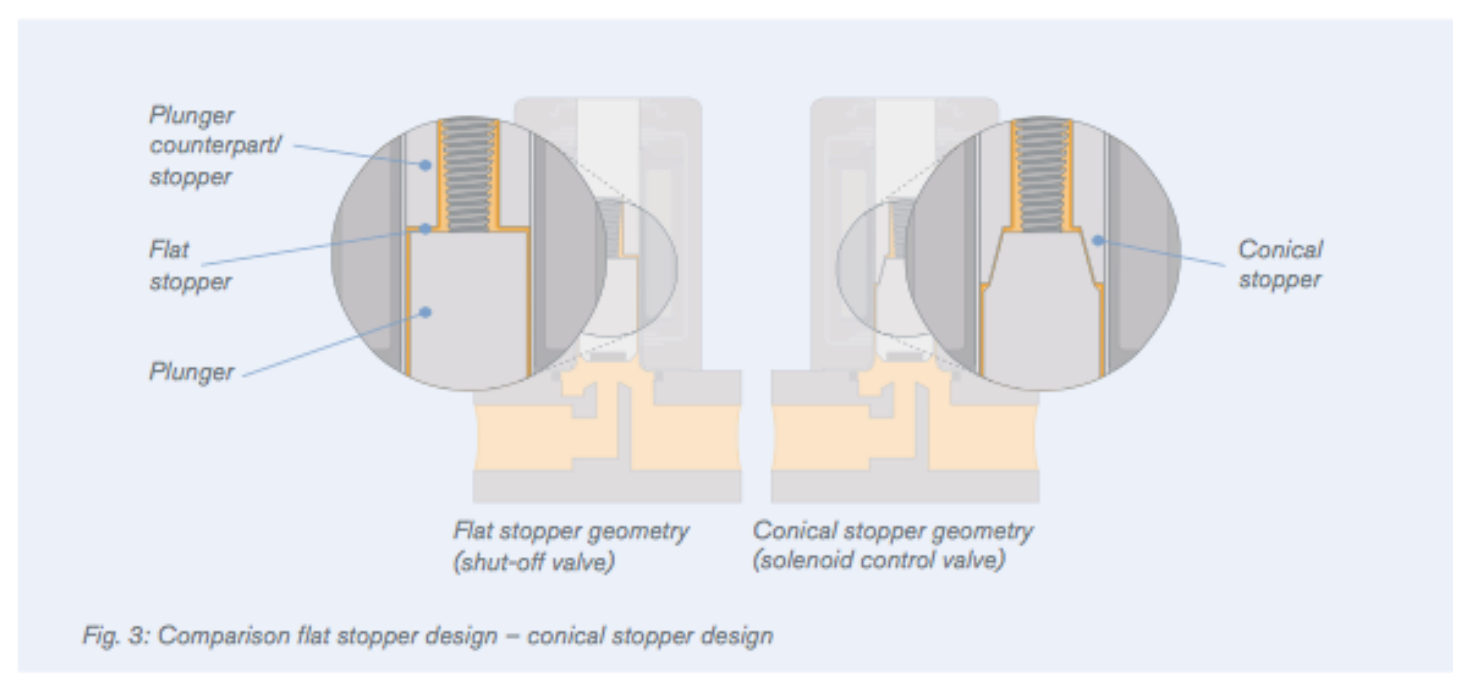

Figure 35 - Comparison flat stopper design - conical stopper design [20]

\subsection{Cases analysed}

In order to provide a complete overview on the effectiveness of the WMS, several analyses have been run. First of all, it is interesting to understand the behaviour of the system when the number of users in the single unit changes. As mentioned before, tests will be performed on a family composed of four people, a couple and a single person. In each different case, the storage tank needed and the flow rate requested by the user are different, but the heat sources provided remain constant. It is interesting to see if the energy source is enough to cover the demand.

Secondly, the heat sources and the user demand are kept constant, but the month of use of the system changes. The solar radiation will definitely vary, along with the air conditioning use, which will change during the entire year. As previously mentioned, the solar radiation value has been provided by NSRDB[36] website. The average air conditioning usage, however, is very difficult to quantify for different reasons. The first factor is the subjectivity of temperature perception, which affects the usage level of air conditioning. In addition, there are some other technical parameters such as the energy efficiency of the house (windows, wall insulation, air condition system 
installed, etc.) that are cannot be considered in this phase of the project. It is therefore quite understandable that errors could be involved associated with the calculation results.

The months and daily hours of usage assumed are listed below:

- January: zero hours of usage during the entire day

- April: air conditioning will be on from 12:00 PM to 5:00 PM

- August: air conditioning will be on from 12:00 PM to 6:00 AM

- November: air conditioning will be on from 12:00 PM to 5:00 PM

\subsubsection{Family}

The average residential electricity rate in Miami is $\mathbf{1 0 . 4} \mathbf{c} / \mathbf{k W h}[37]$.

The average residential electricity rate in Miami is $10.4 \varnothing / \mathrm{kWh}$ throughout the year. Given this data it is possible to estimate the monthly utility bill, based on the assumption previously stated. It has been assumed that an average hot water consumption duration is eight hours per day. Accordingly, the average daily cost is found to be $2.60 \$$, which reflects the market statistics, based on the calculations below:

$$
\begin{gathered}
Q_{\text {daily }}=m_{\mathrm{H}_{2} \mathrm{O}} * c_{\mathrm{pH}_{2} \mathrm{O}} *\left(T_{\text {user }}-T_{\text {waterline }}\right)=8.6 * 10^{-3} * 4186 *(50-21) * 24 \\
=1.045 \mathrm{kWh} * 24=25.08 \mathrm{kWday} \\
\text { Average Daily Cost }=10.4 \frac{\Phi}{\mathrm{kWh}} * 1.045 \mathrm{kWh} * 24=\mathbf{2 . 6 0} \$
\end{gathered}
$$

A more significant parameter is the monthly cost that can be evaluated multiplying the daily cost times 30 days. The monthly cost is around $\$ 78$. It is expected that by using the WMS, it decrease the water heating average daily cost significantly. The objective of the following sections of this chapter is to determine exactly how much a 
family could save in the long term, if the system is installed, and how long does it take to cover the cost.

Before analysing the data obtained, it is important to highlight that the volume of the AC tank used is 100 litres. This amount has been decided after an analysis of the average target temperature obtained with a tank of 50 litres and a tank of of 100 litres. Given the fact that the values obtained with the larger tank have been higher, it has been decided to continue more depth analysis with the one that has a higher thermal capacity.

\subsubsection{Family Water Heating Average Daily Cost with WMS}

The graphs in the following sections provide an overall view of different months of the year. The evidence of the different results obtained with the Forecast and Action Methods is also going to be explained in depth. In order to standardize the analysis, a set of initial fixed parameters, such as the user temperature and the initial temperature of the solar and $\mathrm{AC}$ tanks, have been set.

\subsection{Family - Month of January}

January has been chosen because it is been considered the coldest month of the year in Miami. The solar radiation is at its minimum level and it has been assumed that the $\mathrm{AC}$ is always turned off.

In terms of the heat sources used in the WMS, January is the least favorable month of the year because of the reasons just provided above.

\subsection{FAMILY-MONTH OF JANUARY - FORECAST METHOD}

The WMS operating with the Forecast Method is able to provide an average Target Temperature of $34.66^{\circ} \mathrm{C}$, as shown in Fig. 38, reducing the use of the instant water 
heater. Indeed, instead of heating the water from the water line temperature to the user temperature, the instant water heater is going to use a pre-heated water. This simple

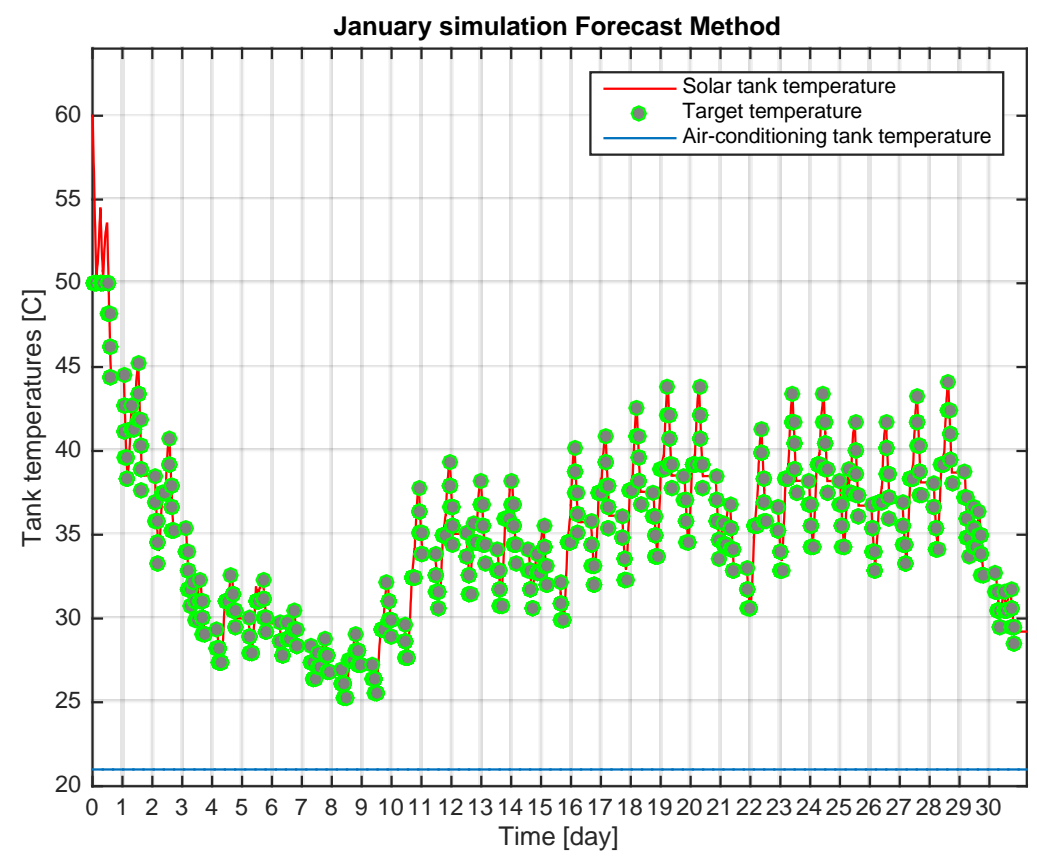

Figure 36 - Family - January - Forecast method

step reduces the daily average cost from $\$ 2.60$ to $\$ 1.37$, meaning the combined system of this study can reduce the daily average cost by the $47.31 \%$, as calculated by the following equations.

$$
\begin{gathered}
Q_{\text {daily }}=m_{\mathrm{H}_{2} \mathrm{O}} * c_{p \square_{2} \mathrm{O}} *\left(T_{\text {user }}-T_{\text {target }}\right)=8.6 * 10^{-3} * 4186 *(50-34.66) * 24 \\
=0.552 \mathrm{kWh} * 24=13.25 \mathrm{kWday}
\end{gathered}
$$

$$
\text { Average Daily Cost }=10.4 \frac{\Phi}{k W h} * 0.552 k W h * 24=\mathbf{1 . 3 7} \$
$$

\subsection{Family - Month of January - Action Method}

When the WMS is operating with the Action Method instead, it is able to provide an average Target Temperature of $33.08^{\circ} \mathrm{C}$, as shown in Fig. 39 The daily average cost is reduced, but less than the previous case: from $\$ 2.60$ to $\$ 1.52$. 
In this case the percentage of cost reduction is equal to $41.54 \%$, as calculated by the following equations, which leads us to conclude that it is better to use the Forecast Method for this specific case.

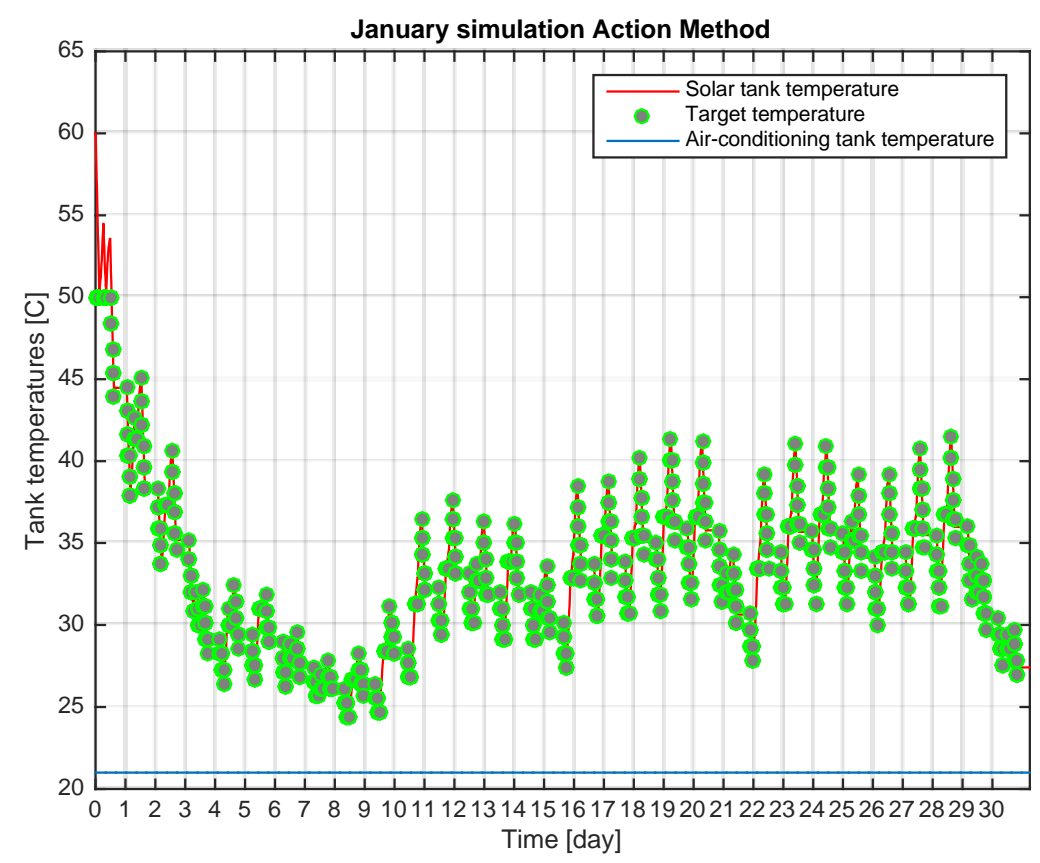

Figure 37 - Family - January - Action Method

$$
\begin{gathered}
Q_{\text {daily }}=m_{\mathrm{H}_{2} \mathrm{O}} * c_{\mathrm{pH}_{2} \mathrm{O}} *\left(T_{\text {user }}-T_{\text {target }}\right)=8.6 * 10^{-3} * 4186 *(50-33.08) * 24 \\
=0.609 \mathrm{kWh} * 24=14.61 \mathrm{kWday}
\end{gathered}
$$

$$
\text { Average Daily Cost }=10.4 \frac{\Phi}{k W h} * 0.552 k W h * 24=\mathbf{1 . 5 2} \$
$$

The initial steep decrease of the solar tank temperature is in relation to the assumption made at the beginning, i.e the initial temperature is constant for all cases analyzed. Therefore, it can be see as an initial adjustment of the graph. From day 3 to 10 it is possible to determine a lower solar radiation, due to the lower solar tank temperature values. After the first 10 days the pattern becomes recognizable, since the solar 
radiation goes back to the average. Finally, it is important to notice that the AC tank has a constant temperature, equal to the water line.

\subsection{Family - Month of April}

April, in Miami represents the beginning of the hurricane season. For this reason it has been chosen as the transitional month from the dry to humid season.

It has been assumed that the $\mathrm{AC}$ is turned on in average for 5 hours a day, from 12PM to $5 \mathrm{PM}$.

\subsection{1 family - month of April - Forecast Method}

The WMS operating with the Forecast Method in the month of April, makes a family of 4 people save $\$ 2.01$ per day. This means a reduction of the energy cost of the $77.30 \%$, which is impressive.

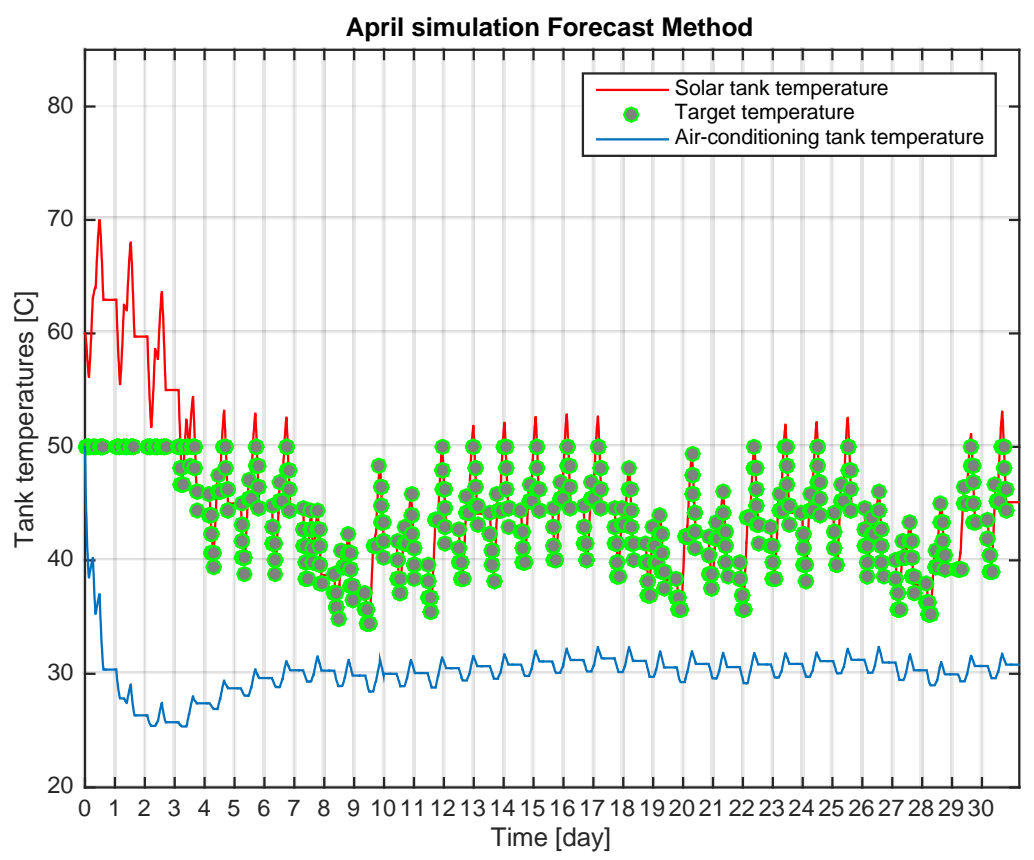

Figure 38 - Family - April - Forecast Method

$$
\begin{gathered}
Q_{\text {daily }}=m_{\mathrm{H}_{2} \mathrm{O}} * c_{\mathrm{pH}_{2} \mathrm{O}} *\left(T_{\text {user }}-T_{\text {target }}\right)=8.6 * 10^{-3} * 4186 *(50-43.45) * 24 \\
=0.236 \mathrm{kWh} * 24=5.65 \mathrm{kWday}
\end{gathered}
$$




$$
\text { Average Daily Cost }=10.4 \frac{\Phi}{k W h} * 0.236 k W h * 24=\mathbf{0 . 5 9} \$
$$

The initial steep decrease of the solar tank temperature is, again, the initial adjustment of the graph. It is possible to notice some decreases of solar radiation around day 8, 20 and 28. For the rest of the month the target temperature provided by the WMS under Forecast Method is $43.45^{\circ} \mathrm{C}$ that means the instant water heater has to use only a low amount of energy to provide the user temperature.

\subsection{2 family - month of April - Action Method}

During the same month, the Action Method makes the same family save \$2 per day, which is still a great result but slightly lower than the previous method.

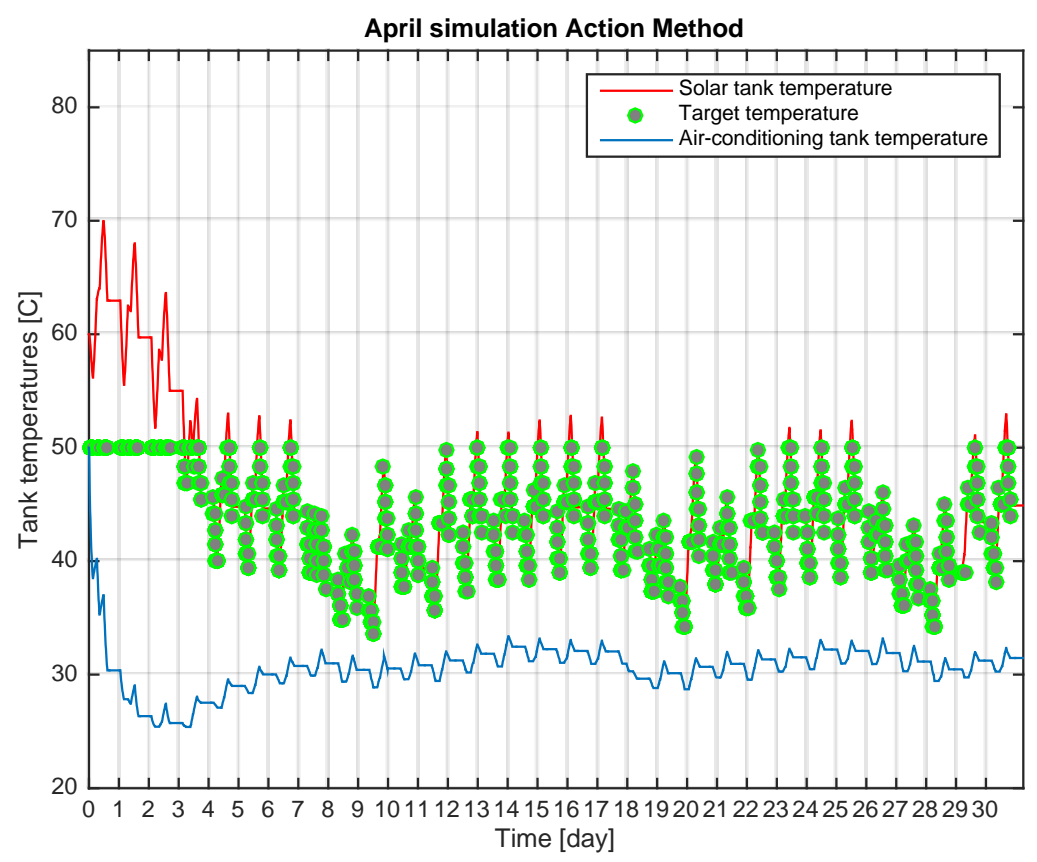

Figure 39 - Family - April - Action Method

$$
\begin{gathered}
Q_{\text {daily }}=m_{\mathrm{H}_{2} \mathrm{O}} * c_{\mathrm{pH}_{2} \mathrm{O}} *\left(T_{\text {user }}-T_{\text {target }}\right)=8.6 * 10^{-3} * 4186 *(50-43.33) * 24 \\
=0.240 \mathrm{kWh} * 24=5.7 \mathrm{kWday}
\end{gathered}
$$




$$
\text { Average Daily Cost }=10.4 \frac{\Phi}{k W h} * 0.240 \mathrm{kWh} * 24=\mathbf{0 . 6 0} \$
$$

\subsection{Family - Month of August}

August is one of the hottest and most humid months in Miami and for this reason it has been selected as an interesting month to analyze. It has been assumed that the AC is turned on in average for 18 hours a day, from 12PM to 6AM which is almost the entire day.

\subsection{1 family - month of August - Forecast Method}

The WMS operating with the Forecast Method in the month of August makes a family of 4 people save $\$ 2.10$ per day. This means the family is saving $80.77 \%$ on the daily energy cost. In the months where the $\mathrm{AC}$ is turned on more, it is clear the savings are higher.

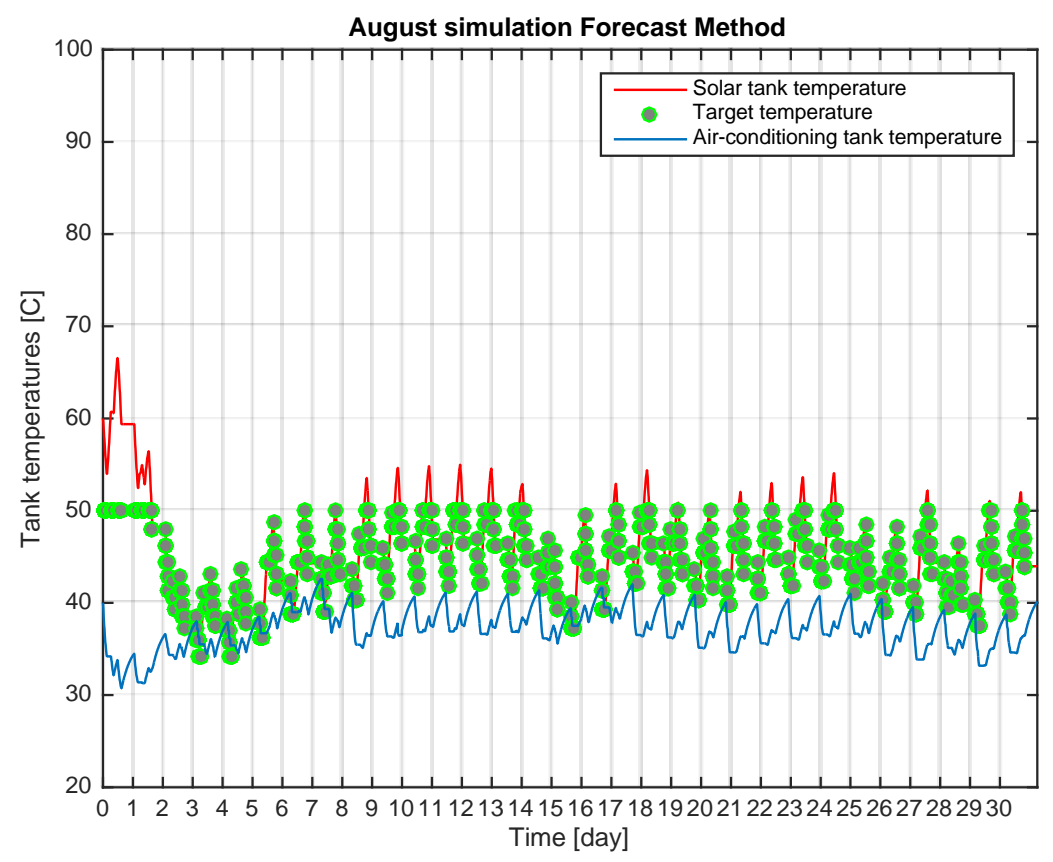

Figure 40 - Family - August - Forecast Method 


$$
\begin{gathered}
Q_{\text {daily }}=m_{\mathrm{H}_{2} \mathrm{O}} * c_{\mathrm{pH}_{2} \mathrm{O}} *\left(T_{\text {user }}-T_{\text {target }}\right)=8.6 * 10^{-3} * 4186 *(50-44.40) * 24 \\
=0.202 \mathrm{kWh} * 24=4.83 \mathrm{kWday}
\end{gathered}
$$

$$
\text { Average Daily Cost }=10.4 \frac{\Phi}{k W h} * 0.202 k W h * 24=\mathbf{0 . 5 0} \$
$$

It has been verified that the average temperatures inside the AC tank are higher than the rest of the year, due to the fact that the usage of AC is higher. The solar radiation instead is lower than April. For these reasons the target temperature obtained is on average with respect to the other months analyzed.

\subsection{2 family - Month of August - Action Method}

Even in this case the Action Method is slightly less efficient than the Forecast one.

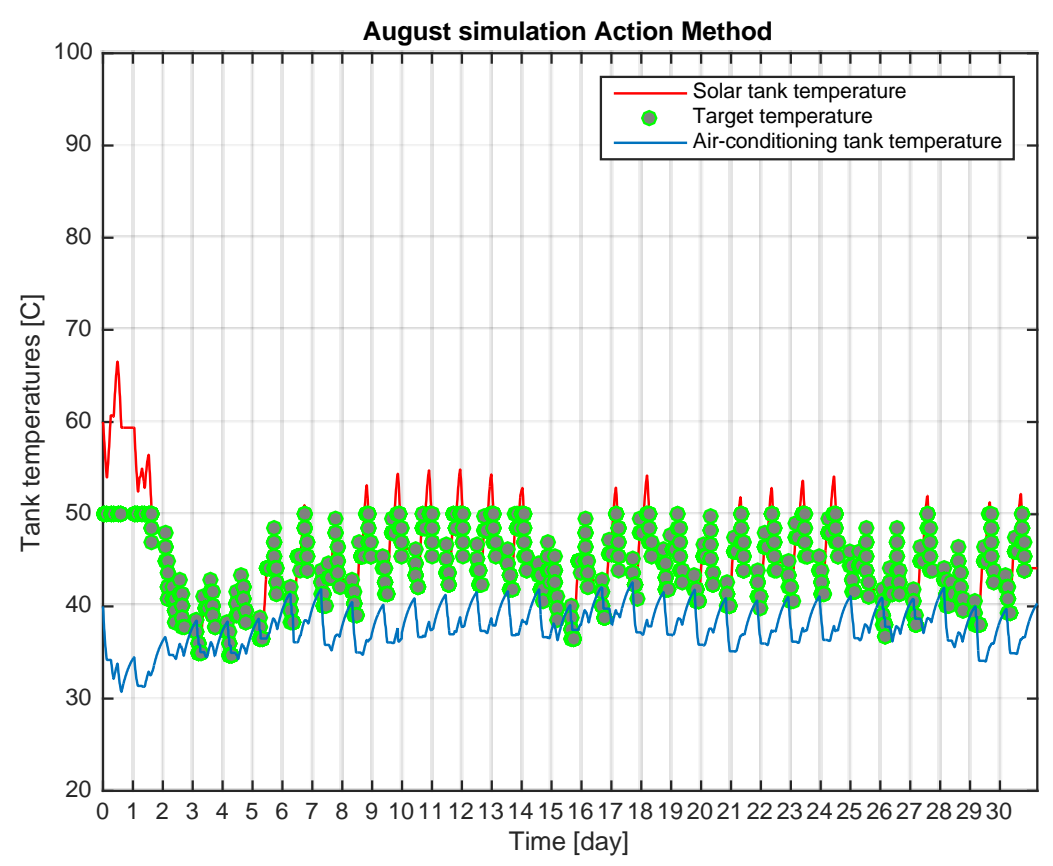

Figure 41 - Family - August - Action Method

$$
\begin{gathered}
Q_{\text {daily }}=m_{\mathrm{H}_{2} \mathrm{O}} * c_{\mathrm{pH}_{2} \mathrm{O}} *\left(T_{\text {user }}-T_{\text {target }}\right)=8.6 * 10^{-3} * 4186 *(50-44.31) * 24 \\
=0.205 \mathrm{kWh} * 24=4.9 \mathrm{kWday}
\end{gathered}
$$

$$
\text { Average Daily Cost }=10.4 \frac{\Phi}{k W h} * 0.205 k W h * 24=\mathbf{0 . 5 1} \$
$$




\subsection{Family - Month of November}

November has been chosen to have a complete overview of the year in Miami. Unfortunately the four seasons are not clearly recognizable in this city and it is hard to choose a real autumnal month. November, occurring in between August and January, is supposedly a good compromise.

\subsection{3 family - month of November - Forecast Method}

The WMS operating with the Forecast Method in the month of November predicts that a family of 4 people could save $\$ 1.25$ per day according to the calculations below.

Accordingly, in this month using the WMS, there is a 51.92\% energy saving on the basis of daily energy cost,

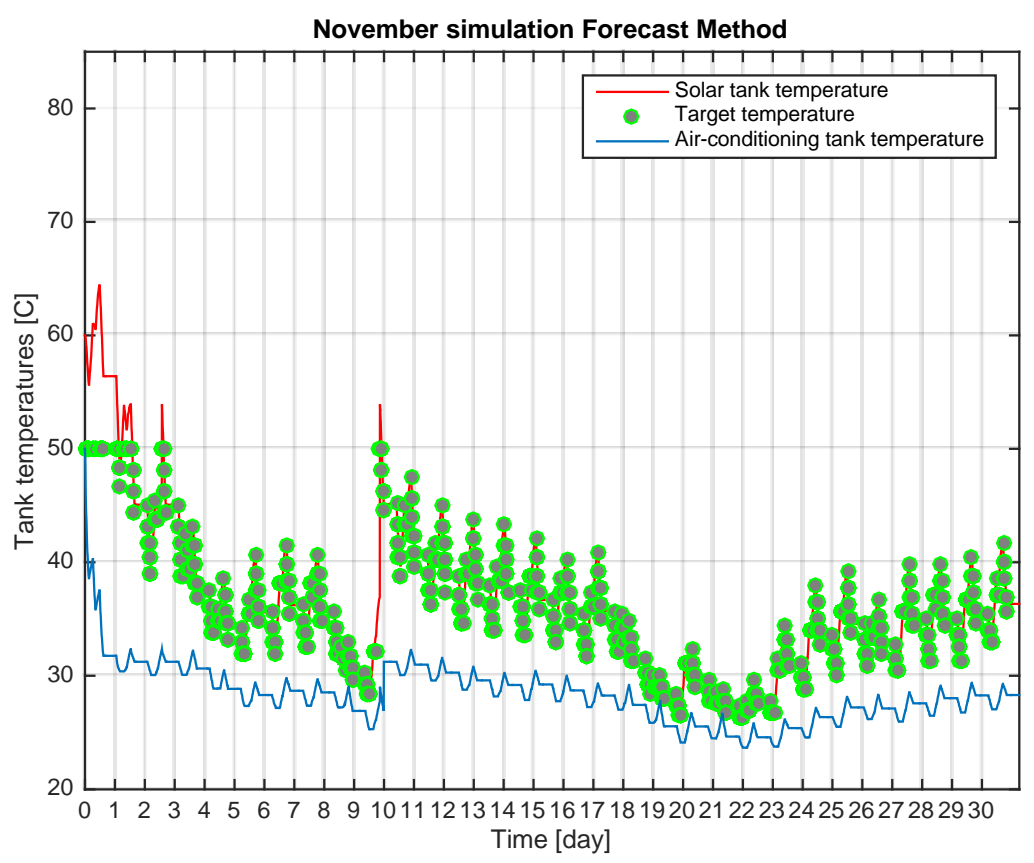

Figure 42 - Family - November - Forecast Method 


$$
\begin{gathered}
Q_{\text {daily }}=m_{\mathrm{H}_{2} \mathrm{O}} * c_{{p \mathrm{H}_{2} \mathrm{O}}} *\left(T_{\text {user }}-T_{\text {target }}\right)=8.6 * 10^{-3} * 4186 *(50-35.99) * 24 \\
=0.504 \mathrm{kWh} * 24=12.10 \mathrm{kWday}
\end{gathered}
$$

$$
\text { Average Daily Cost }=10.4 \frac{\Phi}{k W h} * 0.504 k W h * 24=\mathbf{1 . 2 5} \$
$$

Compared to August, November has a lower amount of solar radiations, which leads to a lower saving rate..

\subsection{4 family - month of November-Action Method}

As the previous data indicate, the Action Method is slightly less efficient and that in this case, the average daily saving is lower than that using the Forecast Method. Since it has demonstrated that the Forecast Method is more efficient than the Action Method, in the rest of analyses, only the Forecast Method is employed.

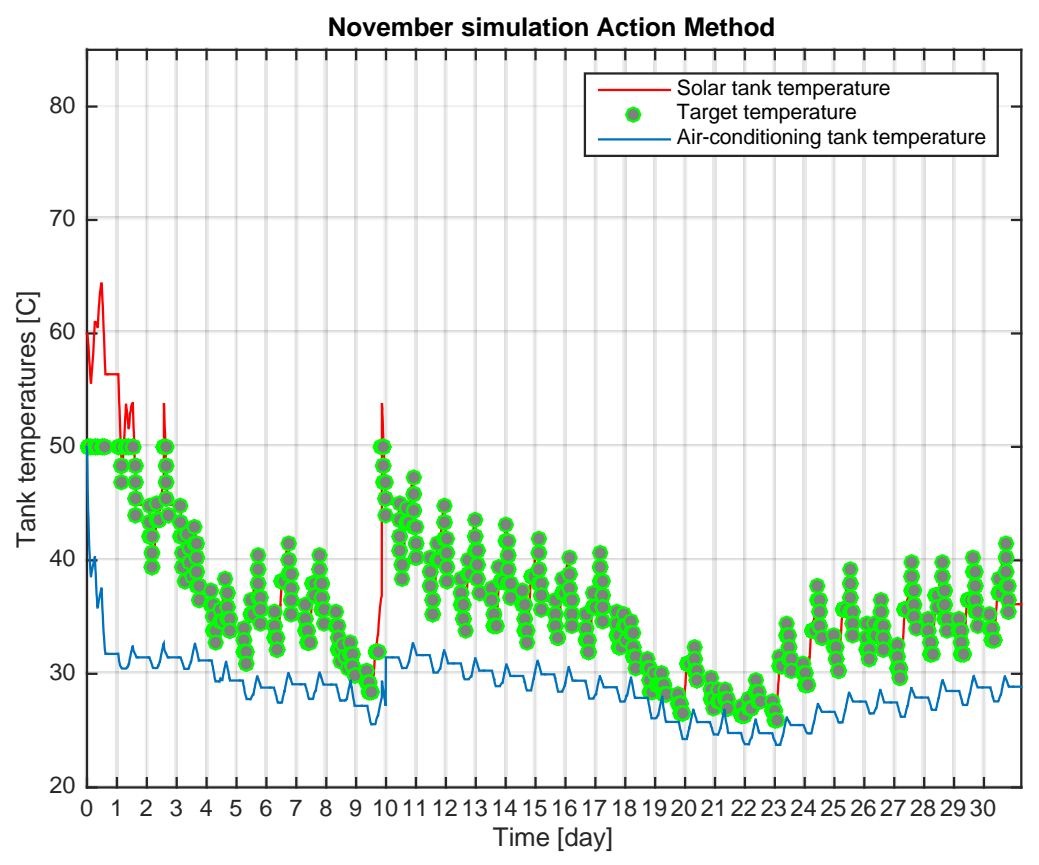

Figure 43 - Family - November - Action Method

$$
\begin{gathered}
Q_{\text {daily }}=m_{\mathrm{H}_{2} \mathrm{O}} * c_{\mathrm{pH}_{2} \mathrm{O}} *\left(T_{\text {user }}-T_{\text {target }}\right)=8.6 * 10^{-3} * 4186 *(50-35.92) * 24 \\
=0.507 \mathrm{kWh} * 24=12.16 \mathrm{kWday}
\end{gathered}
$$




$$
\text { Average Daily Cost }=10.4 \frac{\Phi}{k W h} * 0.507 k W h * 24=\mathbf{1 . 2 7} \$
$$

\subsubsection{Couple households}

By maintaining the average residential electricity rate in Miami as used in the previous calculations, it is possible to estimate the monthly utility bill for different households. It has been assumed an average hot water consumption of eight hours per day, but in this case, the flow rate is lower because there are only 2 people in the house. This takes the average daily cost down to $1.48 \$$, or a monthly utility bill of about $\$ 44$, according to the following computations:

$$
\begin{gathered}
Q_{\text {daily }}=m_{\mathrm{H}_{2} \mathrm{O}} * c_{{p \mathrm{H}_{2} \mathrm{O}}} *\left(T_{\text {user }}-T_{\text {waterline }}\right)=4.9 * 10^{-3} * 4186 *(50-21) * 24 \\
=0.594 \mathrm{kWh} * 24=14.28 \mathrm{kWday}
\end{gathered}
$$

$$
\text { Average Daily Cost }=10.4 \frac{\Phi}{k W h} * 0.594 k W h * 24=\mathbf{1 . 4 8} \$
$$

It is still expected that using the WMS there is a decrease in the water heating average daily cost. Also, since the number of people in the house is lower, probably the payback time will be longer.

The AC tank used in this case is 60 litres. It has found that the system is more capable to reach the highest average target temperatures possible. In order to determine the preferred volume, the result has been compared with the case of a 30 litre tank, and the conclusion is that increase of the tank cost does not affect the overall benefit of the system. 


\subsubsection{Water Heating Average Daily Cost with WMS for Couple households}

As before, the differences between the months of the year are highlighted and visually explained in the next four graphs, respectively for January, April, August and November for the same reasons explained for four people households.

The user temperature and the initial temperature of the solar and $\mathrm{AC}$ tanks are consistently assumed the same.

\subsection{Couple - Month of January -Forecast Method}

The WMS operating with the Forecast Method is able to provide an average Target Temperature of $34.30^{\circ} \mathrm{C}$, reducing the effort of the instant water heater. This simple step reduces the daily average cost from $\$ 1.48$ to $\$ 0.80$, as seen in the following computation, meaning reduction of the daily average cost could reach $45.95 \%$.

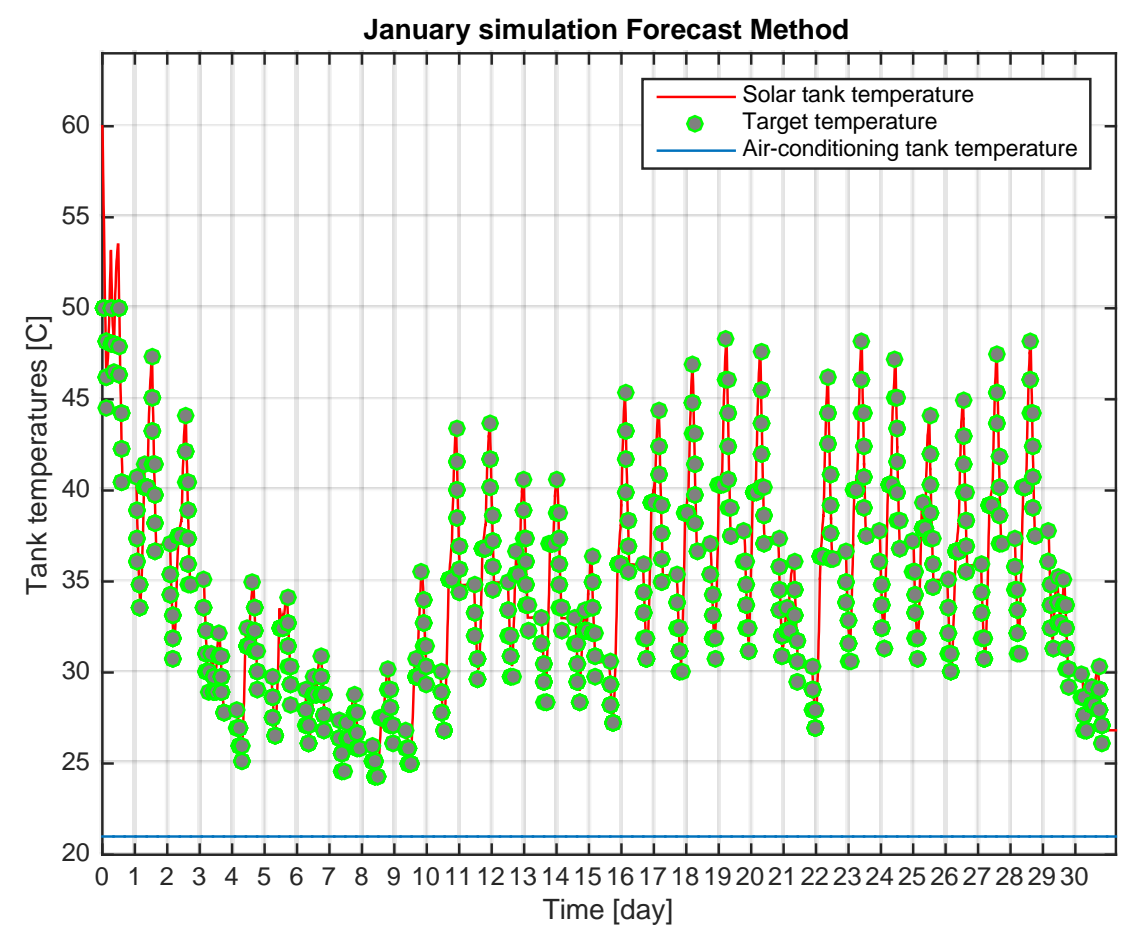

Figure 44 - Couple - January - Forecast Method 


$$
\begin{gathered}
Q_{\text {daily }}=m_{\mathrm{H}_{2} \mathrm{O}} * c_{\mathrm{pH}_{2} \mathrm{O}} *\left(T_{\text {user }}-T_{\text {waterline }}\right)=4.9 * 10^{-3} * 4186 *(50-34.30) * 24 \\
=0.322 \mathrm{kWh} * 24=7.73 \mathrm{kWday}
\end{gathered}
$$

$$
\text { Average Daily Cost }=10.4 \frac{\Phi}{k W h} * 0.322 k W h * 24=\mathbf{0 . 8 0} \$
$$

It has been found that the target temperature is very close to the one found in the case of the four people family during the same month. This is because the solar radiation in January is very low, which prevents the solar tank temperature from reaching a higher value. The target temperature that can be obtained and the temperature of the solar tank are inversely proportional to the tank volume: the bigger the volume of the solar tank at low radiation level, the lower the average tank temperature, due to the fact that the solar tank has less energy to collect.

\subsection{Couple - Month of April -Forecast Method}

The WMS provides an average target temperature of $46.48^{\circ} \mathrm{C}$ during the month of April. This value suggests that the system will positively affect the savings during this month. The daily average cost goes from $\$ 1.48$ to $\$ 0.18$; the saving for this month is the $87.84 \%$. 


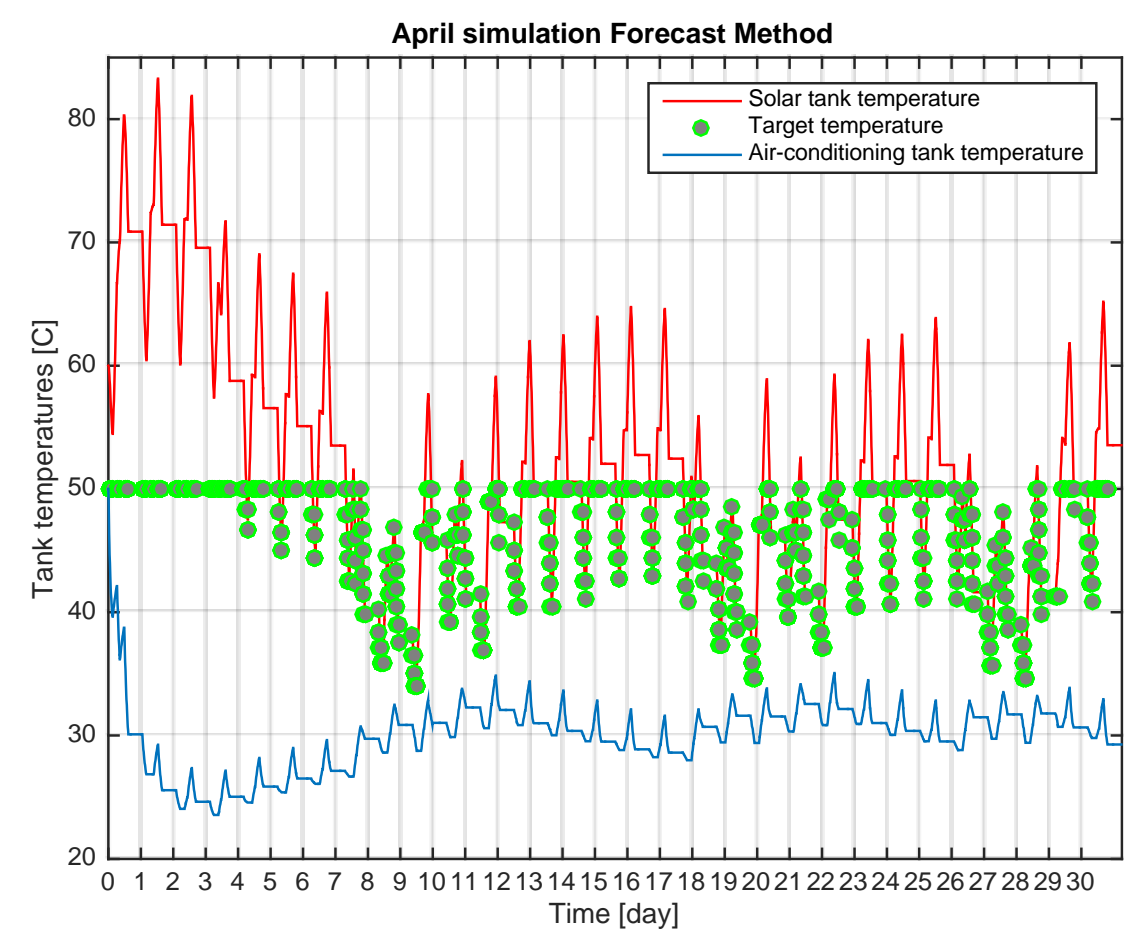

Figure 45 - Couple - April - Forecast Method

$$
\begin{gathered}
Q_{\text {daily }}=m_{\mathrm{H}_{2} \mathrm{O}} * c_{p \mathrm{H}_{2} \mathrm{O}} *\left(T_{\text {user }}-T_{\text {waterline }}\right)=4.9 * 10^{-3} * 4186 *(50-46.48) * 24 \\
=0.072 \mathrm{kWh} * 24=1.73 \mathrm{kWday}
\end{gathered}
$$

$$
\text { Average Daily Cost }=10.4 \frac{\Phi}{k W h} * 0.072 k W h * 24=0.18 \$
$$

April is substantially different from January because of the higher radiation values and higher AC usages. These parameters, in turn, could lead to a higher target temperature.

Comparing family case and the couple case for the month of April,, it is clear the target temperature is higher. This is because of a smaller tank volume and a lower flow rate demanded by the user.

For the first time it is possible to see that a target temperature equals the user temperature over $75 \%$ of the month. Therefore during most of the days in this month, 
the instant water heater remains turned off. The WMS is capable of satisfying the demand of the user by itself alone most of the time.

The temperature of the solar tank is much higher than that in the previous cases, but it never reaches the maximum temperature allowed. There are no safety risks involved related to the usage of the system.

\subsection{Couple - Month of August -Forecast Method}

The average target temperature provided by the WMS in August is $47.99^{\circ} \mathrm{C}$ taking the level of saving to an even higher percentage of $93.24 \%$.

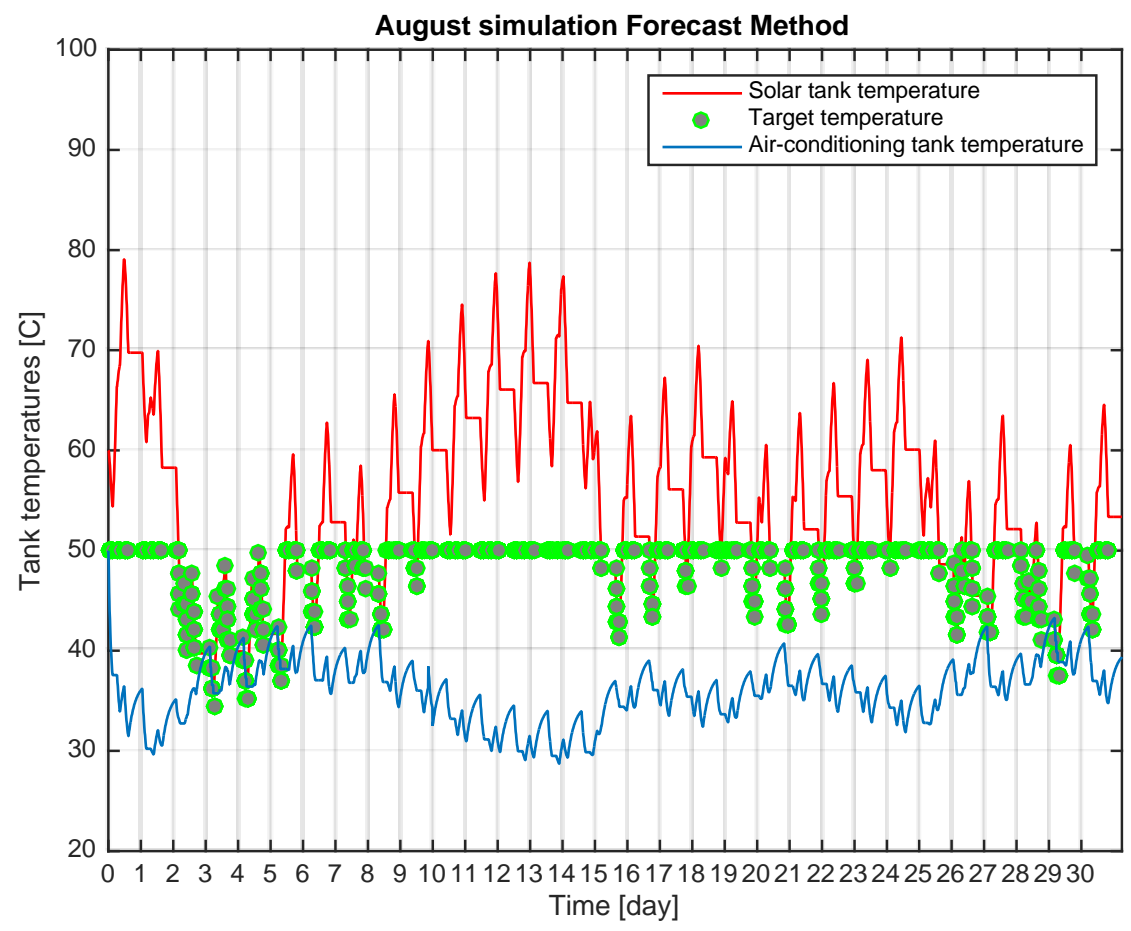

Figure 46 - Couple - August - Forecast Method

$$
\begin{gathered}
Q_{\text {daily }}=m_{\mathrm{H}_{2} \mathrm{O}} * c_{\mathrm{pH}_{2} \mathrm{O}} *\left(T_{\text {user }}-T_{\text {waterline }}\right)=4.9 * 10^{-3} * 4186 *(50-47.99) * 24 \\
=0.041 \mathrm{kWh} * 24=0.99 \mathrm{kWday}
\end{gathered}
$$

$$
\text { Average Daily Cost }=10.4 \frac{\Phi}{k W h} * 0.041 k W h * 24=\mathbf{0 . 1 0} \$
$$


August is characterized by lower radiations compared to April; therefore the solar tank have lower values of temperature, thanks to the higher usage of the AC in which the target temperature obtained is higher than the target temperature obtained in the previous cases. The WMS is able to provide the user temperature for $90 \%$ of the month.

\subsection{Couple - Month of November -Forecast Method}

In November, the system is able to provide an average target temperature of $37.55^{\circ} \mathrm{C}$.

The saving percentage decreases again to $56.75 \%$.

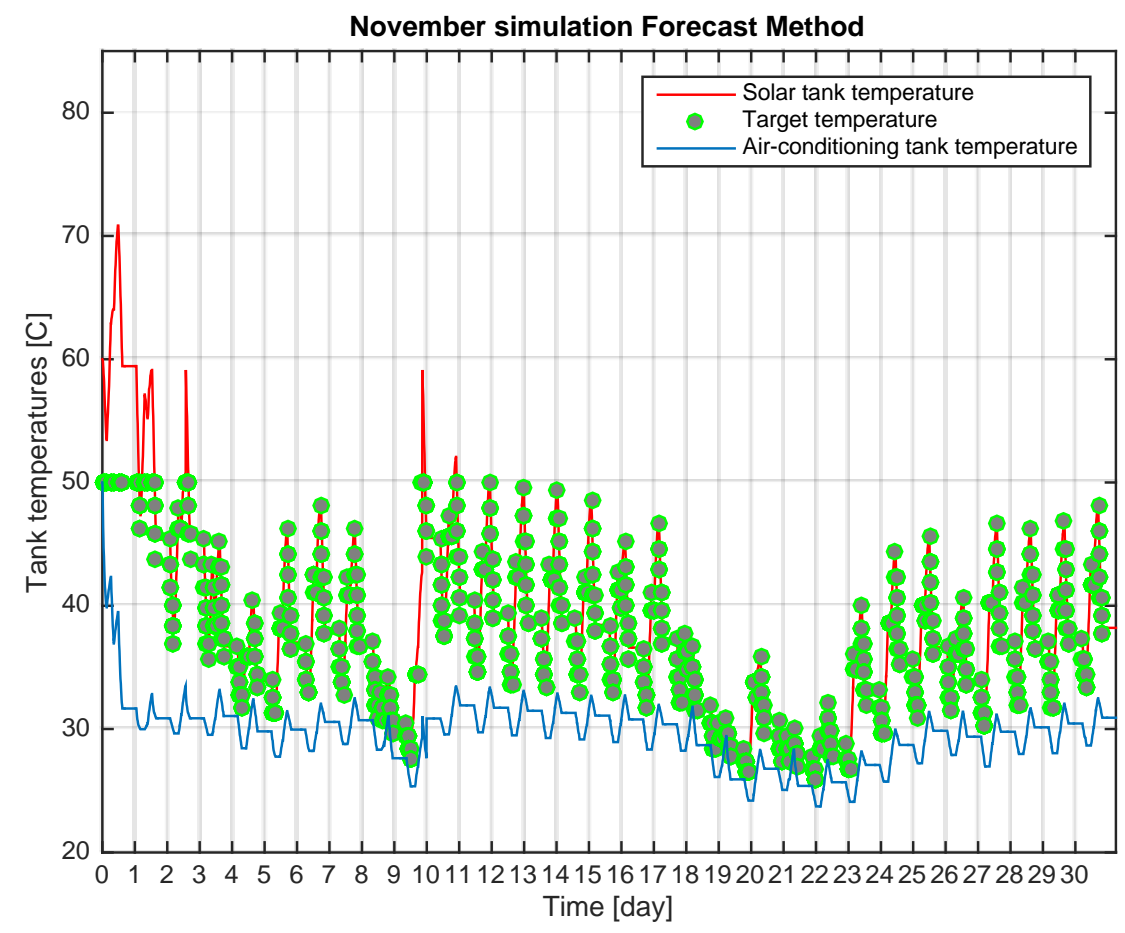

Figure 47 - Couple - November - Forecast Method

$$
\begin{gathered}
Q_{\text {daily }}=m_{\mathrm{H}_{2} \mathrm{O}} * c_{p_{\mathrm{H}_{2} \mathrm{O}}} *\left(T_{\text {user }}-T_{\text {waterline }}\right)=4.9 * 10^{-3} * 4186 *(50-37.55) * 24 \\
=0.255 \mathrm{kWh} * 24=6.13 \mathrm{kWday}
\end{gathered}
$$




$$
\text { Average Daily Cost }=10.4 \frac{\Phi}{k W h} * 0.255 k W h * 24=\mathbf{0 . 6 4 \$}
$$

Comparing the graph of the family case in November and the one for the couple, the same trend can be recognized but the values are generally lower in the case of the family. The general increase in temperatures, in the case of the couple, is due to the fact that the users demand a lower flow rate.

During this month with these conditions, the WMS needs the help of the instant water heater quite often to satisfy the demand.

\subsubsection{Single Person Household}

The monthly utility bill for a single resident in Florida is calculated as follows. It has been assumed an average hot water consumption of eight hours per day but in this case, the flow rate is even lower than the couple. This takes the average daily cost down to $\$ 0.93$, or a monthly utility bill of about $\$ 27.9$.

$$
\begin{gathered}
Q_{\text {daily }}=m_{\mathrm{H}_{2} \mathrm{O}} * c_{\mathrm{pH}_{2} \mathrm{O}} *\left(T_{\text {user }}-T_{\text {waterline }}\right)=3.1 * 10^{-3} * 4186 *(50-21) * 24 \\
=0.376 \mathrm{kWh} * 24=9.03 \mathrm{kWday}
\end{gathered}
$$

$$
\text { Average Daily Cost }=10.4 \frac{\mathbb{}}{\mathrm{kWh}} * 0.162 \mathrm{kWh} * 24=\mathbf{0 . 9 3} \$
$$

The decrease in the water heating average daily cost using the WMS is still expected. The AC tank used in this case is 30 litres.

\subsubsection{Water Heating Average Daily Cost with WMS for Single Person Household}

\subsubsection{1}

The same fixed parameters have been used: the four sample months, the user temperature and the initial temperature of the solar and AC tanks. 


\subsection{Single - Month of January - Forecast Method}

The WMS operating with the Forecast Method is able to provide an average Target Temperature of $38.20^{\circ} \mathrm{C}$ for a single resident in the month of January, reducing the effort of the instant water heater. This simple step reduces the daily average cost from $\$ 0.93$ to $\$ 0.40$, meaning the reduction in the daily average cost could reach $56.99 \%$.

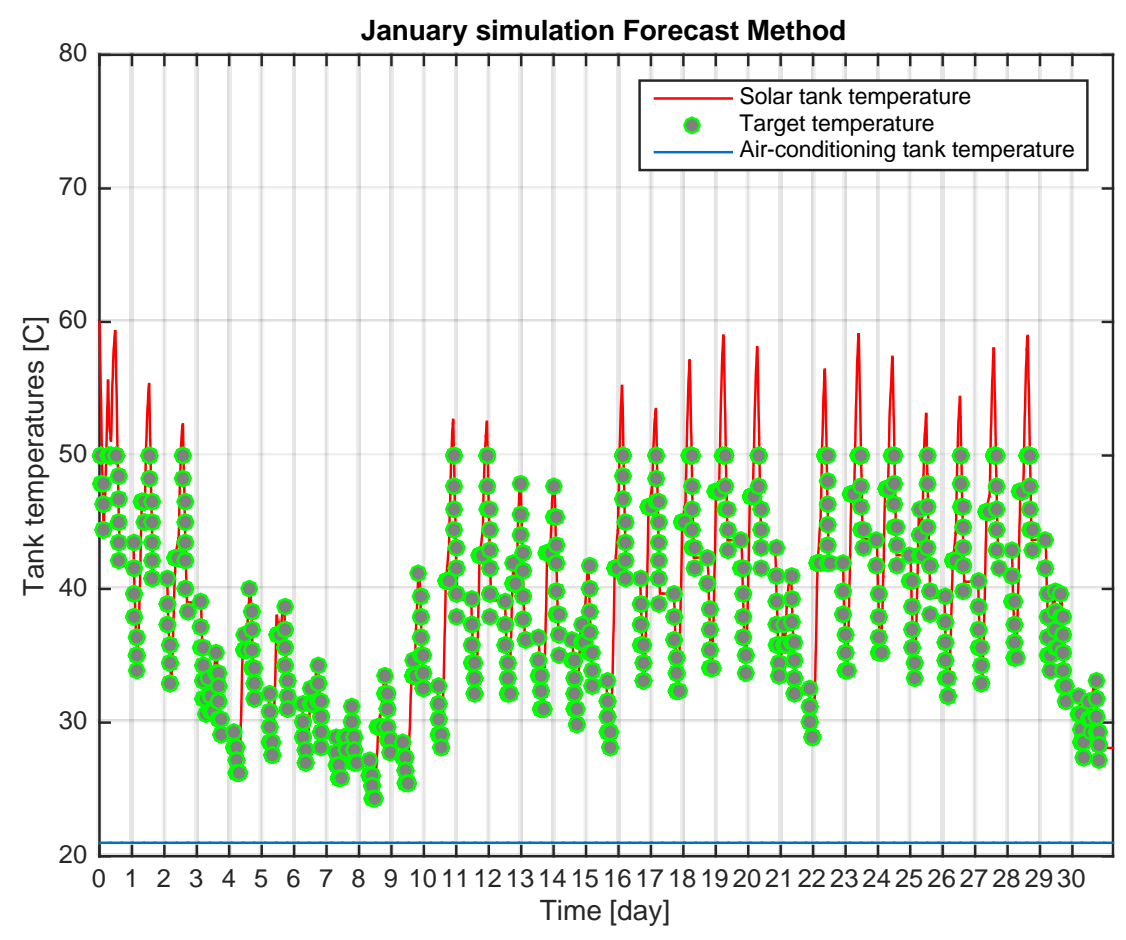

Figure 48 - Single - January - Forecast method

$$
\begin{gathered}
Q_{\text {daily }}=m_{\mathrm{H}_{2} \mathrm{O}} * c_{p_{\mathrm{H}_{2} \mathrm{O}}} *\left(T_{\text {user }}-T_{\text {waterline }}\right)=3.1 * 10^{-3} * 4186 *(50-38.20) * 24 \\
=0.162 \mathrm{kWh} * 24=3.87 \mathrm{kWday}
\end{gathered}
$$

$$
\text { Average Daily Cost }=10.4 \frac{\Phi}{k W h} * 0.162 k W h * 24=\mathbf{0 . 4 0} \$
$$

The temperature trend is similar to the other cases examined in the same month. The difference is caused by the higher average target temperature due to a lower flow rate that leads to a much slower discharge phase. The solar tank, which is smaller in this case, makes the temperature increase faster. 
An iterative process has been necessary to obtain the best combination of user and tank dimension. For example, if a too small tank is chosen, there is not enough storage capacity and the demand may not be satisfied, but the average tank temperature would increase faster.

\subsection{Single - Month of April - Forecast Method}

The WMS, on April, operating with the Forecast Method is able to provide an average Target Temperature of $50^{\circ} \mathrm{C}$ to a single resident, meaning the daily average energy cost related to the water heater is reduced to 0. The System guarantees the energy production for the use of the hot water for the entire month.

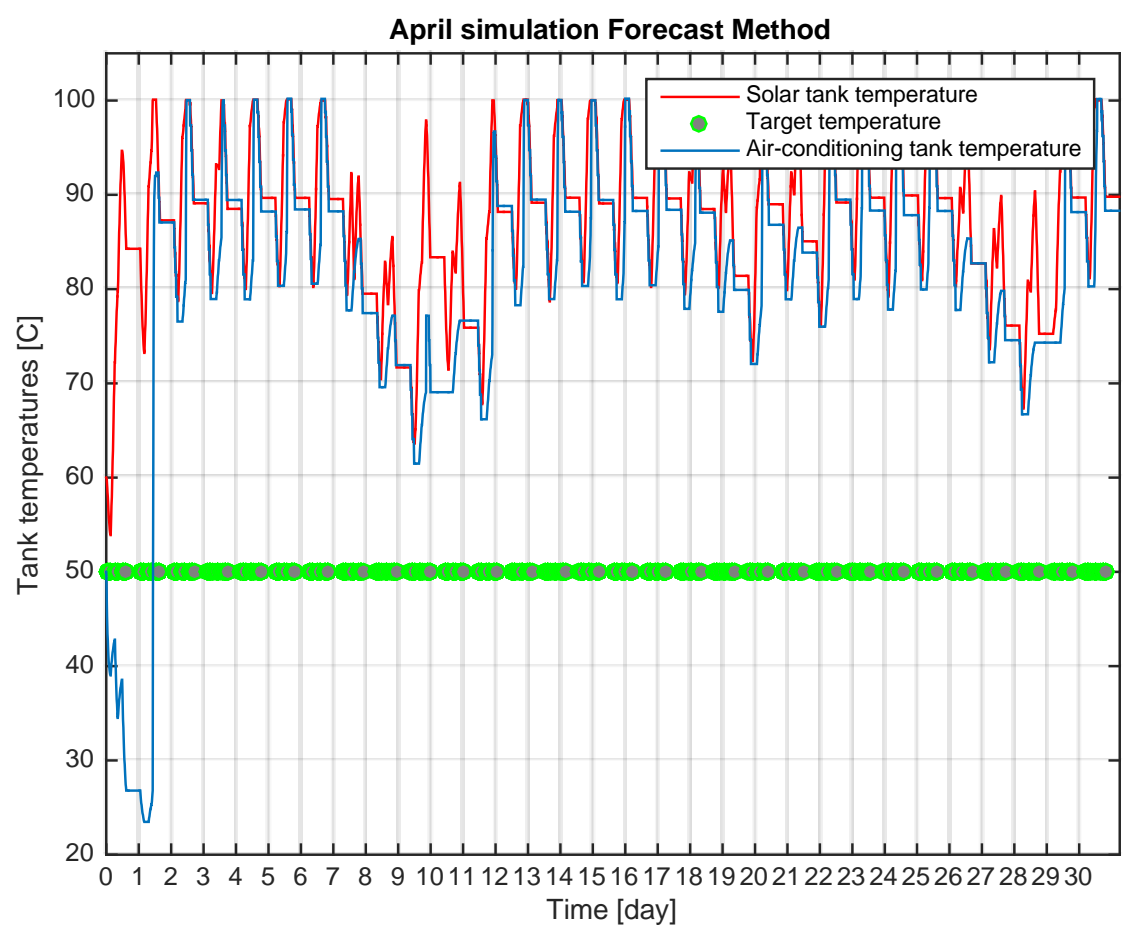

Figure 49 - Single - April - Forecast Method

$$
\begin{gathered}
Q_{\text {daily }}=m_{\mathrm{H}_{2} \mathrm{O}} * c_{\mathrm{pH}_{2} \mathrm{O}} *\left(T_{\text {user }}-T_{\text {waterline }}\right)=3.1 * 10^{-3} * 4186 *(50-50) * 24 \\
=0 \mathrm{kWh} * 24=k W \text { day }
\end{gathered}
$$

Average Daily Cost $=10.4 \frac{\Phi}{k W h} * 0 k W h * 24=\mathbf{0} \$$ 
April is the month with the highest solar radiation level, as previously seen and the single user is the one that requests the lowest flow rate. For these two reasons, the temperature requested is equal to the target temperature, making the usage of the boiler equal to 0 - this is the optimal situation that the WMS would like to furnish.

\subsection{Single - Month of August - Forecast Method}

The average target temperature provided by the WMS to the single user in August is $49.42^{\circ} \mathrm{C}$ taking the level of saving to a very high percentage of $97.96 \%$. It believed that this situation is optimal within the entire years.

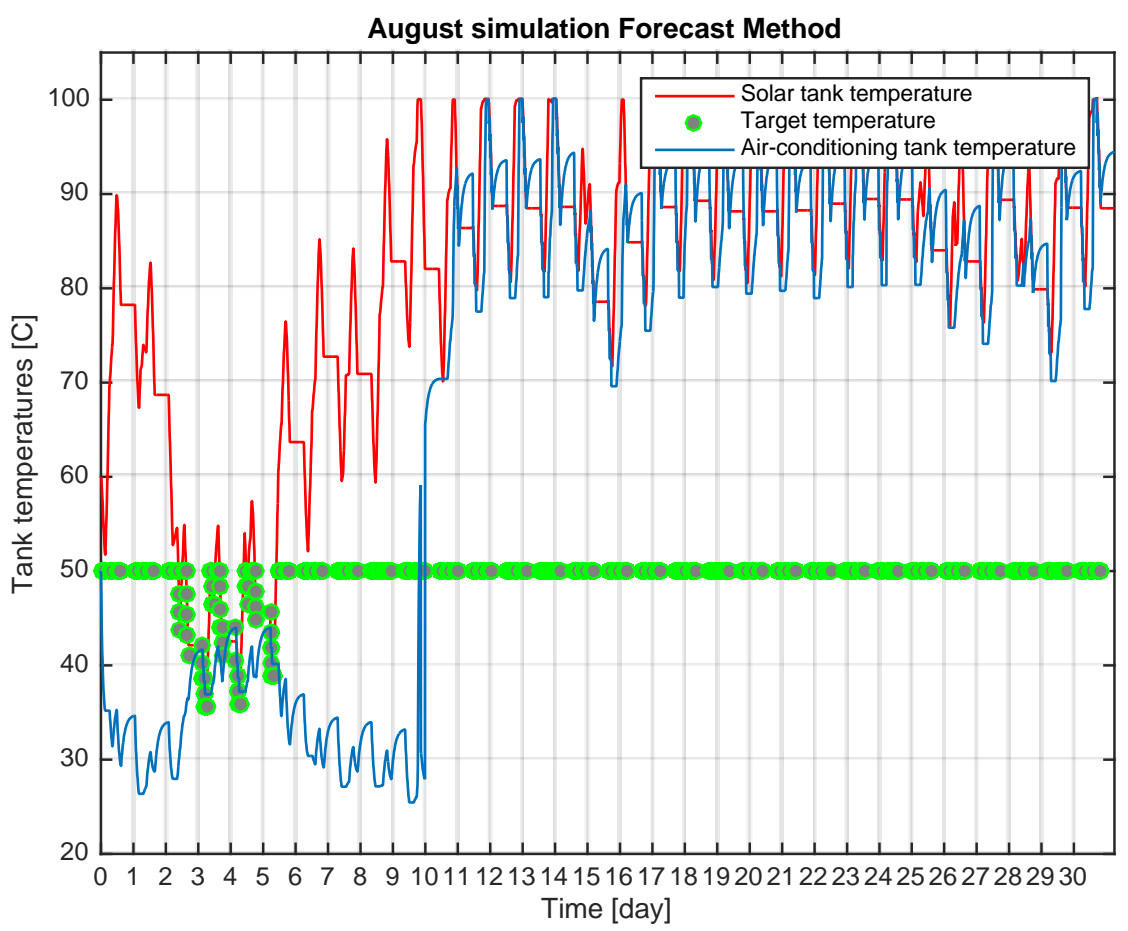

Figure 50 - Single - August - Forecast Method

$$
\begin{gathered}
Q_{\text {daily }}=m_{\mathrm{H}_{2} \mathrm{O}} * c_{p_{\mathrm{H}_{2} \mathrm{O}}} *\left(T_{\text {user }}-T_{\text {waterline }}\right)=3.1 * 10^{-3} * 4186 *(50-49.42) * 24 \\
=7.5 * 10^{-3} \mathrm{kWh} * 24=0.18 \mathrm{kWday}
\end{gathered}
$$

$$
\text { Average Daily Cost }=10.4 \frac{\Phi}{k W h} * 7.5 * 10^{-3} k W h * 24=\mathbf{0 . 0 1 9} \$
$$


The average target temperature obtained is very close to the user temperature. The instant water heater remains turned off for $95 \%$ of the month.

\subsection{Single - Month of November - Forecast Method}

In November the System has been able to provide an average target temperature of $44.28^{\circ} \mathrm{C}$, and the saving percentage goes down to $80.65 \%$.

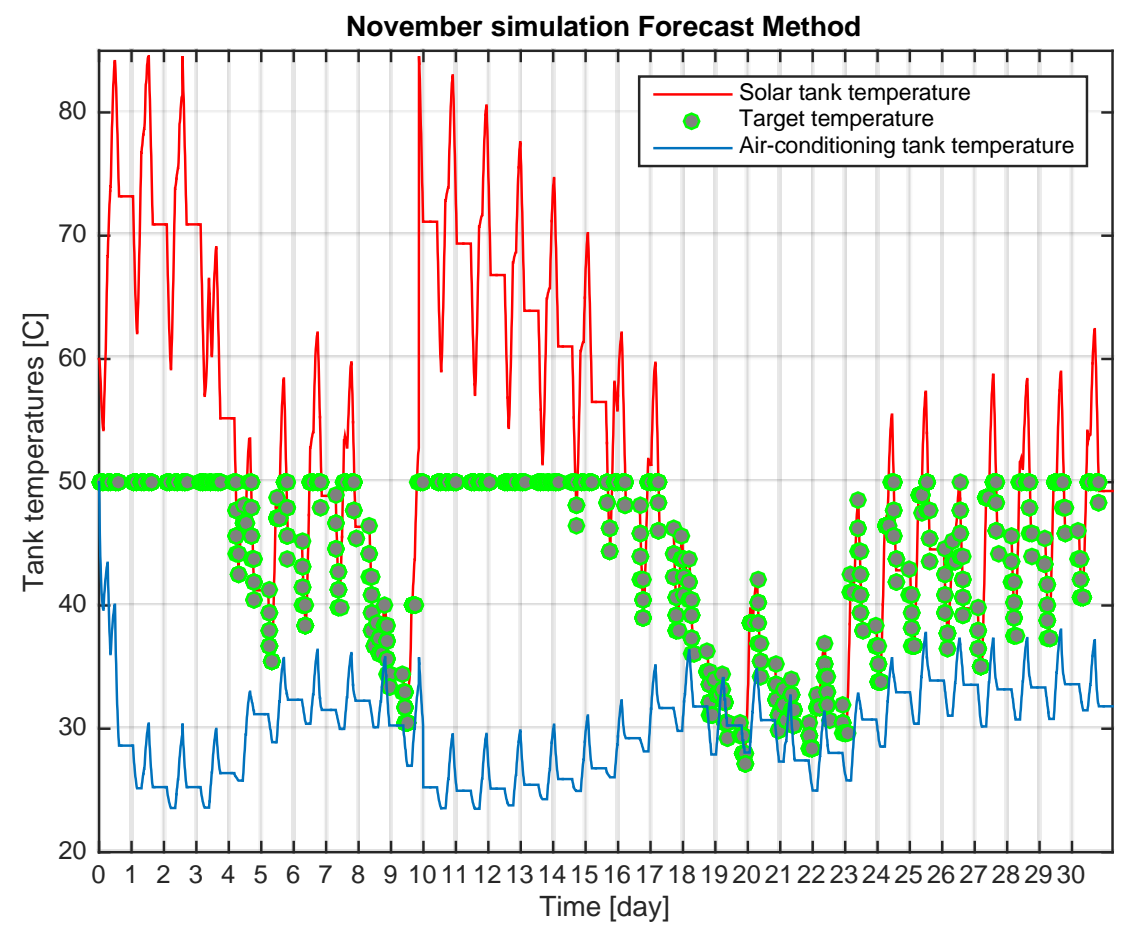

Figure 51 - Single - November - Forecast method

$$
\begin{gathered}
Q_{\text {daily }}=m_{\mathrm{H}_{2} \mathrm{O}} * c_{p \mathrm{H}_{2} \mathrm{O}} *\left(T_{\text {user }}-T_{\text {waterline }}\right)=3.1 * 10^{-3} * 4186 *(50-44.28) * 24 \\
=0.074 \mathrm{kWh} * 24=1.78 \mathrm{kWday}
\end{gathered}
$$

$$
\text { Average Daily Cost }=10.4 \frac{\Phi}{k W h} * 0.074 k W h * 24=\mathbf{0 . 1 8} \$
$$

Given the lower demand, the solar tank has the ability to increase the internal temperature compared to the family and couple cases. This means that the target temperature increases drastically, but it is not sufficient to satisfy the demand for the entire month. The instant water heater is going to be activated for about $50 \%$ of the period tested. 


\subsubsection{PVT System - renewable energy only}

In order to make sure that the WMS has a real benefit on the reduction of electrical bill in both short and long terms, it has been decided to test the house's average daily cost when only the PVT System is used to heat the water needed by the user.

\subsubsection{January - PVT System}

\subsection{Family - January - PVT System}

The PVT system provides an average Target Temperature of $34.66^{\circ} \mathrm{C}$ and it reduces the daily average cost from $\$ 2.60$ to $\$ 1.37$. This means it can reduce the daily average cost by $47.31 \%$.

$$
\begin{gathered}
Q_{\text {daily }}=m_{\mathrm{H}_{2} \mathrm{O}} * c_{\mathrm{pH}_{2} \mathrm{O}} *\left(T_{\text {user }}-T_{\text {target }}\right)=8.6 * 10^{-3} * 4186 *(50-34.66) * 24 \\
=0.552 \mathrm{kWh} * 24=13.25 \mathrm{kWday}
\end{gathered}
$$

$$
\text { Average Daily Cost }=10.4 \frac{\Phi}{k W h} * 0.552 k W h * 24=\mathbf{1 . 3 7} \$
$$

\subsection{Couple - January - PVT System}

The PVT system provides an average Target Temperature of $34.30^{\circ} \mathrm{C}$, and it reduces the daily average cost from $\$ 1.48$ to $\$ 0.80$. This means that it can reduce the daily average cost by $45.95 \%$.

$$
\begin{gathered}
Q_{\text {daily }}=m_{\mathrm{H}_{2} \mathrm{O}} * c_{\mathrm{pH}_{2} \mathrm{O}} *\left(T_{\text {user }}-T_{\text {waterline }}\right)=4.9 * 10^{-3} * 4186 *(50-34.30) * 24 \\
=0.322 \mathrm{kWh} * 24=7.73 \mathrm{kWday}
\end{gathered}
$$

$$
\text { Average Daily Cost }=10.4 \frac{\Phi}{k W h} * 0.322 k W h * 24=\mathbf{0 . 8 0} \$
$$




\subsection{Single - January - PVT System}

The PVT system provides an average Target Temperature of $38.20^{\circ} \mathrm{C}$, and it reduces the daily average cost from $\$ 0.93$ to $\$ 0.40$. This means that it can reduce the daily average cost by $56.98 \%$.

$$
\begin{gathered}
Q_{\text {daily }}=m_{\mathrm{H}_{2} \mathrm{O}} * c_{p_{\mathrm{H}_{2} \mathrm{O}}} *\left(T_{\text {user }}-T_{\text {waterline }}\right)=3.1 * 10^{-3} * 4186 *(50-38.20) * 24 \\
=0.162 \mathrm{kWh} * 24=3.87 \mathrm{kWday}
\end{gathered}
$$

$$
\text { Average Daily Cost }=10.4 \frac{\Phi}{k W h} * 0.162 k W h * 24=\mathbf{0 . 4 0} \$
$$

\subsubsection{April - PVT System}

\subsection{Family - April -PVT System}

The PVT system in the month of April, makes a family of 4 people save $\$ 1.89$ per day. This means it can reduce the energy cost of $72.69 \%$.

$$
\begin{gathered}
Q_{\text {daily }}=m_{\mathrm{H}_{2} \mathrm{O}} * c_{\mathrm{pH}_{2} \mathrm{O}} *\left(T_{\text {user }}-T_{\text {target }}\right)=8.6 * 10^{-3} * 4186 *(50-42.08) * 24 \\
=0.285 \mathrm{kWh} * 24=6.84 \mathrm{kWday}
\end{gathered}
$$

$$
\text { Average Daily Cost }=10.4 \frac{\Phi}{k W h} * 0.285 k W h * 24=\mathbf{0 . 7 1} \$
$$

\subsection{Couple - April -PVT System}

The PVT system is able to provide an average Target Temperature of $44.81^{\circ} \mathrm{C}$, reducing the effort of the instant water heater. This means that it can reduce the daily average cost from $\$ 1.48$ to $\$ 0.27$ or by $81.75 \%$.

$$
\begin{gathered}
Q_{\text {daily }}=m_{\mathrm{H}_{2} \mathrm{O}} * c_{p_{\mathrm{H}_{2} \mathrm{O}}} *\left(T_{\text {user }}-T_{\text {waterline }}\right)=4.9 * 10^{-3} * 4186 *(50-44.81) * 24 \\
=0.106 \mathrm{kWh} * 24=2.55 \mathrm{kWday}
\end{gathered}
$$




$$
\text { Average Daily Cost }=10.4 \frac{\Phi}{k W h} * 0.106 k W h * 24=0.27 \$
$$

\subsection{Single - April -PVT System}

The PVT system is able to provide an average Target Temperature of $49.99^{\circ} \mathrm{C}$. This simple step reduces the daily average cost from $\$ 0.93$ to $\$ 3.1 * 10^{-3}$. This means that it can readuce the daily average cost by $99.66 \%$.

$$
\begin{gathered}
Q_{\text {daily }}=m_{\mathrm{H}_{2} \mathrm{O}} * c_{\mathrm{pH}_{2} \mathrm{O}} *\left(T_{\text {user }}-T_{\text {waterline }}\right)=3.1 * 10^{-3} * 4186 *(50-49.99) * 24 \\
=1.3 * 10^{-4} \mathrm{kWh} * 24=3.11 * 10^{-3} \mathrm{kWday}
\end{gathered}
$$

$$
\text { Average Daily Cost }=10.4 \frac{\Phi}{\mathrm{kWh}} * 1.3 * 10^{-4} \mathrm{kWh} * 24=3.1 * 10^{-3} \$
$$

\subsubsection{August-PVT System}

\subsection{Family - August - PVT System}

The PVT system in the month of August, makes a family of 4 people save $\$ 1.85$ per day. This means a reduction of the energy cost is $71.15 \%$.

$$
\begin{gathered}
Q_{\text {daily }}=m_{\mathrm{H}_{2} \mathrm{O}} * c_{\mathrm{pH}_{2} \mathrm{O}} *\left(T_{\text {user }}-T_{\text {target }}\right)=8.6 * 10^{-3} * 4186 *(50-41.65) * 24 \\
=0.301 \mathrm{kWh} * 24=7.21 \mathrm{kWday}
\end{gathered}
$$

$$
\text { Average Daily Cost }=10.4 \frac{\Phi}{k W h} * 0.301 k W h * 24=\mathbf{0 . 7 5} \$
$$

\subsection{Couple - August - PVT System}

The PVT system is able to provide an average Target Temperature of $44.07^{\circ} \mathrm{C}$. This simple step reduces the daily average cost from $\$ 1.48$ to $\$ 0.30$. This means that it can reduce the daily average cost by $81.75 \%$. 


$$
\begin{gathered}
Q_{\text {daily }}=m_{\mathrm{H}_{2} \mathrm{O}} * c_{\mathrm{pH}_{2} \mathrm{O}} *\left(T_{\text {user }}-T_{\text {waterline }}\right)=4.9 * 10^{-3} * 4186 *(50-44.07) * 24 \\
=0.121 \mathrm{kWh} * 24=2.9 \mathrm{kWday}
\end{gathered}
$$

$$
\text { Average Daily Cost }=10.4 \frac{\Phi}{k W h} * 0.121 k W h * 24=\mathbf{0 . 3 0} \$
$$

\subsection{Single - August - PVT System}

The PVT system in August is able to provide an average Target Temperature of $49.30^{\circ} \mathrm{C}$ to a single user. The daily average cost is reduced from $\$ 0.93$ to $\$ 0.023$. This means that it can reduce the daily average cost by $99.66 \%$.

$$
\begin{gathered}
Q_{\text {daily }}=m_{\mathrm{H}_{2} \mathrm{O}} * c_{\mathrm{pH}_{2} \mathrm{O}} *\left(T_{\text {user }}-T_{\text {waterline }}\right)=3.1 * 10^{-3} * 4186 *(50-49.30) * 24 \\
=9.08 * 10^{-3} \mathrm{kWh} * 24=0.22 \mathrm{kWday}
\end{gathered}
$$

$$
\text { Average Daily Cost }=10.4 \frac{\Phi}{k W h} * 9.08 * 10^{-3} k W h * 24=0.023 \$
$$

\subsubsection{November-PVT System}

\subsection{Family - November - PVT System}

The PVT system in the month of November makes a family of 4 people save $\$ 1.19$ per day. This means a reduction of the energy cost is $46.15 \%$.

$$
\begin{gathered}
Q_{\text {daily }}=m_{\mathrm{H}_{2} \mathrm{O}} * c_{\mathrm{pH}_{2} \mathrm{O}} *\left(T_{\text {user }}-T_{\text {target }}\right)=8.6 * 10^{-3} * 4186 *(50-34.26) * 24 \\
=0.566 \mathrm{kWh} * 24=13.59 \mathrm{kWday}
\end{gathered}
$$

$$
\text { Average Daily Cost }=10.4 \frac{\Phi}{k W h} * 0.566 k W h * 24=\mathbf{1 . 4 1} \$
$$




\subsection{Couple - November - PVT System}

The PVT system is able to provide to a couple an average Target Temperature of $35.29^{\circ} \mathrm{C}$ in November. This simple step reduces the daily average cost from $\$ 1.48$ to $\$ 0.75$, or by $81.75 \%$.

$$
\begin{gathered}
Q_{\text {daily }}=m_{\mathrm{H}_{2} \mathrm{O}} * c_{\mathrm{pH}_{2} \mathrm{O}} *\left(T_{\text {user }}-T_{\text {waterline }}\right)=4.9 * 10^{-3} * 4186 *(50-35.29) * 24 \\
=0.301 \mathrm{kWh} * 24=7.2 \mathrm{kWday}
\end{gathered}
$$

$$
\text { Average Daily Cost }=10.4 \frac{\Phi}{k W h} * 0.301 k W h * 24=\mathbf{0 . 7 5} \$
$$

\subsection{Single - November - PVT System}

The PVT system with the Forecast Method is able to provide to a single user an average Target Temperature of $41.78^{\circ} \mathrm{C}$ in November, reducing the effort of the instant water heater. This simple step reduces the daily average cost from $\$ 0.93$ to $\$ 0.26$. This means a reduction of $99.66 \%$.

$$
\begin{gathered}
Q_{\text {daily }}=m_{\mathrm{H}_{2} \mathrm{O}} * c_{\mathrm{pH}_{2} \mathrm{O}} *\left(T_{\text {user }}-T_{\text {waterline }}\right)=3.1 * 10^{-3} * 4186 *(50-41.78) * 24 \\
=0.106 \mathrm{kWh} * 24=2.5 \mathrm{kWday}
\end{gathered}
$$

$$
\text { Average Daily Cost }=10.4 \frac{\$}{k W h} * 0.106 k W h * 24=0.26 \$
$$

\subsection{Summary of Results}

The computational results obtained in this chapter are summarized in Tables 1-5 in terms of cost and saving as well as payback times, and in Figs. 54-55 in terms of the savings in different months and the dependence on the operational hours of AC system, which would make it easier to analyze the outcome of this study. 


\begin{tabular}{|c|c|c|c|c|c|c|c|c|c|c|c|}
\hline & & \multicolumn{2}{|c|}{ Instant water heater } & \multicolumn{4}{|c|}{ WMS } & \multicolumn{4}{|c|}{ PVT System } \\
\hline & & Daily Cost & $\begin{array}{l}\text { Monthly } \\
\text { Cost }\end{array}$ & Daily Cost & \begin{tabular}{|c|}
$\begin{array}{c}\text { Monthly } \\
\text { Cost }\end{array}$ \\
\end{tabular} & \begin{tabular}{|c|} 
Monthly \\
Saving
\end{tabular} & \%S & Daily Cost & $\begin{array}{c}\text { Monthly } \\
\text { Cost }\end{array}$ & $\begin{array}{c}\text { Monthly } \\
\text { Saving }\end{array}$ & $\% \mathrm{~S}$ \\
\hline \multirow{3}{*}{ January } & Family & $\$ 2,60$ & $\$ 78,00$ & $\$ 1,37$ & $\$ 41,10$ & $\$ 36,90$ & \begin{tabular}{|l|}
47,31 \\
\end{tabular} & $\$ 1,37$ & $\$ 41,10$ & $\$ 36,90$ & 47,31 \\
\hline & Couple & $\$ 1,48$ & $\$ 44,00$ & $\$ 0,68$ & $\$ 20,40$ & $\$ 23,60$ & 45,95 & $\$ 0,68$ & $\$ 20,40$ & $\$ 23,60$ & 45,95 \\
\hline & Single & $\$ 0,93$ & $\$ 27,90$ & $\$ 0,71$ & $\$ 21,30$ & $\$ 6,60$ & 56,98 & $\$ 0,71$ & $\$ 21,30$ & $\$ 6,60$ & 56,98 \\
\hline \multirow{3}{*}{ April } & Family & $\$ 2,60$ & $\$ 78,00$ & $\$ 0,59$ & $\$ 17,70$ & $\$ 60,30$ & 77,30 & $\$ 0,71$ & $\$ 21,30$ & $\$ 56,70$ & 72,69 \\
\hline & Couple & $\$ 1,48$ & $\$ 44,00$ & $\$ 0,18$ & $\$ 5,40$ & $\$ 38,60$ & 87,84 & 0.27 & $\$ 8,10$ & $\$ 35,90$ & 81,75 \\
\hline & Single & $\$ 0,93$ & $\$ 27,90$ & $\$ 0,00$ & $\$ 0,00$ & $\$ 27,90$ & 100,00 & $3.1+10^{-2}$ & $\$ 0,09$ & $\$ 27,81$ & 99,66 \\
\hline \multirow{3}{*}{ August } & Family & $\$ 2,60$ & $\$ 78,00$ & $\$ 0,50$ & $\$ 15,00$ & $\$ 63,00$ & 80,77 & $\$ 0,75$ & $\$ 22,50$ & $\$ 55,50$ & 71,15 \\
\hline & Couple & $\$ 1,48$ & $\$ 44,00$ & $\$ 0,10$ & $\$ 3,00$ & $\$ 41,00$ & 93,24 & $\$ 0,30$ & $\$ 9,00$ & $\$ 35,00$ & 79,73 \\
\hline & Single & $\$ 0,93$ & $\$ 27,90$ & $\$ 0,02$ & $\$ 0,57$ & $\$ 27,33$ & 97,95 & $\$ 0,02$ & $\$ 0,69$ & $\$ 27,21$ & 97,52 \\
\hline \multirow{3}{*}{ November } & Family & $\$ 2,60$ & $\$ 78,00$ & $\$ 1,25$ & $\$ 37,50$ & $\$ 40,50$ & 51,92 & $\$ 1,41$ & $\$ 42,30$ & $\$ 35,70$ & 46,15 \\
\hline & Couple & $\$ 1,48$ & $\$ 44,00$ & $\$ 0,64$ & $\$ 19,20$ & $\$ 24,80$ & 56,75 & $\$ 0,75$ & $\$ 22,50$ & $\$ 21,50$ & 49,32 \\
\hline & Single & $\$ 0,93$ & $\$ 27,90$ & $\$ 0,18$ & $\$ 5,40$ & $\$ 22,50$ & 80,64 & $\$ 0,26$ & $\$ 7,80$ & $\$ 20,10$ & 72,04 \\
\hline
\end{tabular}

Table 1 - Costs and Saving summary

August shows the highest saving amounts as shown in Table 1. The only exception is in April, where in the case of the single resident there is a saving rate of $100 \%$. This is possible because the radiation level is high and the demand is low, therefore the WMS is able to provide the energy itself for the entire month.

August has a lower radiation with respect to April but higher saving rates thanks to the higher level of AC usage. Indeed the average saving rate is about the $90 \%$ in August and it decreases to $80 \%$ if only the PVT system is in use.

January has the same saving rate in the WMS and PVT system analyses because the $\mathrm{AC}$ remains turned off for the entire month.

In general, it is important to notice that the saving rates are higher using the Water Mixing System (WMS), compared to the PVT system only. This conclusion is confirmed in Table 2. To calculate the average yearly saving, it has been decided to use January as a sample for only 1 month, November as a sample for 3 months, and the April and August, respectively, as sample for 4 months each. This is the closest representation of a year in Miami, because the seasons are not well defined. 


\begin{tabular}{|c|c|r|r|r|r|}
\hline & $\begin{array}{c}\text { yearly } \\
\text { energy } \\
\text { cost with } \\
\text { instant } \\
\text { water } \\
\text { heater }\end{array}$ & $\begin{array}{c}\text { Average } \\
\text { Yearly } \\
\text { Saving } \\
\text { with WMS }\end{array}$ & $\begin{array}{c}\text { Payback } \\
\text { time } \\
\text { (years) } \\
\text { with } \\
\text { WMS }\end{array}$ & $\begin{array}{c}\text { Average } \\
\text { Yearly } \\
\text { Saving } \\
\text { with PVT } \\
\text { system }\end{array}$ & $\begin{array}{c}\text { Payback } \\
\text { time } \\
\text { (years) } \\
\text { with } \\
\text { PVT } \\
\text { system }\end{array}$ \\
\hline Family & $\$ 936,00$ & $\$ 651,60$ & 2,76 & $\$ 592,80$ & 2,11 \\
\hline Couple & $\$ 528,00$ & $\$ 416,40$ & 3,72 & $\$ 371,70$ & 2,69 \\
\hline Single & $\$ 334,80$ & $\$ 295,02$ & 5,25 & $\$ 286,97$ & 3,48 \\
\hline
\end{tabular}

Table 2 - Return On Investments

With these data, it has been possible to calculate the number of years needed to recover the investment. In the four-people family case, the investment may be recovered in less than 3 years; in the couple case, the payback period is almost 4 years; and in the single person case, the payback period slightly exceeds 5 years, as shown in Table 2. In all the cases, the payback time for the WMS investment is higher than the one for the PVT system because of its lower investment.

The main parameter that influences the payback time is the cost necessary to manufacture the plant as well as the installation of the plant. The components that affect the cost of the plant are the AC tank and the number of solar panels installed. Indeed the family case has the highest cost because the number of solar panels installed doubles and the $\mathrm{AC}$ tank is bigger. For example, the component cost for the four-people family is $\$ 1,800$ vs. $\$ 1,550$ for a single case.

Here below are the tables (Tables 3-5, respectively for four-people family, couple, and single) that list the savings for the first 15 years after the plant has been installed. Highlighted in green, is the year during which the user pays back the investment cost.

At the bottom of each following table, Tables. 3-5, the saving percentages over the entire 15 years are provided for both the WMS and the PVT systems. In the family case, the difference between these two systems is 6 percentage points, in the couple case is 9 points, and in the single user case is only 3 points. 


\begin{tabular}{|c|c|c|c|c|c|}
\hline FAMILY & $\begin{array}{c}\text { yearly } \\
\text { energy } \\
\text { cost with } \\
\text { instant } \\
\text { water } \\
\text { heater }\end{array}$ & $\begin{array}{c}\text { yearly } \\
\text { energy } \\
\text { cost with } \\
\text { WMS }\end{array}$ & $\begin{array}{c}\text { yearly } \\
\text { savings } \\
\text { with WMS }\end{array} \mid$ & $\begin{array}{c}\text { yearly } \\
\text { energy } \\
\text { cost with } \\
\text { PVT } \\
\text { system }\end{array}$ & $\begin{array}{c}\text { yearly } \\
\text { savings } \\
\text { with PVT } \\
\text { system }\end{array}$ \\
\hline \begin{tabular}{|l|} 
year 1 \\
\end{tabular} & $936,00 \mathrm{\epsilon}$ & $284,40 \mathrm{C}$ & $651,60 \mathrm{C}$ & $343,20 \mathrm{C}$ & $592,80 \mathrm{C}$ \\
\hline year 2 & $1.872,00 \mathrm{C}$ & $568,80 \mathrm{C}$ & $1.303,20 \mathrm{C}$ & \begin{tabular}{|l|}
$686,40 \mathrm{C}$ \\
\end{tabular} & $1.185,60 \mathrm{C}$ \\
\hline year 3 & $2.808,00 \mathrm{C}$ & $853,20 \mathrm{C}$ & $1.954,80 \mathrm{C}$ & \begin{tabular}{|l|l|}
$1.029,60 \mathrm{C}$ \\
\end{tabular} & $1.778,40 \mathrm{C}$ \\
\hline year 4 & $3.744,00 \mathrm{C}$ & \begin{tabular}{|l|}
$1.137,60 \mathrm{C}$ \\
\end{tabular} & $2.606,40 €$ & \begin{tabular}{|l|}
$1.372,80 \mathrm{C}$ \\
\end{tabular} & $2.371,20 \mathrm{C}$ \\
\hline year 5 & $4.680,00 \mathrm{C}$ & $1.422,00 \mathrm{C}$ & $3.258,00 €$ & $1.716,00 \mathrm{C}$ & $2.964,00 \mathrm{C}$ \\
\hline year 6 & $5.616,00 \mathrm{C}$ & $1.706,40 \mathrm{C}$ & $3.909,60 \mathrm{C}$ & $2.059,20 €$ & $3.556,80 \mathrm{C}$ \\
\hline year 7 & $6.552,00 \mathrm{C}$ & $1.990,80 \mathrm{C}$ & $4.561,20 \mathrm{C}$ & $2.402,40 \mathrm{C}$ & $4.149,60 \mathrm{C}$ \\
\hline year 8 & $7.488,00 \mathrm{C}$ & $2.275,20 \mathrm{C}$ & $5.212,80 \mathrm{C}$ & $2.745,60 \mathrm{C}$ & $4.742,40 \mathrm{C}$ \\
\hline year 9 & $8.424,00 €$ & $2.559,60 \mathrm{C}$ & $5.864,40 €$ & $3.088,80 \mathrm{C}$ & $5.335,20 \mathrm{C}$ \\
\hline year 10 & $9.360,00 \mathrm{C}$ & $2.844,00 \mathrm{C}$ & $6.516,00 \mathrm{C}$ & $3.432,00 \mathrm{C}$ & $5.928,00 €$ \\
\hline year 11 & $10.296,00 \mathrm{C}$ & \begin{tabular}{|l|}
$3.128,40 \mathrm{C}$ \\
\end{tabular} & $7.167,6 n c$ & $2775,20 \mathrm{C}$ & $6.520,80 \mathrm{C}$ \\
\hline year 12 & $11.232,00 \mathrm{C}$ & $3.412,80 \mathrm{C}$ & $7.819,20 \mathrm{C}$ & $4.118,4) \mathrm{C}$ & $7.113,60 \mathrm{C}$ \\
\hline year 13 & $12.168,00 \mathrm{C}$ & $3.697,20 \mathrm{C}$ & $8.470,00 \mathrm{c}$ & $1.401,60 \mathrm{C}$ & $7.706,40 \mathrm{C}$ \\
\hline year 14 & $13.104,00 \mathrm{C}$ & \begin{tabular}{|l|}
$3.981,60 \mathrm{C}$ \\
\end{tabular} & $9.122,40 \mathrm{C}$ & \begin{tabular}{|l|l|}
$4.804,80 \mathrm{C}$ \\
\end{tabular} & $8.299,20 \mathrm{C}$ \\
\hline year 15 & $14.040,00 \mathrm{C}$ & $4.266,00 \mathrm{C}$ & $9.774,00 \mathrm{C}$ & \begin{tabular}{|l|l|l}
$5.148,00 \mathrm{C}$ \\
\end{tabular} & $8.892,00 \mathrm{C}$ \\
\hline
\end{tabular}

SAVING \%

\begin{tabular}{|c|c|c|c|c|c|}
\hline COUPLE & \begin{tabular}{|c|} 
yearly \\
energy cost \\
with \\
instant \\
water \\
heater
\end{tabular} & $\begin{array}{l}\text { yearly } \\
\text { energy } \\
\text { cost with } \\
\text { WMS }\end{array}$ & $\begin{array}{c}\text { yearly } \\
\text { savings } \\
\text { with WMS }\end{array}$ & $\begin{array}{c}\text { yearly } \\
\text { energy } \\
\text { cost with } \\
\text { PVT } \\
\text { system }\end{array}$ & $\begin{array}{l}\text { yearly } \\
\text { savings } \\
\text { with PVT } \\
\text { system }\end{array}$ \\
\hline year 1 & $528,00 \mathrm{C}$ & $111,60 \mathrm{C}$ & $416,40 \mathrm{E}$ & $156,30 \mathrm{C}$ & $371,70 \mathrm{C}$ \\
\hline year 2 & $1.056,00 \mathrm{C}$ & $223,20 \mathrm{C}$ & $832,80 \mathrm{C}$ & & $743,40 \mathrm{C}$ \\
\hline year 3 & $1.584,00 \mathrm{C}$ & $334,80 \mathrm{C}$ & 1.249 , & 468 & $1.115,10 \mathrm{C}$ \\
\hline year 4 & $2.112,00 \mathrm{C}$ & $446,40 \mathrm{E}$ & $1.665,60 \mathrm{C}$ & & $6,80 \mathrm{C}$ \\
\hline year 5 & $2.640,00 \mathrm{C}$ & $558,00 \mathrm{C}$ & $2.082,00 \mathrm{C}$ & $781,50 \mathrm{C}$ & $1.858,50 \mathrm{C}$ \\
\hline year 6 & $3.168,00 \mathrm{C}$ & $669,60 \mathrm{C}$ & $2.498,40 €$ & $937,80 \mathrm{C}$ & $2.230,20 \mathrm{\epsilon}$ \\
\hline year 7 & $3.696,00 \mathrm{C}$ & $781,20 \mathrm{C}$ & $2.914,80 \mathrm{C}$ & $1.094,10 \mathrm{C}$ & $2.601,90 \mathrm{C}$ \\
\hline year 8 & $4.224,00 \mathrm{C}$ & $892,80 \mathrm{C}$ & $3.331,20 \mathrm{C}$ & $1.250,40 \mathrm{C}$ & $2.973,60 €$ \\
\hline year 9 & $4.752,00 \mathrm{C}$ & $1.004,40 \mathrm{C}$ & $3.747,60 €$ & $1.406,70 \mathrm{C}$ & $3.345,30 \mathrm{C}$ \\
\hline year 10 & $5.280,00 \mathrm{C}$ & $1.116,00 \mathrm{C}$ & $4.164,00 \mathrm{C}$ & $1.563,00 \mathrm{C}$ & $3.717,00 \mathrm{C}$ \\
\hline year 11 & $5.808,00 \mathrm{C}$ & $1.227,60 \mathrm{C}$ & $4.580,40 €$ & $1.719,30 \mathrm{C}$ & $4.088,70 €$ \\
\hline year 12 & $6.336,00 \mathrm{C}$ & $1.339,20 \mathrm{C}$ & $4.996,80 \mathrm{C}$ & $1.875,60 \mathrm{C}$ & $4.460,40 €$ \\
\hline year 13 & $6.864,00 \mathrm{C}$ & $1.450,80 \mathrm{C}$ & $5.413,20 \mathrm{\epsilon}$ & $2.031,90 \mathrm{C}$ & $4.832,10 €$ \\
\hline year 14 & $7.392,00 \mathrm{C}$ & $1.562,40 \mathrm{C}$ & $5.029,000$ & $2.188,20 \mathrm{C}$ & $5.203,80 \mathrm{C}$ \\
\hline year 15 & $7.920,00 \mathrm{C}$ & $1.674,000$ & $6.246,00 \mathrm{C}$ & $2.344,50 \mathrm{C}$ & $5.575,50 \mathrm{C}$ \\
\hline SAVING $\%$ & & & 78,86 & & 70,40 \\
\hline
\end{tabular}

Table 3 - Family Yearly Savings for 15 years

Table 4 - Couple Yearly Savings for 15 years

\begin{tabular}{|c|c|c|c|c|c|}
\hline SINGLE & $\begin{array}{c}\text { yearly } \\
\text { energy } \\
\text { cost with } \\
\text { instant } \\
\text { water } \\
\text { heater }\end{array}$ & $\begin{array}{c}\text { yearly } \\
\text { energy } \\
\text { cost with } \\
\text { WMS }\end{array}$ & $\begin{array}{c}\text { yearly } \\
\text { savings } \\
\text { with WMS }\end{array}$ & $\begin{array}{l}\text { yearly } \\
\text { energy } \\
\text { cost with } \\
\text { PVT } \\
\text { system }\end{array}$ & $\begin{array}{c}\text { yearly } \\
\text { savings } \\
\text { with PVT } \\
\text { system }\end{array}$ \\
\hline year 1 & $334,80 \mathrm{C}$ & $39,78 \mathrm{C}$ & $295,02 \mathrm{\epsilon}$ & $47,83 \mathrm{C}$ & $286,97 \mathrm{C}$ \\
\hline year 2 & $669,60 \mathrm{\epsilon}$ & $79,56 \mathrm{C}$ & $590,04 \epsilon$ & $95,66 \mathrm{C}$ & $573,94 \mathrm{C}$ \\
\hline year 3 & $1.004,40 \mathrm{C}$ & $119,34 \mathrm{C}$ & $885,06 \mathrm{C}$ & $143,50 \mathrm{C}$ & 860,906 \\
\hline year 4 & $1.339,20 \mathrm{C}$ & $159,12 \mathrm{C}$ & $1.180,08 \mathrm{C}$ & $191,33 \mathrm{C}$ & $1.147,876$ \\
\hline year 5 & $1.674,00 €$ & $198,90 \mathrm{C}$ & $1.475,10 \mathrm{C}$ & $239,16 \mathrm{C}$ & $1.434,846$ \\
\hline year 6 & $2.008,80 \mathrm{C}$ & $238,68 \mathrm{C}$ & $1.770,12 \mathrm{C}$ & $286,99 \mathrm{C}$ & $1.721,816$ \\
\hline year 7 & $2.343,60 \mathrm{C}$ & $278,46 \mathrm{C}$ & $2.065,14 \mathrm{C}$ & $334,82 \mathrm{C}$ & $2.008,78 \mathrm{C}$ \\
\hline year 8 & $2.678,40 \mathrm{C}$ & $318,24 \mathrm{C}$ & $2.360,16 \mathrm{C}$ & $382,66 \mathrm{C}$ & $2.295,746$ \\
\hline \begin{tabular}{|l|} 
year 9 \\
\end{tabular} & $3.013,20 \mathrm{C}$ & $358,02 \mathrm{C}$ & $2.655,18 \mathrm{C}$ & $430,49 \mathrm{C}$ & $2.582,71 \mathrm{C}$ \\
\hline year 10 & $3.348,00 \mathrm{C}$ & $397,80 \mathrm{C}$ & $2.950,20 \mathrm{C}$ & $478,32 \mathrm{C}$ & $2.869,68 \mathrm{C}$ \\
\hline year 11 & $3.682,80 \mathrm{C}$ & $437,58 \mathrm{C}$ & $3.245,22 \mathrm{C}$ & $526,15 \mathrm{C}$ & $3.156,65 \mathrm{C}$ \\
\hline year 12 & $4.017,60 \mathrm{C}$ & $477,36 \mathrm{C}$ & $3.540,24 \mathrm{C}$ & $573,98 \mathrm{C}$ & $3.443,62 \mathrm{C}$ \\
\hline year 13 & $4.352,40 \mathrm{C}$ & 517,146 & $3.835,26 \mathrm{C}$ & $621,82 \mathrm{C}$ & $3.730,58 \mathrm{C}$ \\
\hline year 14 & $4.687,20 \mathrm{C}$ & $556,92 \mathrm{C}$ & $4.130,28 \mathrm{C}$ & $669,65 \mathrm{C}$ & $4.017,556$ \\
\hline year 15 & $5.022,00 \mathrm{C}$ & $596,70 \mathrm{C}$ & $4.425,30 \mathrm{C}$ & $717,48 \mathrm{C}$ & $4.304,52 \mathrm{C}$ \\
\hline
\end{tabular}

SAVING \% 88,12 85,71

Table 5 - Single Yearly Savings for 15 years 
It is interesting to see how the WMS is more effective during some months with respect to others. As shown in Fig. 52, in the single user case, the period in which the WMS is the most effective is April; this is the result of a combination of the lower flow rate demanded by the user, higher solar radiation, and moderate AC usage. Since this combination is ideal, the saving rate is equal to $100 \%$. In the other two cases examined, the most effective result is obtained in August. The reason for this difference is that in April, the higher flow rate requested by the multiple users makes it impossible for the solar source to fully meet the demand. On the other end, in August, the solar radiation is moderate and the AC usage is very high, therefore the efficiency increases.

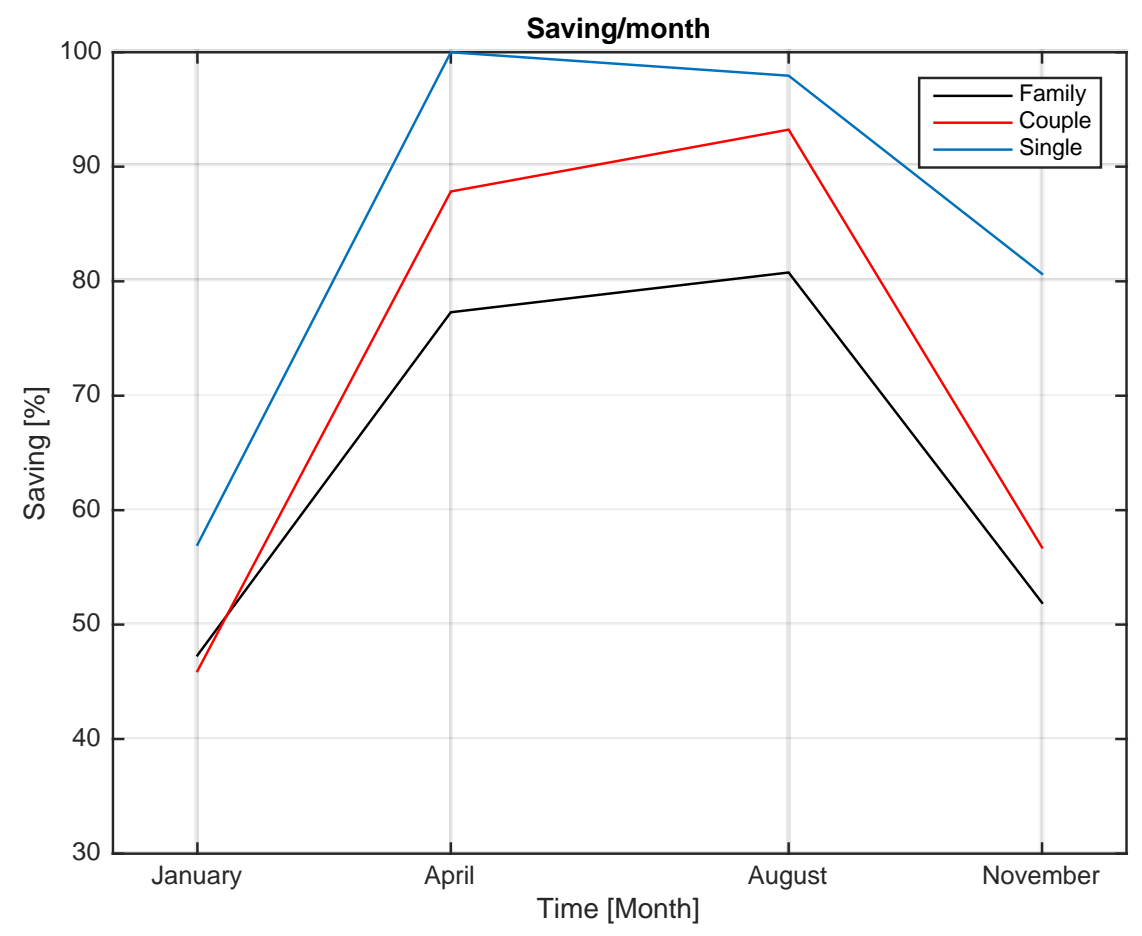

Figure 52 - Savings \% in the different months

Another interesting trend to be examined is that the saving percentage variation depends on the $\mathrm{AC}$ daily operating hours. In order to show this variation the average level of solar radiation is set as a constant value. So, under this condition the increase in AC operating hours affects the saving rate proportionally. 


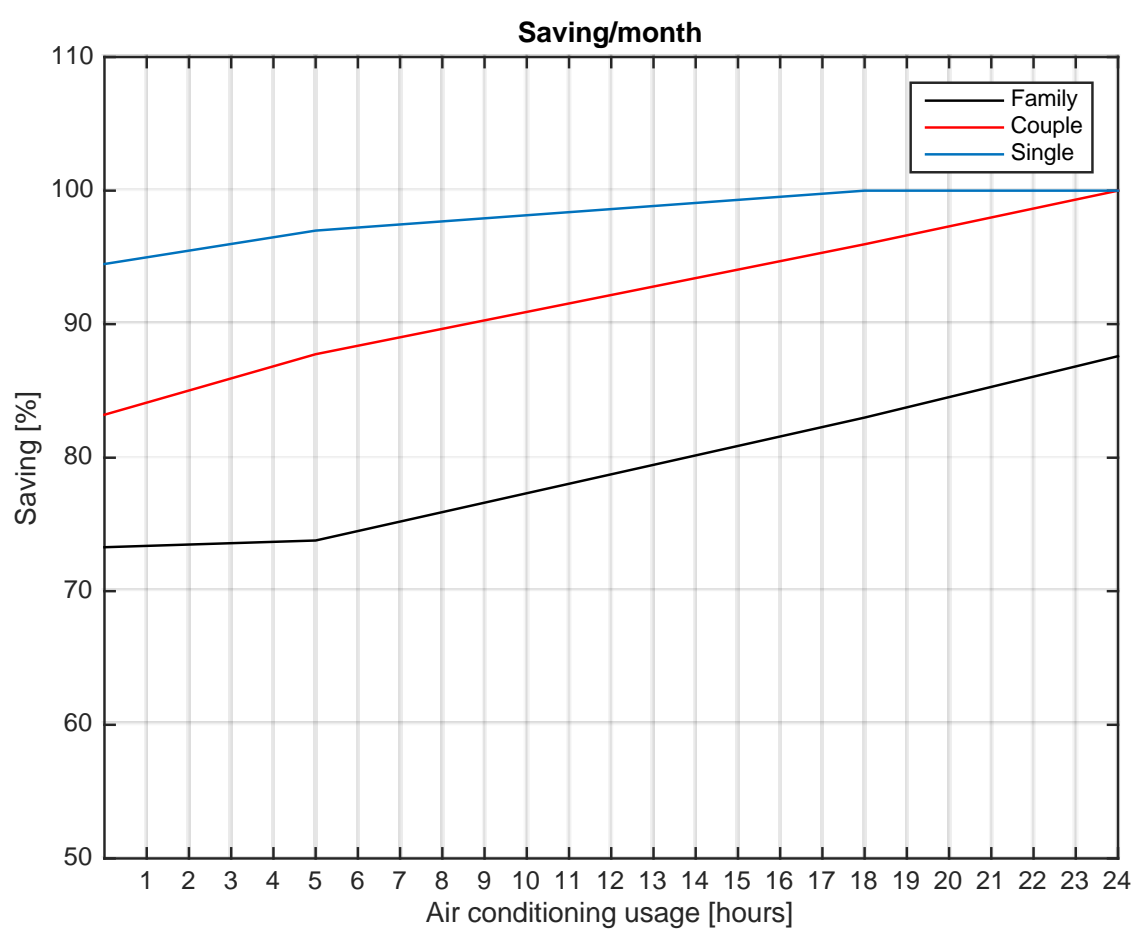

Figure 53 - Saving \% depending on AC operating hours

Figure 53 shows the change of percentage saving of WMS that varies with AC operating hours in January. At the zero AC operating hour, the saving rates are corresponding to the cases of PVT when the AC is completely turned off. As the AC operating hour increases, the WMS saving increases accordingly above that of PVT. At the 24 hour AC operation, the WMS saving reaches a maximum that is approximately $15 \%$ higher than that of PVT only.

It would be very interesting to study the same system that switches the AC source with a different heat sources such as the geothermal sources. These two heat sources have a similar energy level and they would probably enhance the saving rates. 


\section{Conclusions}

The Water Mix System (WMS) with the heat sources from PVT and A/C proposed in this thesis is a new approach to reduce hot-water energy consumption for residential households. The study shows that by using the WMS, the energy saving for hot water could be up to $100 \%$ and the payback time could be as short as 2.76 years. More detailed results are summarized below:

- In general, August shows the highest saving amounts. It has a lower radiation with respect to April but higher saving rates thanks to the higher level of AC usage. The only exception where August does not provide the highest saving rate is in the case of the single-person household in the month of April with a saving rate of $100 \%$. It is important to notice that the saving rates are generally higher with the Water Mixing System, compared to the PVT system only. For instance the average saving rate is about the $90 \%$ in August for WMS, and it decreases to $80 \%$ if only the PVT system is in use.

- A fundamental parameter for this analysis is the Payback Time. In the fourpeople family case the investment may be recovered in less than 3 years, while in the couple and single cases, the payback periods are about 4 and 5 years, respectively. The family has the highest cost because of the larger number of solar panels installed and higher AC tank volume. The component costs for the family is $\$ 1,800$ vs. $\$ 1,550$ for the single, which takes longer time to recover the cost of the plant installation.

- It is also interesting to see how the WMS is more effective during some months with respect to others. In the single user case, the month in which the WMS is most effective is April (about 100\%), which is the result of a combination of the low flow rate demanded, high solar radiation, and the moderate AC usage. In the four-people family and couple household cases, 
the most effective result is obtained in August. In April, the higher flow rate demanded by the multiple users makes it impossible for the solar source to fully meet the demand. On the other end, in August, the solar radiation is moderate compared to April and the AC usage is very high, therefore the efficiency increases.

- To provide an overall understanding of the effectiveness of the Water Mixing System a cost analysis comparison of the system using a hybrid panel as heat source and solar water collector has been studied. Anyways, the cost of the hybrid panel is less than $20 \%$ higher and this leads to a not considerable difference between the two cases in order of Pay Back Time. The monthly savings are constant because the electricity collected by the PV-T panel is not considered during the entire thesis. The use of the solar water collector is suitable when there is not need or no capability to set up a system that allows storing energy in form of electricity. 


\section{References}

[1]U.S. Energy Information and Administration: Independent Statistics \& Analysis http://www.eia.gov/todayinenergy/detail.cfm?id=6570

[2] British thermal unit (Btu) https://en.wikipedia.org/wiki/British_thermal_unit

[3] U.S. Energy Information and Administration: Residential Energy Consumption Survey (RECS)

http://www.eia.gov/todayinenergy/detail.cfm?id=10271\&src=\%E2\%80\%B9\%20Consumption $\% 2$ 0\%20\%20\%20\%20\%20Residential\%20Energy\%20Consumption\%20Survey\%20(RECS)-b1

[4 ] Primary energy (PE) https://en.wikipedia.org/wiki/Primary_energy

[5] U.S. Energy Information and Administration: Household electricity use http://www.eia.gov/todayinenergy/detail.cfm?id=10251 [6 ]U.S. Department of Energy: Distributed Wind Market Report http://energy.gov/sites/prod/files/2015/08/f25/2014-Distributed-Wind-Market-Report-8.7_0.pdf

[7] Wind Power https://en.wikipedia.org/wiki/Wind_power

[8] https://www.go-gba.org/resources/green-building-methods/geothermal-energy/

[9] Geothermal Power https://en.wikipedia.org/wiki/Geothermal_energy

[10 ]National Renewable Energy Laboratory (NREL)

http://www.nrel.gov/learning/re_photovoltaics.html

[11] Solar Energy Industries Association (SEIA) http://www.seia.org/research-resources/solarmarket-insight-2015-q4

[12] Solar Server: Global Solar Industry Website

http://www.solarserver.com/knowledge/basic-knowledge/solar-collectors.html

[13] Anil Kumar, Prashant Baredar,"Renewable and Suitlble energy review”. 
[14] Adnan Ibrahim, "Thermal theoretical study on PV/T water based collectors";Solar energy Research Energy

[15 ] Ibrahim A, Othman MY, Ruslan MH, Alghoul MA, Yahya M, Zaharim A, et al., "Performance of photovoltaic thermal collector (PVT) with different absorbers design", WSEAS Transactions on Environment and Development, 2009, 5:321-30.

[16] Indoor air quality. https://en.wikipedia.org/wiki/Indoor_air_quality

[17 ] John S.Cundiff, Fluid Power Circuits and Controls, 2001, Chap.12

[18] La misura e la stima della radiazione solare: l'archivio dell'ENEA e il sito Internet dell'Atlante italiano della radiazione solare per la pubblicazione dei dati Di Francesco Spinelli, Augusto Maccari, Euro Giovanni Cogliani e Mauro Milone.

ENEA, 2007. Rapporto SOL/RS/2007/21.

http://www.solaritaly.enea.it/Previsioni/previsioni.php

[19 ]Yunus A.Cengel, and Michael A. Boles. Thermodynamics an engineering approach, 2002, McGraw Hill, Chap. 4:166-184

[20] Yunus A.Cengel, and Michael A. Boles. Thermodynamics an engineering approach, 2002, McGraw Hill, Chap. 4:166-184

[21]Yunus A.Cengel, and Michael A. Boles. Thermodynamics an engineering approach, 2002, McGraw Hill, Chap. 4:166-184

[22] Yunus A.Cengel, and Michael A. Boles. Thermodynamics an engineering approach, 2002, McGraw Hill,

[23] Yunus A.Cengel, and Michael A. Boles. Thermodynamics an engineering approach, 2002, McGraw Hill,

[24] http://www.solimpeks.com/wp-content/uploads/2012/06/pvt_presentation_en.pdf

[25] Solimpeks company, Volther Hybrid PV-T Panel 
[26]Simplified Sizing Procedure for Solar Domestic Hot Water Systems, http://www.fsec.ucf.edu/en/publications/pdf/FSEC-GP-10-83.pdf

[27]Simplified Sizing Procedure for Solar Domestic Hot Water Systems, http://www.fsec.ucf.edu/en/publications/pdf/FSEC-GP-10-83.pdf

[28 ] National Solar Radiation Data Base, http://rredc.nrel.gov/solar/old_data/nsrdb/

[29]Simplified Sizing Procedure for Solar Domestic Hot Water Systems, http://www.fsec.ucf.edu/en/publications/pdf/FSEC-GP-10-83.pdf

[30]Israel Urieli , Engineering Thermodynamics

,https://www.ohio.edu/mechanical/thermo/Intro/Chapt.1_6/refrigerator/water_ac.html

[31]Israel Urieli , Engineering Thermodynamics , https://www.ohio.edu/mechanical/thermo/Intro/Chapt.1_6/refrigerator/water_ac.html

[33] Burkert company, Fluids control systems http://www.process-

valves.com/media/specs/Burkert_Type_2836_2-2_Way_Solenoid_Control_Valve.pdf

[34 ] Burkert company, Fluids control systems https://www.burkert-

usa.com/en/content/download/7480/229630/version/19/file/EN_ProductOverview_ProportionalVa lves_Version04-2015_Print04-2015.pdf

[35] Burkert company, Fluids control systems http://www.processvalves.com/media/specs/Burkert_Type_2836_2-2_Way_Solenoid_Control_Valve.pdf

[36] National Solar Radiation Data Base (NSRDB) http://rredc.nrel.gov/solar/old_data/nsrdb/

[37 ]Electricity Local http://www.electricitylocal.com/states/florida/miami/ 